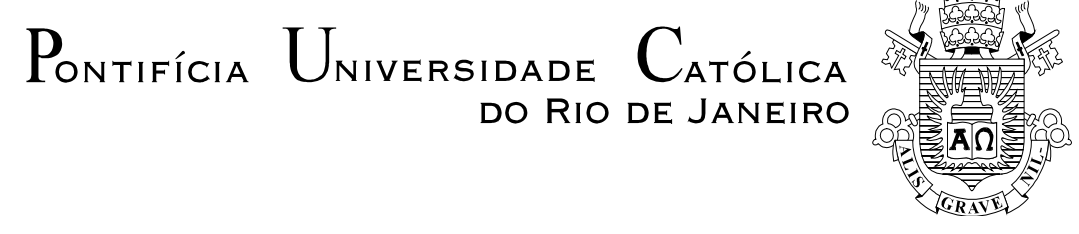

Marcelo Braga Correa de Mello

\title{
Avaliação de Projetos de Investimentos com Opções Reais: Cálculo do Valor da Opção de Espera de um Sistema Fotovoltaico Conectado à Rede
}

\section{Dissertação de Mestrado}

\begin{abstract}
Dissertação apresentada ao Programa de Pós-Graduação em Administração de Empresas da PUC-Rio como requisito parcial para obtenção do título de Mestre em Administração de Empresas.
\end{abstract}

Orientador: Prof.Leonardo Lima Gomes 


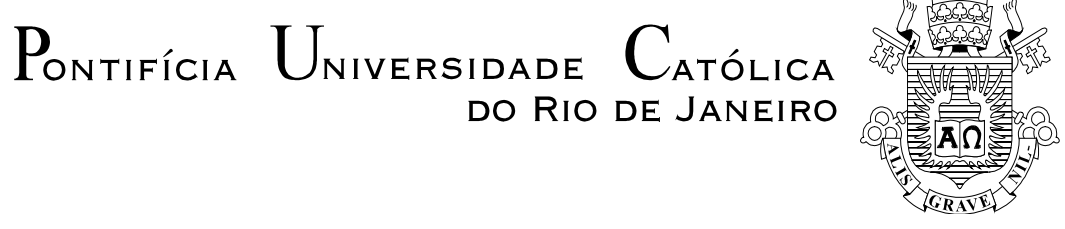

Marcelo Braga Correa de Mello

\begin{abstract}
Avaliação de Projetos de Investimentos com Opções
Reais: Cálculo do Valor da Opção de Espera de um Sistema Fotovoltaico Conectado à Rede
\end{abstract}

Dissertação apresentada como requisito parcial para obtenção do grau de Mestre pelo Programa de PósGraduação em Administração de Empresas da PUC-Rio. Aprovada pela Comissão Examinadora abaixo assinada.

Prof. Leonardo Lima Gomes

Orientador

Departamento de Administração - PUC-Rio

Prof. Luiz Eduardo Teixeira Brandão

Departamento de Administração - PUC-Rio

Prof. Carlos de Lamare Bastian Pinto

Grupo IBMEC

Profa. Mônica Herz

Vice-Decana de Pós-Graduação do CCS - PUC-Rio

Rio de Janeiro, 10 de abril de 2015 
Todos os direitos reservados. É proibida a reprodução total ou parcial do trabalho sem autorização da universidade, do autor e do orientador.

\section{Marcelo Braga Corrêa de Mello}

Graduou-se em Engenharia de Telecomunicações pelo Centro Federal de Educação Tecnológica do Rio de Janeiro (CEFETRJ) em 1999, tendo concluído o MBA em Finanças na COPPEAD/UFRJ em 2011 e o MBA Internacional na Católica Porto Business School (Portugal) em 2014. Atua no mercado de telecomunicações há 15 anos e, atualmente, exerce a função de Head of Radio Engineering na Nokia Networks para a região da América Latina.

Ficha Catalográfica

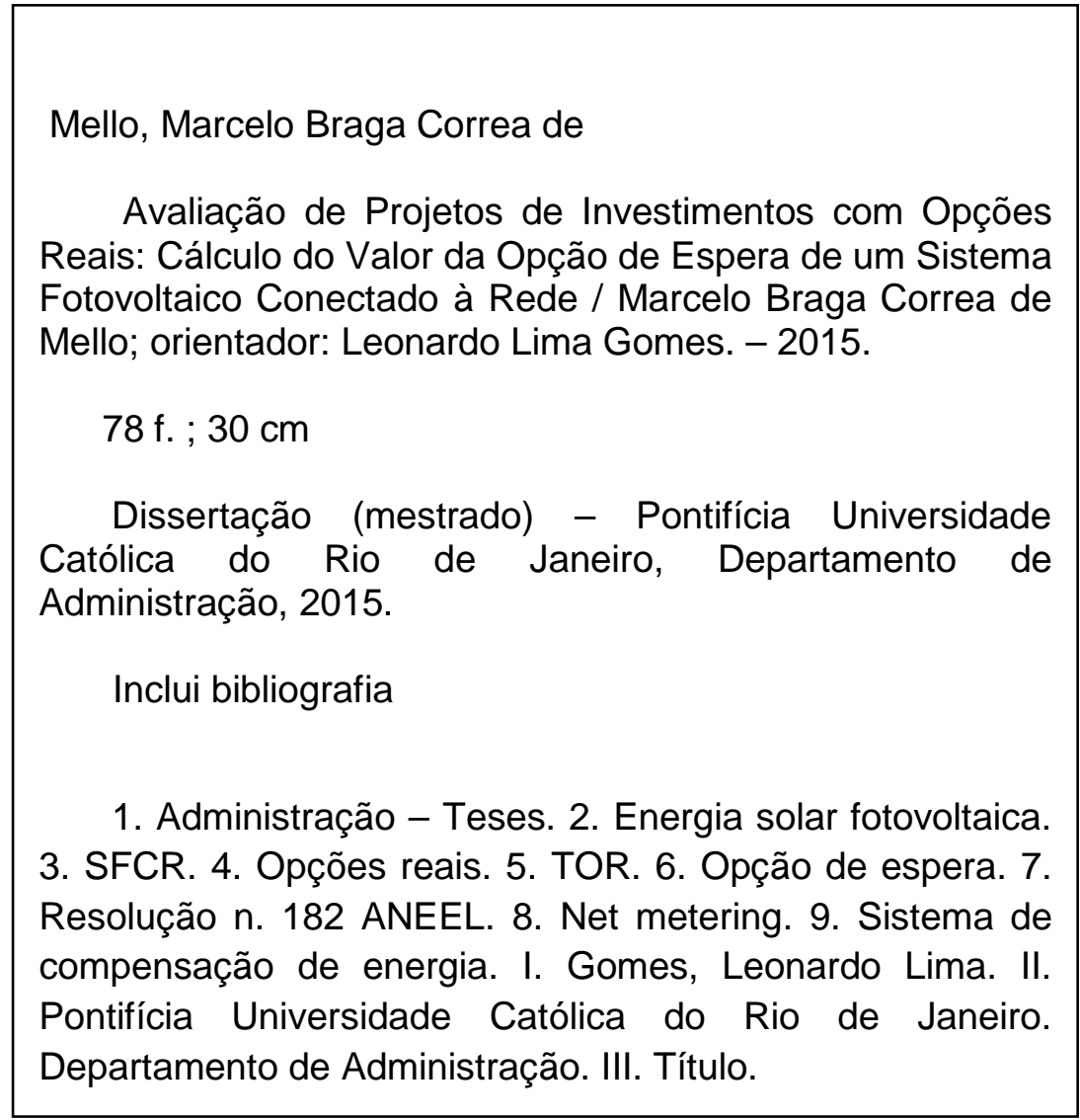

CDD: 658 


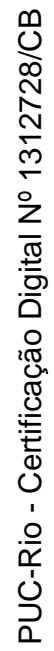

Ao pequeno Ícaro 


\section{Agradecimentos}

Ao meu orientador Leonardo Gomes Lima pelos ensinamentos, discussões e explicações que foram essenciais para a conclusão do trabalho.

Aos professores do Mestrado da PUC-Rio.

Aos amigos da PUC-Rio.

Aos meus pais, Carlos Ramiro (in memoriam) e Liège, pelo carinho e pela formação recebida ao longo da vida. Obrigado pra sempre.

Ao meu filho Ícaro pela compreensão e companheirismo, apesar dos meus períodos de ausência.

À minha esposa Giselle, pelo apoio incondicional e por entender que o mestrado, mais do que um projeto pessoal, é um projeto de toda família. 


\section{Resumo}

Mello, Marcelo Braga Corrêa de; Gomes, Leonardo Lima (Orientador). Avaliação de Projetos de Investimentos com Opções Reais: Cálculo do Valor da Opção de Espera de um Sistema Fotovoltaico Conectado à Rede. Rio de Janeiro, 2015. 78p. Dissertação de Mestrado - Departamento de Administração, Pontifícia Universidade Católica do Rio de Janeiro.

Nos últimos anos, a energia fotovoltaica ganhou um espaço muito grande no cenário internacional e se tornou a terceira maior fonte mundial de geração de energia renovável, ficando atrás somente da energia hidroelétrica e da energia eólica. No Brasil, apesar de todas as características naturais favoráveis, tanto do ponto de vista de disponibilidade solar como de possibilidades de produção de silício com alto grau de pureza, a energia fotovoltaica tem uma participação incipiente na matriz energética. A Agência Nacional de Energia Elétrica (ANEEL), através da publicação da Resolução $n^{0} 482$, procurou estabelecer as condições gerais e reduzir as barreiras regulatórias existentes visando a expansão desse tipo de geração através da introdução do sistema de compensação de energia elétrica (net metering). O presente estudo buscou analisar o melhor momento para investir num projeto de implantação de um sistema de geração fotovoltaica conectado à rede (SFCR) sob a ótica do investidor, aplicando a Teoria de Opções Reais (TOR). As análises foram baseadas no fluxo de caixa estimado durante toda a vida útil do sistema gerador e o valor do projeto foi calculado considerando que o investidor poderia implantá-lo imediatamente ou ter a opção de espera por um momento mais apropriado. Os métodos tradicionais de avaliação de investimento como o Valor Presente Líquido (VPL), Taxa Interna de Retorno (TIR) e payback foram utilizados nessas análises, bem como a Teoria de Opções Reais. A partir das análises, foi possível concluir que, dada as condições específicas do projeto proposto, a melhor opção seria a realização imediata do projeto do SFCR.

\section{Palavras-chave}

Energia Solar Fotovoltaica; SFCR; Opções Reais; TOR; Opção de Espera; Resolução n 482 ANEEL; Net metering, Sistema de Compensação de Energia. 


\section{Abstract}

Mello, Marcelo Braga Corrêa de; Gomes, Leonardo Lima (Advisor). Investment Project Evaluation using Real Options: Standby Option Value Calculation of a Grid-connected Photovoltaic System. Rio de Janeiro, 2015. 78p. MSc Dissertation - Departamento de Administração, Pontifícia Universidade Católica do Rio de Janeiro.

In recent years, photovoltaics gained a very large space in the international arena and have become the world's third largest source of renewable energy, second only to hydropower and wind energy. In Brazil, despite all the favorable natural features in terms of solar availability and production of high quality silicon's possibilities, photovoltaics has an incipient participation in the energy matrix. The Agency National of Electric Energy (ANEEL), through the Resolution 482, sought to establish the general conditions and reduce existing regulatory barriers aimed at the expansion of this type of generation through the introduction of electric power compensation system (net metering). This study investigates the best time to invest in a project to establish a gridconnected photovoltaic system, from the perspective of the investor, applying the Theory of Real Options (TOR). The analysis was based on estimated cash flow throughout the life of the generating system and the project value was calculated considering that the investor could deploy it immediately or have the option of waiting for a more appropriate time. Traditional methods of investment appraisal as the Net Present Value (NPV), Internal Rate of Return (IRR) and payback were used and real option theory (TOR) as well. From the analysis done in this study, it was concluded that, given the specific conditions of the proposed project, the best option would be held immediately the grid-connected photovoltaic system.

\section{Keywords}

Photovoltaics; Grid-connected photovoltaic system; Real Options; Postponed investment; Resolution 482 ANEEL; Net metering, Electric Power Compensation System. 


\section{Sumário}

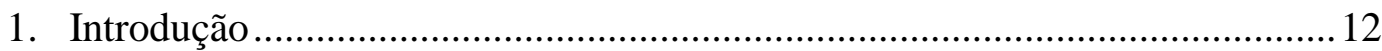

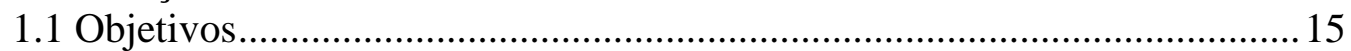

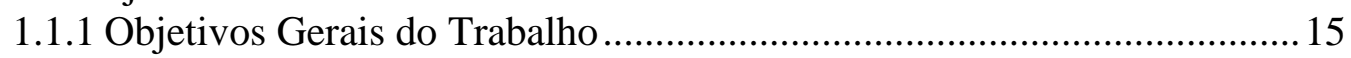

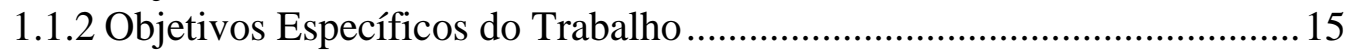

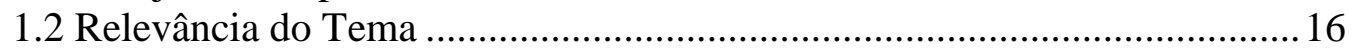

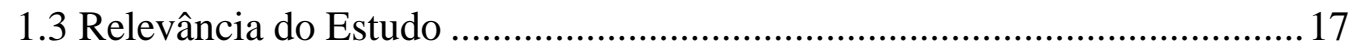

1.4 Delimitação do escopo do estudo ............................................................... 17

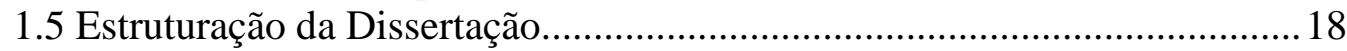

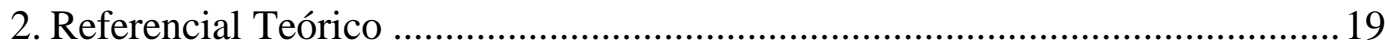

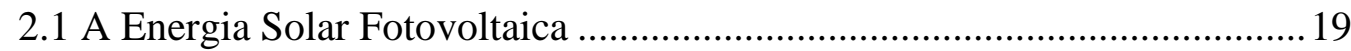

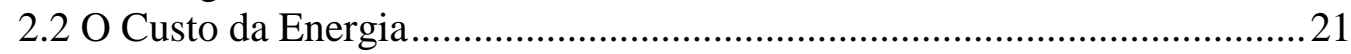

2.2.1 O Novo Sistema de Bandeiras Tarifárias ..................................................22

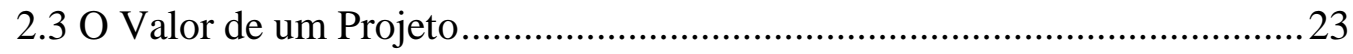

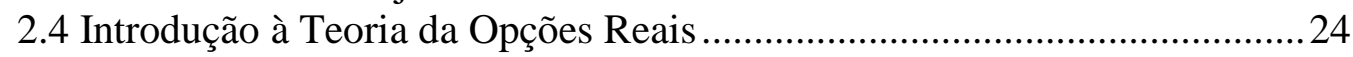

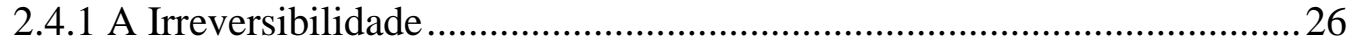

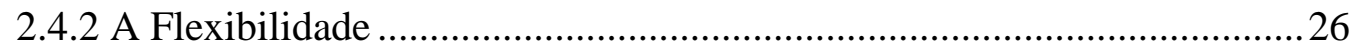

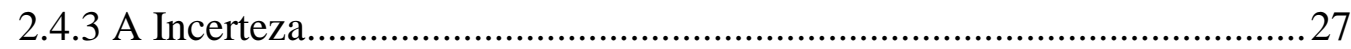

2.4.4 As Opções Financeiras ...........................................................................2

2.4.5 Analogia entre as Opções Financeiras e as Opções Reais........................30

2.4.6 O Modelo Binomial ................................................................................. 31

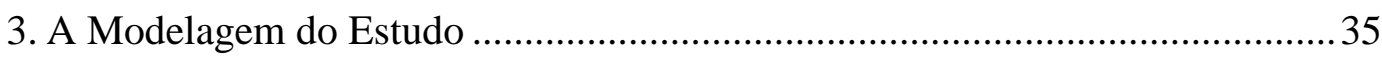

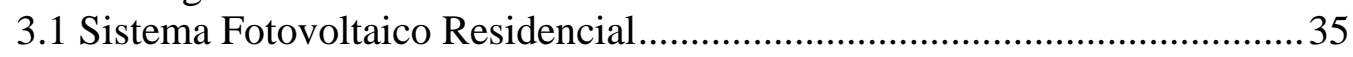

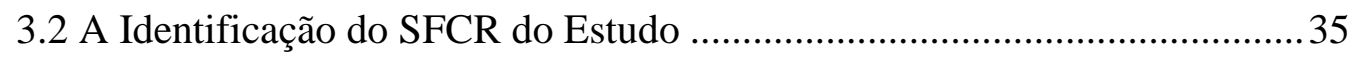

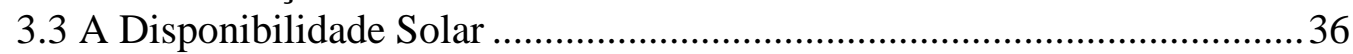

3.4 A Capacidade Instalada e Geração Anual .....................................................37

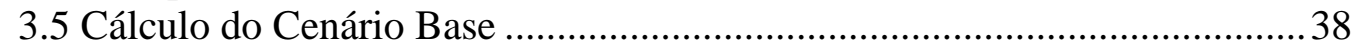

3.6 Valor do Projeto com Investimento Postergado .........................................45

3.6.1 A Volatilidade da Tarifa de Energia Elétrica ...........................................45

3.6.2 A Volatilidade do Custo de Implementação do SFCR ............................. 47

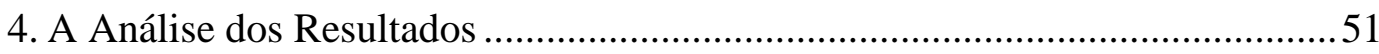

4.1 Análise de Sensibilidade das Variáveis .....................................................51

4.1.1 Opção de Adiar 01 ano - Custo da Energia Elétrica.................................51

4.1.2 Opção de Adiar 01 ano - Custos de Implantação ......................................55

4.2 A Opção de Espera - Tarifa e Custo de Implantação .....................................59

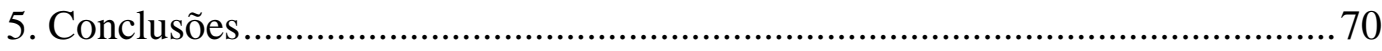

5.1 Principais Resultados e Considerações Finais........................................... 70

5.2 Sugestões de Estudos Futuros .............................................................. 71

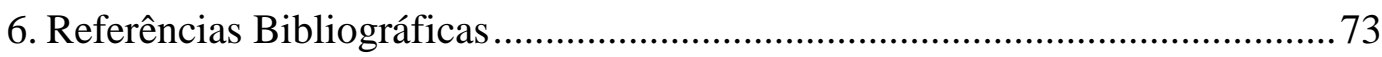

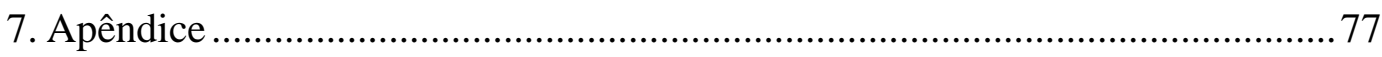




\section{Lista de Figuras}

Figura 1 - Compra de Opção de Compra 28

Figura 2 - Venda de Opção de Compra 28

Figura 3 - Compra de Opção de Venda 29

$\begin{array}{ll}\text { Figura } 4 \text { - Venda de Opção de Venda } & 29\end{array}$

Figura 5 - Analogia entre Opções Reais e Opções Financeiras 30

Figura 6 - Modelo de Cox, Ross e Rubinstein 33

Figura 7 - Preço da Ação no Processo Binomial 34

Figura 8 - Insolação Média Diária do Brasil 37

Figura 9 - Planejamento do Sistema Fotovoltaico 38

Figura 10 - Tarifas do Consumidor Residencial (B1) da CEMIG de 2004 a

201446

$\underset{\infty}{\mathscr{0}}$ Figura 11 - Preço de Implementação do SFCR na Alemanha de 2006 a 2014

Figura 12 - Histórico e Previsão dos Custos de Implantação do SFCR nos EUA

Figura 13 - Custo Médio de Implantação do SFCR de 2006 a 2014

Figura 14 - Árvore Binomial para o Adiamento de 01 ano - Energia Elétrica

Figura 15 - Árvore Binomial para o Adiamento de 01 ano - SFCR 56

Figura 16 - Árvore Binomial - Bivariável

Figura 17 - Árvore Binomial para o Adiamento de 01 ano - Energia

Elétrica

Figura 18 - Árvore Binomial para o Adiamento de 01 ano - SFCR

Figura 19 - Árvore Binomial Bivariável para o Adiamento de 01 ano 


\section{Lista de tabelas}

Tabela 1 - Consumo de Mensal de Eletricidade em kWh 36

Tabela 2 - Funcionamento do Sistema de Compensação de Energia 39

Tabela 3 - Previsão da Tarifa de Energia em 2015 para Consumidor B1 41

Tabela 4 - Previsão de Conta de Energia Mensal ao longo de 2015

Tabela 5 - Previsão do Cenário Base do Net Metering 43

Tabela 6 - Previsão do Net Metering ao longo dos 25 anos 43

Tabela 7 - VPL, TIR e Payback do Modelo Determinístico 44

Tabela 8 - Volatilidade da Tarifa de Energia Elétrica da CEMIG de 2004 a $2014 \quad 47$

Tabela 9 - Estimativa dos Custos de Implantação SFCR nos EUA 49

Tabela 10 - Volatilidade do Custo de Implantação do SFCR de 2006 a 2014

Tabela 11 - Parâmetros do Modelo Binomial - Energia Elétrica

Tabela 12 - VPL, TIR e Payback para o Adiamento de 01 ano - Aumento da Tarifa de Energia Elétrica

Tabela 13 - VPL, TIR e Payback para o Adiamento de 01 ano - Queda da Tarifa de Energia Elétrica

Tabela 14 - Parâmetros do Modelo Binomial para o Adiamento de 01 ano

- SFCR

Tabela 15 - VPL, TIR e Payback para o Adiamento de 01 ano - Aumento do Custo de Implantação

Tabela 16 - VPL, TIR e Payback para o Adiamento de 01 ano - Queda do Custo de Implantação

Tabela 17 - VPL, TIR e Payback para o Cenário 1 - Aumento da Energia

E Aumento da Implantação

Tabela 18 - VPL, TIR e Payback para o Cenário 2 - Aumento da Energia

E Queda da Implantação

Tabela 19 - VPL, TIR e Payback para o Cenário 3 - Queda da Energia E Aumento da Implantação 
Tabela 20 - VPL, TIR e Payback para o Cenário 4 - Queda da Energia E Queda da Implantação

Tabela 21 - Sistema de Compensação de Energia Elétrica - 25 anos - Rio de Janeiro

Tabela 22 - VPL, TIR e Payback do Modelo Determinístico - Rio de Janeiro 


\section{Introdução}

Ao longo dos últimos anos, a energia fotovoltaica ganhou um espaço muito importante no cenário internacional. De acordo com o relatório Global Market Outlook for Photovoltaics 2014-2018 da Associação Europeia da Indústria Fotovoltaica (EPIA), ao final do ano de 2009 a capacidade mundial de geração fotovoltaica instalada era de $23 \mathrm{GW}$, mas, ao final de 2010, essa capacidade já era de 40.3 GW e um ano mais tarde, essa capacidade evoluiu para 70.5 GW. Em 2012 e 2013, a capacidade instalada saltou para 100 GW e 138 GW respectivamente. Esse crescimento fez com que a Energia Solar se tornasse a terceira maior fonte de geração de energia renovável, ficando atrás somente da energia hidroelétrica e da energia eólica.

Segundo o relatório da EPIA, ao longo de 2013, os mercados na Europa e em todo o mundo continuaram a fazer progressos rápidos em direção à competitividade do uso da energia solar para a geração de eletricidade. A diminuição do preço da tecnologia fotovoltaica e a elevação dos preços da eletricidade tiveram um importante papel nesse ganho de competitividade da tecnologia.

De acordo com a edição de 2014 do Solar Photovoltaic Energy da IEA (Agência Internacional de Energia), o padrão geográfico de implantação de sistemas fotovoltaicos vem mudando ao longo dos últimos anos. Enquanto a Alemanha e a Itália iniciaram a expansão dos sistemas fotovoltaicos em grande escala há alguns anos, agora, esses sistemas estão sendo implantados em outros países ao redor do mundo. Ao longo de 2013, a China liderou as implantações de geração fotovoltaica, sendo seguida por Japão e Estados Unidos.

Essas experiências em países como Alemanha, China, Itália, Japão e Estados Unidos apresentaram importantes contribuições para a análise sobre a expansão de mercado, ganhos de escala de produção e redução de custo para os investidores. Ainda segundo o relatório do IEA (2014), os preços de implantação dos sistemas fotovoltaicos foram divididos por 3 nos últimos seis anos na maioria 
dos mercados, enquanto que os preços somente dos módulos fotovoltaicos foram divididos por 5.

Segundo a EPIA (2014), apesar da grande capacidade instalada pela China em 2013, a Europa permanece com a liderança regional em termos de capacidade fotovoltaica instalada com aproximadamente 82 GW (59\% do total instalado), seguido pelos países asiáticos (40,6 GW) e pelos países das Américas (13,7 GW). Dessa capacidade instalada de 13,7 GW nas Américas, o Brasil, apesar de todo o seu potencial para geração fotovoltaica, possui somente $22 \mathrm{MW}$, destinados, principalmente, ao atendimento de sistemas isolados e remotos, em situações em que a extensão da rede de distribuição não se mostra economicamente viável.

De acordo com a Nota Técnica (NT) emitida pela Empresa de Pesquisa Energética (EPE) no ano de 2012, sobre a Análise da Inserção da Geração Solar na Matriz Elétrica Brasileira, do ponto de vista estratégico, o Brasil possui diversas características naturais favoráveis (como altos níveis de insolação e grandes reservas de quartzo de qualidade) que podem gerar importantes vantagens competitivas para a produção de silício com alto grau de pureza, células e módulos solares. Esses fatores podem potencializar a atração de investidores e incentivar o desenvolvimento do mercado interno, permitindo que se vislumbre um papel importante deste tipo de tecnologia na matriz elétrica brasileira.

Ainda segundo a NT da EPE (2012), com o objetivo de fomentar o desenvolvimento da tecnologia fotovoltaica no Brasil, a Agência Nacional de Energia Elétrica (ANEEL) publicou, em 17/04/2012, a Resolução n ${ }^{0} 482$ para estabelecer as condições gerais para o acesso de micro geração e mini geração distribuída aos sistemas de distribuição de energia elétrica. Essa resolução visa reduzir as barreiras regulatórias existentes para a conexão de geração de pequeno porte disponível na rede de distribuição a partir de fontes de energia incentivadas, bem como introduzir o sistema de compensação de energia elétrica (net metering), buscando estabelecer ainda as adequações necessárias nos Procedimentos de Distribuição - PRODIST.

No mesmo dia 17/04/2012, visando incentivar a utilização de energia solar para a geração de energia elétrica, a ANEEL também publicou a Resolução Normativa $\mathrm{n}^{0} 481$, pela qual estipulou que, para a fonte solar com potência injetada menor ou igual a $30 \mathrm{MW}$ nos sistemas de transmissão ou distribuição, durante os 10 (dez) primeiros anos de operação um desconto de 80\% (oitenta por 
cento) nas tarifas de uso dos sistemas elétricos de transmissão e de distribuição (TUST e TUSD) para àqueles empreendimentos que entrarem em operação comercial até 31/12/ 2017. A ANEEL estabeleceu ainda que esse desconto seria reduzido para 50\% (cinquenta por cento) após o décimo ano de operação da usina geradora.

Num cenário onde o investidor tem incertezas em relação ao custo de implantação da geração fotovoltaica (cada vez menor em função da curva de aprendizagem), o investidor tem indefinições em relação ao preço das tarifas de energia elétrica que serão praticados pelas distribuidoras (com perspectivas de alta no curto prazo); cabe ao investidor definir o melhor momento de investir (ou não investir) na implantação de um sistema fotovoltaico residencial.

A implantação desse tipo de sistema, além de ser um investimento de alto custo, possui como característica a irreversibilidade (depois de realizado, não é possível desfazê-lo) e isso faz com que seja de grande importância, nesse ambiente de incertezas para o investidor, poder escolher entre investir imediatamente ou poder postergar o investimento caso identifique que necessita de mais informações sobre as variáveis desse projeto. Nesse cenário onde a possibilidade de adiamento do investimento está presente, essa opção de espera pode ser avaliada pela teoria das opções reais (TOR). É sobre esse tema que trata o referido estudo.

De acordo com Dixit e Pindyck (1994), a diferença entre o valor da oportunidade de espera de um projeto com flexibilidade e o valor presente do investimento sem flexibilidade é o valor da opção de espera.

Como o investimento em sistemas fotovoltaicos possui um elevado custo de implementação e possui um elevado período de recuperação do capital investido através da redução das contas de energia (net metering), uma método apropriado de avaliação deve ser identificado para possibilitar uma análise da relação custo $x$ benefício do investimento realizado na implantação desse sistema. 


\section{1}

\section{Objetivos}

\subsection{1}

\section{Objetivos Gerais do Trabalho}

O objetivo final do trabalho é avaliar se o investimento de implementação dum sistema fotovoltaico residencial de geração de energia, sob a ótica de um investidor, deve ser realizado de forma imediata ou deve ser postergado para aguardar um momento mais apropriado (valor da opção de espera), através da teoria de opções reais (TOR). No estudo realizado, as variáreis estocásticas consideradas são: o preço da energia elétrica e o custo de implementação do sistema fotovoltaico.

\section{1 .2}

\section{Objetivos Específicos do Trabalho}

- Projetar o fluxo de caixa do sistema fotovoltaico até final de sua vida útil prevista (2034);

- Avaliar o modelo pelo Fluxo de Caixa Descontado (FCD) sem flexibilidade;

- Estimar a volatilidade do projeto considerando as suas principais variáveis de incerteza: preço da energia elétrica e custo de implementação do sistema fotovoltaico;

- Construir uma árvore de eventos e uma árvore de decisão, com base na volatilidade encontrada para o projeto;

- Obter um valor para o projeto através de uma avaliação utilizando a Teoria de Opções Reais (TOR) utilizando o modelo Binomial de valoração de opções;

- Comparar os valores dos projeto obtidos com a avaliação por opções reais e pelo Fluxo de Caixa Descontado. 


\section{2}

\section{Relevância do Tema}

No âmbito nacional, os debates acerca da geração de energia elétrica ganham cada vez mais relevância na medida em que, ao longo dos anos, a evolução demográfica e o crescimento das atividades econômicas têm resultado num constante aumento do consumo de energia elétrica no país. Portanto, diante desse quadro, é preciso pensar em alternativas que respondam às necessidades de expansão e diversificação do parque gerador elétrico brasileiro. É nesse contexto que estão inseridas as pequenas centrais geradoras fotovoltaicas residenciais.

Segundo Dixit e Pindyck (1994) todo investimento possui três características: irreversibilidade, incerteza e timing.

O projeto de implantação de um sistema fotovoltaico é considerado um investimento. E como tal, também apresenta essas mesmas características. A sua implementação é irreversível, pois, uma vez que se opta pelo início do projeto não haverá mais a opção de retornar o capital investido. Apresenta incertezas, como o preço futuro da energia elétrica e a variação do custo de implementação do sistema. Além disso, essa implementação apresenta um timing, característica que nos possibilita decidir qual o melhor momento de se investir em um projeto, presente nas duas outras características citadas acima.

Isso nos ajuda a definir se todas as informações atuais são suficientes ou se precisamos esperar até que algumas informações sejam esclarecidas, pois encontrar o momento ótimo de investir é o objetivo de todo investidor e a TOR nos auxilia com a definição do valor dessas opções ao longo do tempo.

Segundo Brandão (2002), quando existem significativas flexibilidades gerenciais como a de adiar, abandonar, expandir, suspender ou retomar um projeto com investimento irreversível em condições de incerteza, o método das opções reais pode elevar a valores substancialmente maiores que os determinados pelos métodos do fluxo de caixa descontado. A implicação disso é que os métodos tradicionais tendem a subestimar projetos que apresentem opções.

Copeland e Antikarov (2001) sugerem que a TOR substituirá o Fluxo de Caixa Descontado (FCD) como paradigma central para a decisão de investimentos uma vez que conseguem complementar o espaço deixado por esse método. 


\section{3}

\section{Relevância do Estudo}

A ANEEL, em seu caderno temático sobre a micro e mini geração distribuída, ressalta que atualmente a geração de energia elétrica a partir de fontes renováveis é uma tendência viável em diversos países, inclusive com a concessão de incentivos à geração de distribuída de pequeno porte. A agência sinaliza ainda que esses estímulos são justificados por poder proporcionar ao sistema elétrico a postergação de investimentos em expansão nos sistemas de distribuição e transmissão; o baixo impacto ambiental; a redução no carregamento das redes; a redução de perdas e a diversificação da matriz energética, entre outros.

Nesse mesmo caderno temático (ANEEL,2014), o órgão regulador deixa clara a intenção de, através da publicação da Resolução Normativa $n^{0}$ 482, fomentar o desenvolvimento do mercado de geração fotovoltaico através da implementação do sistema de compensação de energia (net metering).

Em consonância com a discussão, o Atlas Brasileiro de Energia Solar, elaborado pelo Instituto Nacional de Pesquisas Espaciais (INPE, 2006), ressalta que na geração de energia elétrica no Brasil, a energia fotovoltaica tem uma participação incipiente, tendo despertado pouquíssimo interesse no mercado nacional.

Face o grande potencial para a geração fotovoltaica, o arcabouço legal criado pelo órgão regulador e os incentivos oferecidos para fomentar a implantação desses sistemas, o referido estudo torna-se relevante por buscar identificar, através da teoria de opções reais, se tais medidas adotas pelo órgão regulador e pelos atores do mercado de energia solar são suficientes para incentivar ou não a implementação de um sistema residencial fotovoltaico de forma imediata

\section{4}

\section{Delimitação do escopo do estudo}

Para atingir os objetivos traçados para esta dissertação foi necessário o estabelecimento de algumas delimitações no estudo, que estão descritas a seguir. 
Embora a saibamos que a Resolução $n^{0} 482$ da ANEEL versa sobre micro (até $100 \mathrm{~kW}$ ) e mini geração (de $100 \mathrm{~kW}$ a 1 MW), o estudo está limitado à micro geração, uma vez que a regra de compensação de energia é distinta para cada um desses cenários de geração.

O estudo em questão foi realizado na rede de distribuição da CEMIG (Companhia Energética de Minas Gerais), concessionária da capital do Estado de Minas Gerais, visto que os valores considerados na regra de compensação variam de concessionária para concessionária e são premissas para a definição da capacidade do sistema fotovoltaico gerador.

O estudo em tela está limitado ao Estado de Minas Gerais, uma vez que e Estado onde a residência do modelo de estudo está localizada, pois, em função das regras tributárias serem diferentes para cada Estado, a localização tem um impacto considerável no Valor Presente Líquido (VPL) do projeto.

\section{5}

\section{Estruturação da Dissertação}

O presente estudo é composto de cinco capítulos. Além desta parte introdutória, é composto por uma seção de referencial teórico, em que são apresentados os principais conceitos a respeito da Teoria de Opções Reais. Os capítulos seguintes são estruturados através da modelagem do estudo, da análise dos resultados e da conclusão, complementados pelas seções de referências bibliográficas e, por fim, os apêndices e anexos.

O Capítulo 2, Referencial Teórico, traz a revisão da literatura sobre o sistema fotovoltaico, sobre avaliação de projetos e sobre a Teoria de Opções Reais (TOR); e através da revisão dessa literatura fundamentou-se a preparação dos dados que foram estudados nessa análise.

No Capítulo 3 é descrita a abordagem da modelagem utilizada para a realização desse estudo.

No Capítulo 4, a Análise dos Resultados, estão contidas as análises e as interpretações dos dados contidos nesse trabalho.

O Capítulo 5 contém a conclusão do estudo, incluindo as considerações finais e propostas sugeridas para futuras pesquisas sobre o tema. 


\section{2}

\section{Referencial Teórico}

\section{1}

\section{A Energia Solar Fotovoltaica}

Segundo o relatório da EPIA (2014), nos últimos 10 anos, a tecnologia fotovoltaica tem mostrado potencial para tornar-se uma das fontes de eletricidade predominantes no mundo - com um crescimento robusto e contínuo mesmo em tempos de crise financeira e econômica como nos dias de hoje. O crescimento dessa fonte de geração de energia é esperado ao longo dos próximos anos, não somente pela redução dos custos, mas respaldado pela conscientização das vantagens da energia fotovoltaica.

De acordo com Fthenakis e Kim (2011), a energia solar fotovoltaica é considerada uma das fontes de energia mais limpas existentes, pois, não emite gases do efeito estufa nem outros poluentes na geração, deixando os impactos ambientais restritos à fabricação dos equipamentos e ao seu descarte futuro.

Braga (2008) ressalta que a geração elétrica fotovoltaica não consome combustível, não produz resíduos ou poluentes e não gera calor ou barulho. Os módulos fotovoltaicos necessitam de pouca manutenção durante sua vida útil, que é superior a 20 anos, e são resistentes a condições climáticas extremas.

Segundo a EPIA, a geração fotovoltaica apresenta algumas vantagens que justificam o incentivo para sua utilização em larga escala em todo o mundo. Dentre as vantagens do sistema fotovoltaico, podemos destacar:

- A utilização de uma fonte de energia gratuita e inesgotável (sol), não necessitando de gastos adicionais com combustível durante sua operação;

- A modularidade para expansão, pois, novos painéis fotovoltaicos podem ser adicionados ao sistema para aumentar a potência e geração de energia do mesmo;

- A facilidade de instalação, que não requer a realização de grandes obras civis; 
- O ciclo de vida dos módulos fotovoltaicos é de mais de 25 anos, podendo os painéis serem reciclados ao fim de sua vida útil;

- A facilidade de instalação em locais próximos aos consumo, como em casas e edifícios, minimizando as perdas por transmissão e distribuição de energia e reduzindo a necessidade de investimentos em novas linhas de transmissão;

- Os custos baixos de manutenção, uma vez que não apresentam partes móveis, bastando que os painéis sejam limpos periodicamente;

- As instalações fotovoltaicas, quando instalado em edifícios, não necessitam de área física dedicada, uma vez que a área necessária já é ocupada pela edificação.

De acordo com o EPE (2012), o Brasil possui elevados índices de radiação solar, variando de $1500 \mathrm{kWh} / \mathrm{m}^{2} / \mathrm{ano}$ a $2200 \mathrm{kWh} / \mathrm{m}^{2} / \mathrm{ano}$, bem superiores aos encontrados na maioria dos países europeus, como a Alemanha (líder mundial no uso da tecnologia) que variam entre $900 \mathrm{kWh} / \mathrm{m}^{2} /$ ano e $1.250 \mathrm{kWh} / \mathrm{m}^{2} / \mathrm{ano}$. Nesse cenário, de acordo com Rüther \& Zilles (2011), bastaria que 0,04\% do território brasileiro estivesse coberto com módulos fotovoltaicos para gerar toda a eletricidade consumida no país atualmente.

Porém, apesar de possuir todas as condições e das inúmeras vantagens apresentadas, segundo a EPE (2012), a geração de energia elétrica via sistemas fotovoltaicos é ainda bem incipiente por aqui.

Esses sistemas de geração fotovoltaicos podem ser tanto isolados (instalados em áreas remotas e longe das linhas de distribuição elétrica como em postes, torres de comunicação e comunidades sem acesso à eletricidade); como conectados à rede (usinas centralizadas ou em ambientes urbanos, próximo ao ponto de consumo). Esta última modalidade é uma forma de geração distribuída e recebe o nome de sistemas fotovoltaicos conectados à rede (SFCR). E por estarem conectados à rede, o SFCR permitem que quando a geração de energia seja superior ao consumo próprio, esse excesso de energia seja injetado na rede de distribuição e possam gerar créditos que poderão ser utilizados quando o consumo for superior a geração. 
Buscando fomentar a implantação de novos SFCRs (Sistemas Fotovoltaicos Conectados às Redes, a ANEEL através da publicação da Resolução Normativa $n^{0} 482$ de 17/04/2012 estabeleceu um sistema de compensação de energia (net metering), cujas regras simplificadas de operação foram assim definidas pela concessionária CEMIG:

- A Energia Cobrada = Energia Consumida - Energia Injetada;

- Caso o resultado seja menor que o "custo de disponibilidade" (CDD) cobra-se do consumidor as seguintes taxas:

0 100 KWh para ligação trifásica;

o 50 KWh para ligação bifásica;

o 30 kWh para ligação monofásica

- Caso a Energia Injetada seja maior que a consumida, será gerado um crédito válido por 36 meses ou que pode ser utilizado em outra unidade da mesma pessoa física (mesmo CPF - Cadastro de Pessoa Física).

\section{2}

\section{O Custo da Energia}

O valor da tarifa de energia elétrica brasileira no mercado residencial é formado pela soma do valor da TUSD (Tarifa de Uso do Sistema de Distribuição) e pela soma da TE (Tarifa de Energia) que, desde 2013, aparecem na conta de energia elétrica de forma separada, de acordo com a resolução normativa $n^{0}$ 479/2012 da Agência Nacional de Energia Elétrica (ANEEL).

A informação discriminada serve para que o cliente possa identificar, ao ler a fatura, a parcela correspondente ao consumo de energia (TE) e aquilo que corresponde à utilização do sistema de distribuição de energia elétrica (TUSD). Esses valores que aparecem nas contas se referem aos valores em megawatt-hora (MWh) consumidos. Para saber o valor por quilowatt-hora (kWh), basta dividir o valor da tarifa por 1.000 . 


\subsection{1}

\section{O Novo Sistema de Bandeiras Tarifárias}

Ao longo de 2014, a ANEEL realizou testes para a implantação do sistema de bandeiras tarifárias com o objetivo de sinalizar, aos consumidores faturados pela distribuidora por meio da Tarifa de Energia (TE), os custos atuais da geração dessa energia elétrica consumida. Ao longo desses testes, foram simulados os resultados obtidos com a aplicação hipotética das bandeiras amarela e vermelha, além de explicar aos consumidores os procedimentos de aplicação do sistema.

Basicamente, esse sistema tem como objetivo informar aos consumidores quando o país precisa utilizar fontes de energia diferentes da hidrelétrica, que é a forma de geração mais utilizada no Brasil e cujo custo de geração é o menor.

Em períodos de pouca chuva, a reserva de água nos reservatórios diminui e para garantir o fornecimento de energia é necessário acionar as usinas termelétricas que aumentam o custo de geração. Por outro lado, quando há muita água armazenada, as térmicas não precisam ser ligadas e o custo de geração é menor.

A aplicação das bandeiras tarifárias permitirá que os consumidores tenham informações mais claras sobre o custo de energia, podendo reduzir o consumo, se assim decidirem, além de reduzir os gastos das distribuidoras no curto prazo, uma vez que o repasse pelo maior custo de geração ocorrerá no mês subsequente.

Em resumo, podemos entender as três bandeiras desse novo sistema tarifário da seguinte maneira:

- Bandeira Verde: Condições Favoráveis de Geração de Energia. Não implica em nenhuma tarifa adicional;

- Bandeira Amarela: Condições de Geração Menos Favoráveis. Acréscimo de R\$0,015 por kWh ao valor da tarifa de energia (TE), líquida de tributos;

- Bandeira Vermelha: Condições Mais Custosas de Geração. Acréscimo de $\mathrm{R} \$ 0,030$ por $\mathrm{kWh}$ ao valor da tarifa de energia (TE), líquida de tributos.

Vale ressaltar que durante esse período de testes, apesar de ter apresentado bandeira vermelha em quase todo o período, o sistema de bandeiras foi aplicado apenas para efeitos de simulação, sem nenhum impacto no custo da conta de 
energia do consumidor final. Porém, coube à distribuidora destacar nas faturas dos consumidores qual a bandeira estaria sendo aplicada no período se o sistema estivesse operacional (verde, amarela ou vermelha).

Esse sistema de bandeiras tarifárias entrará em operação a partir de Janeiro de 2015, quando efetivamente os novos valores começam a ser cobrados.

\section{3}

\section{O Valor de um Projeto}

As decisões financeiras quanto ao valor de um projeto ou empresa são geralmente baseados em algum modelo de avaliação.

Segundo Neto (2010), as decisões de investimento de longo prazo consistem na utilização de métodos de avaliação econômica com vista em se apurar os resultados das aplicações do capital por parte do investidor. Esses modelos quantitativos de análises visam buscar parâmetros indicativos de sua viabilidade, consistindo em verificar se os retornos que foram originados no decorrer do projeto justificam ou não os investimentos realizados nos mesmos.

De acordo com Copeland e Antikarov (2001), a técnica do Fluxo de Caixa Descontado (FCD) oferece mais confiança e sofisticação na avaliação do valor de uma empresa. O valor presente líquido (VPL) é uma ferramenta que utiliza a técnica do FCD e tem sido muito usada para análise de projetos de investimentos. O critério de aceitação dessa técnica é bastante simples e de fácil aplicação. Caso o valor presente da projeção dos fluxos de caixa futuros seja superior ao investimento realizado (VPL >0), o projeto deve ser aceito; caso contrário, se o valor presente da projeção dos fluxos de caixa futuros for inferior ao investimento com o projeto (VPL $<0$ ), o mesmo deve ser rejeitado pelo investidor.

Os métodos mais tradicionais de avaliação de um projeto, como o VPL, a taxa interna de retorno (TIR) e o payback são baseados nas previsões de fluxos de caixa futuros do empreendimento. Esses fluxos de caixa futuros são estimados e os riscos desses fluxos não corresponderem ao esperado são inseridos na análise por meio da taxa de desconto ajustada ao risco. Porém, ao longo do ciclo de vida de um projeto, as variáveis que influenciam o mesmo (premissas) podem mudar consideravelmente. Essas mudanças podem ocorrer tanto na fase de avaliação do projeto, como durante todo o ciclo de vida do mesmo. Num ambiente de grande 
incerteza com relação ao futuro, é necessário levarmos em consideração as flexibilidades gerenciais frente às mudanças no cenário empresarial. Porém, essa metodologia tradicional de avaliação de projetos ignora essas possíveis flexibilidades gerenciais.

\section{4}

\section{Introdução à Teoria da Opções Reais}

A teoria das opções reais (TOR) é originada da teoria de opções financeiras existentes desde os trabalhos de Black \& Scholes (1973) e Merton (1976), a partir das quais surgiu a ideia de se incorporar métodos semelhantes ao problema do investimento sob condições de incerteza.

De acordo com Copeland \& Antikarov (2001) a análise pelo método de opções reais é mais relevante quanto maior for a incerteza e quanto maior for a capacidade de se adaptar a ela.

Segundo Bastian-Pinto (2009), a ferramenta mais adequada para quantificar as flexibilidades gerenciais e estratégicas embutidas tanto nos projetos corporativos quanto no valor das empresas, é a avaliação pela Teoria de Opções Reais (TOR), a qual avalia com maior precisão a capacidade da gestão em adaptar-se às novas informações.

Trigeorgis (1996) ressalta que, sob incerteza, o valor futuro de uma variável é caracterizado por uma distribuição de probabilidade, sendo sua variabilidade uma medida do risco de tal variável com impacto nos fluxos de caixa futuros de um projeto.

McDonald e Siegal (1987) foram os pioneiros a perceber as brechas existentes no método de Fluxo de Caixa Descontado (FCD), uma vez que esse método considera que todos os projetos com o VPL positivo criam valor para os acionistas. Eles mostraram que a decisão ótima de investir num projeto ocorre quando o VPL do mesmo excede o valor da opção de espera.

Para Pindyck (1991), os métodos tradicionais não consideram duas características importantes existentes na maioria dos projetos de investimentos: os investimentos podem ser adiados e os investimentos iniciais são muitas vezes irreversíveis. Essa possibilidade de adiamento dos investimentos permite aos investidores esperarem por novas informações (preços, custos ou outras condições 
de mercado etc) antes de realizarem quaisquer investimentos, enquanto que a irreversibilidade indica que, muitas vezes, os investimentos realizados não poderão ser recuperados e se tornarão custos afundados.

Em consonância com a discussão, Minardi (2004) ressalta que as técnicas tradicionais de avaliação de projetos são baseadas em pressupostos de que os fluxos de caixa não se alteram no decorrer da vida útil de um projeto e que as incertezas ligadas a ele, bem como as reações dos gestores às mudanças das condições que o envolvam, são tratadas superficialmente ou ignoradas, ou seja, uma vez tomada a decisão, esta deverá ser mantida até o final de seu ciclo de vida.

Segundo Ross et al. (1995), uma empresa tomará decisões de investimento e decisões operacionais em relação a um projeto durante todo o seu ciclo de vida. As avaliações realizadas no momento presente partem do princípio que as decisões futuras serão ótimas, porém, não se sabe ainda quais serão essas decisões, uma vez que grande parte das informações ainda estão por serem descobertas. Portanto, a possibilidade de adiamento de um investimento é uma opção importante e não deve ser desconsiderada na avaliação da viabilidade de um projeto.

A utilização da teoria de opções reais tem sido utilizada nas mais diversas áreas desde que Dixit e Pindyck (1994) e Trigeorgis (1996) escreveram seus primeiros livros com os principais conceitos para avaliação dos diversos tipos de opções reais. A TOR já vem sendo amplamente utilizada e aceita em análise de projetos de longo prazo, em setores de infraestrutura e em diversos outros setores.

Griffes, Hsu et al. (1999) discorrem sobre os tipos de opções reais que podem existir na avaliação de unidades termelétricas. Gomes (2002) faz uso de um modelo de opções reais para escolher melhor momento de construção de um empreendimento considerando a incerteza externa na expansão da oferta de termelétricas, enquanto Bastian-Pinto (2009) faz uso da TOR na indústria brasileira de etanol.

De acordo com Brandão (2002), para que um projeto apresente valor de opção, três condições são necessárias: a irreversibilidade (que o investimento seja total ou pelo menos parcialmente irreversível), a flexibilidade (que permita ao gerente operar o projeto de forma diferenciada: adiando, suspendendo, abandonando etc) e que exista incerteza sobre os fluxos de caixas que serão gerados pelo projeto. 


\subsection{1}

\section{A Irreversibilidade}

Por que uma despesa de investimento pode ser irreversível?

Existem diversos investimentos que são específicos de alguma empresa ou setor. São investimentos que depois de realizados não permitem que o seu investidor recupere o seu capital investido no projeto. Esses investimentos são também chamados custos afundados.

A irreversibilidade do investimento é uma das características que leva ao investidor a diversos questionamentos sobre o melhor momento de investir em um projeto.

Segundo Brandão (2002), tomar uma decisão de investimento irreversível tem um custo de oportunidade que precisa ser considerado na correta avaliação da decisão de investimento. Portanto, mesmo que a empresa ainda não tenha realizado tal investimento, o valor da opção de investir deve ser precificado nessa análise, pois, esse valor é perdido quando o projeto é realizado. Ou seja, o valor do projeto deve cobrir não apenas o custo do seu investimento inicial, mas também o custo de oportunidade da opção de investir.

McDonald e Siegel (1987), ressaltam que a decisão de investir se torna irreversível pelo fato da planta operacional da empresa não poder ser utilizada para outros propósitos, porém, a decisão de diferir o investimento antes da sua realização é reversível. Os autores estabelecem modelos que permitem ao gestor determinar o timing ótimo para a realização de um projeto e consideraram que a opção de adiamento tem uma importância significativa no valor total do projeto.

\subsection{2}

\section{A Flexibilidade}

A flexibilidade gerencial na implementação é uma característica que nem sempre está presente nos investimentos. Ela indica que o investidor tem a possibilidade de adaptar as suas ações às informações vai recebendo ao longo do ciclo de vida do projeto. Algumas análises estratégicas podem fazer com que os investidores antecipem a realização de investimentos. Porém, na maioria dos casos, o adiamento ou alteração na implementação dos projetos é possível. 
Minardi (2000) enfatiza que a flexibilidade pode ser entendida como uma série de opções reais que uma empresa pode adotar como uma resposta adaptativa às incertezas e às informações que vão surgindo ao longo do desenvolvimento de um projeto. Segundo a autora, são exemplos de opções reais capazes de serem adotados: o adiamento de um projeto para se obter melhores informações sobre o mercado (minimizando algumas incertezas); o abandono temporário ou definitivo (caso as condições de mercado se tornem muito desfavoráveis a sua execução) e a expansão ou a contração da escala de produção (caso as condições do mercado se tornem melhores ou piores que as previstas inicialmente).

\subsection{3}

\section{A Incerteza}

Segundo Rigolon (1999), a incerteza sobre o futuro é a terceira característica importante da decisão de investir. Os valores do projeto, da opção de investir e da própria decisão de investir são afetados pela incerteza associada a variáveis relevantes, como o preço do produto, o custo dos insumos, a taxa de juros, a taxa de câmbio, a oferta de crédito e a regulação.

\subsection{4}

\section{As Opções Financeiras}

O desenvolvimento teórico da teoria das opções iniciou-se com Black \& Scholes (1973), ao desenvolver uma fórmula para a avaliação de opções financeiras.

Segundo Silva e de Araújo (1996), uma opção é um contrato entre duas partes, que dá a seu titular ou comprador um direito, mas não a obrigação, de comercializar uma quantidade fixa de determinado ativo a um preço estabelecido.

De acordo com COSTA, COSTA et al. ( 2010), existem basicamente dois tipos de opções: a opção de compra (call) e a opção de venda (put). Na opção de compra, o detentor tem o direito, mas não a obrigação, de comprar o ativo subjacente por determinado preço de exercício em uma determinada data futura ou antes de determinada data futura. Enquanto que na opção de venda, o detentor 
tem o direito de vender o ativo subjacente por um determinado preço de exercício em uma data futura ou antes de determinada data futura.

Ainda segundo COSTA, COSTA et al. (2010), existem duas posições para cada tipo de opção: posição comprada (long), que significa ter comprado uma opção, e posição vendida (short), que significa ter vendido uma posição. Assim, se um investidor realizar uma operação de compra ou de venda de opções, existem quatro tipos de resultados (payoff) associados às opções. Abaixo, são exemplificados os gráficos dos resultados de cada um desses cenários, tendo como referência um valor de exercício $\left(S_{t}\right)$ de 100:

- Compra de opção de compra: máx. $\left(\mathbf{S}_{\mathbf{t}}-\mathbf{X} ; \mathbf{0}\right)$

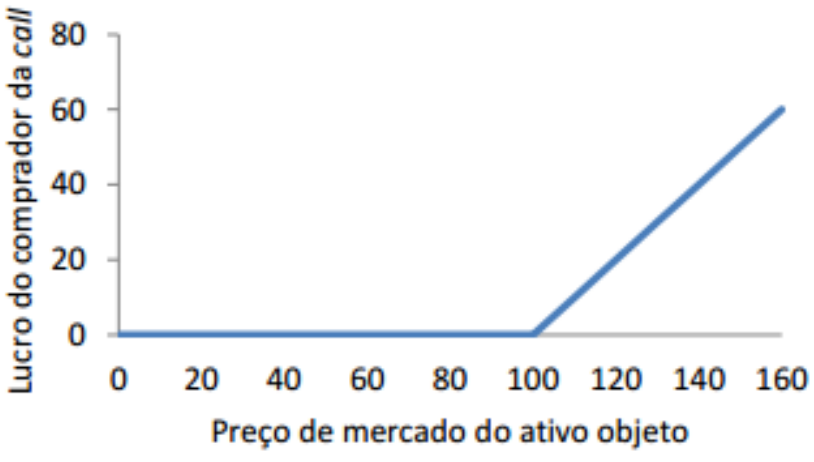

Figura 1 - Compra de Opção de Compra

- Venda de opção de compra: mín. $\left(\mathbf{X}-\mathbf{S}_{\mathbf{t}} ; \mathbf{0}\right)$

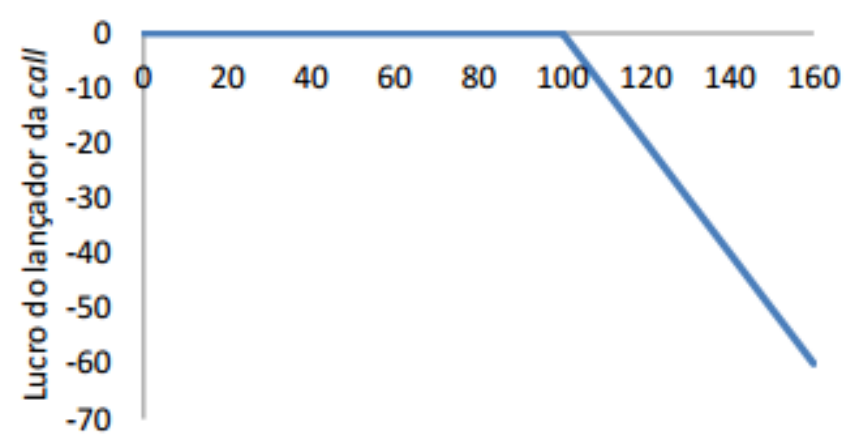

Figura 2 - Venda de Opção de Compra 
- Compra de opção de venda: máx. $\left(\mathbf{X}-\mathbf{S}_{\mathbf{t}} ; \mathbf{0}\right)$

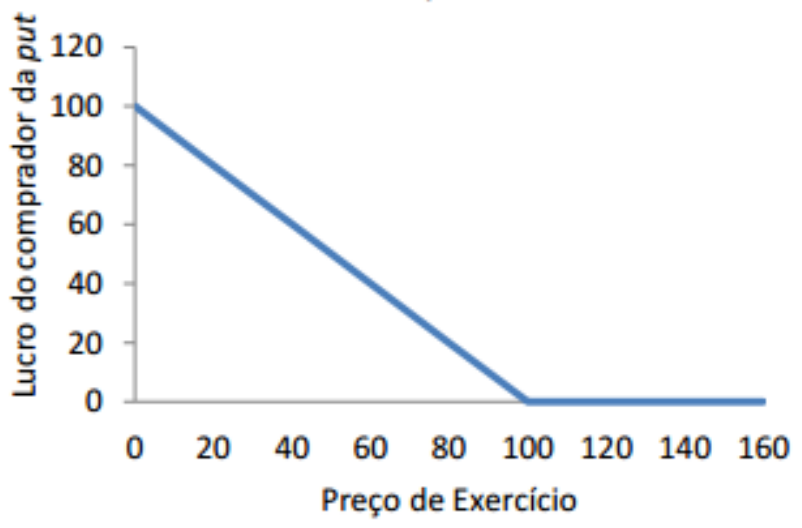

Figura 3 - Compra de Opção de Venda

- Venda de opção de venda: mín. $\left(\mathbf{S}_{\mathbf{t}}-\mathbf{X} ; \mathbf{0}\right)$

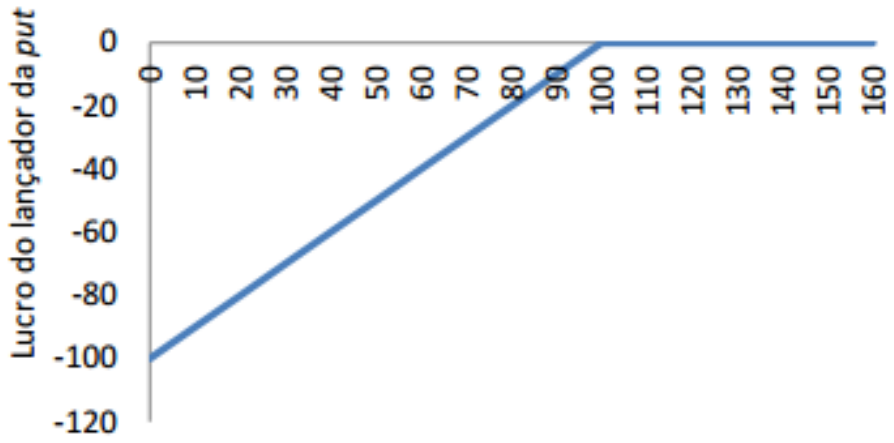

Figura 4 - Venda de Opção de Venda

As opções de compra e de venda podem ainda ser classificadas como opções europeias ou opções americanas. Opções europeias são àquelas exercidas na maturidade, ou seja, na data de vencimento de seu prazo, enquanto as opções americanas são àquelas que podem ser exercidas antecipadamente até a sua maturidade, isto é, até a data de vencimento de seu prazo.

Para valoração de uma opção financeira podemos utilizar dois métodos distintos: o método desenvolvido por Black \& Scholes (1973) e o método binomial (desenvolvido por Cox, Ross e Rubinstein em 1979).

O método Black \& Scholes foi desenvolvido em 1973 através de um modelo para avaliação de opção de compra do tipo europeia. Eles partiram do pressuposto de que o preço de uma ação segue um processo estocástico conhecido como Movimento Geométrico Browniano. Tal modelo é utilizado para precificar 
opções de compra e opções de venda europeia quando o ativo não paga dividendos.

O modelo binomial é uma técnica de modelagem em tempo discreto que permite a precificação de opções sobre um ativo objeto através da construção da chamada árvore binomial, que representa as diferentes trajetórias que o valor do ativo objeto poderá seguir durante a vida das opções. Esse modelo foi desenvolvido para aproximar um processo contínuo seguido por um ativo objeto e calcular o preço de uma opção americana.

\subsection{5}

\section{Analogia entre as Opções Financeiras e as Opções Reais}

Segundo COSTA, COSTA et al. (2010), uma diferença existente entre opções financeiras e opções reais é que nessas últimas, os ativos subjacentes sobre os quais elas se baseiam, geralmente, não são negociados em mercados financeiros. Apesar dessa diferença, muitos dos princípios existentes nas opções financeiras se aplicam às opções reais.

A figura abaixo compara as opções reais às financeiras em suas principais variáveis determinantes de uma opção:

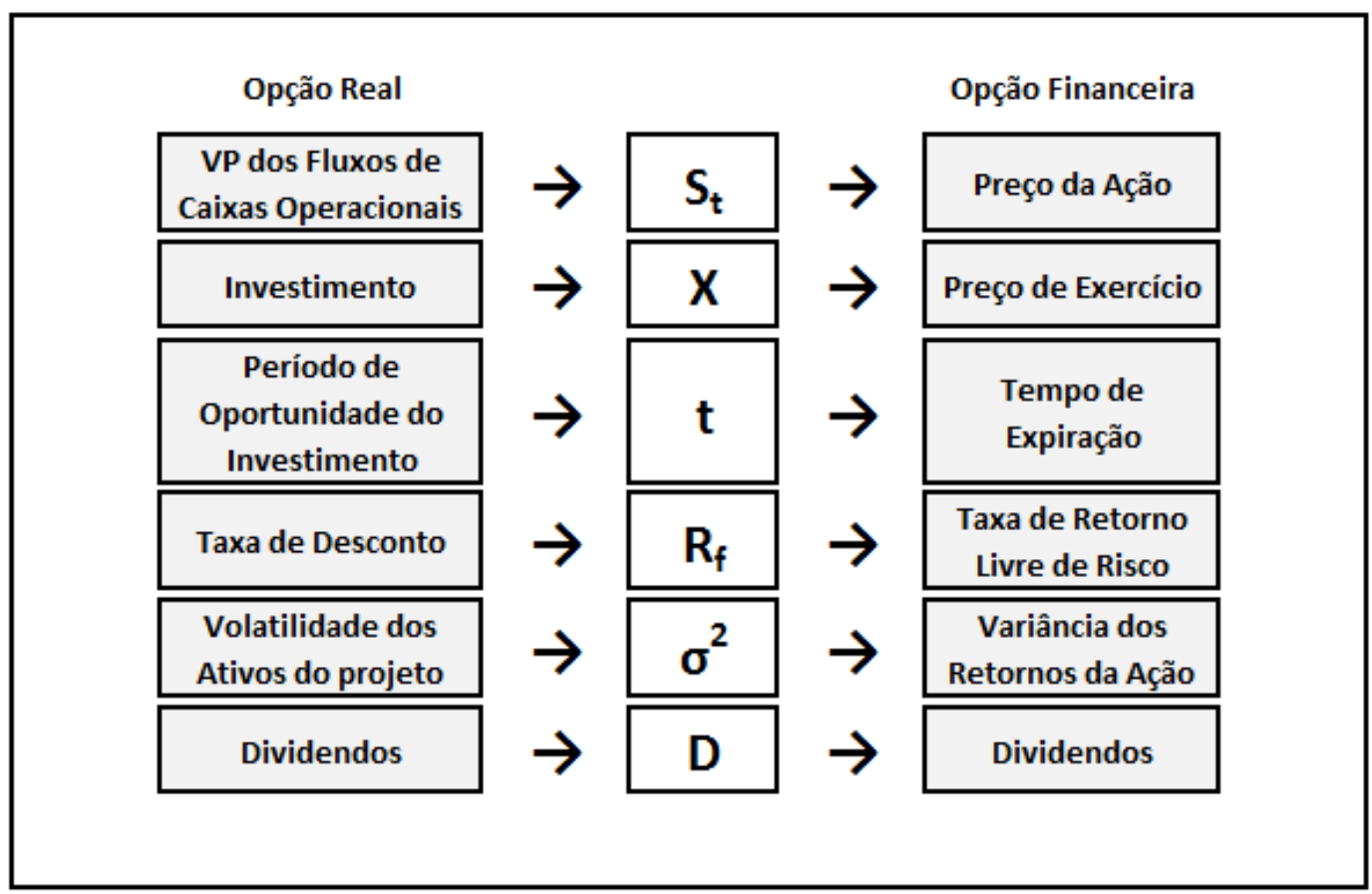

Figura 5 - Analogia entre Opções Reais e Opções Financeiras 
COSTA, COSTA et al. ( 2010) ressaltam que, de forma semelhante às opções financeiras, o valor das opções reais depende de seis importantes variáveis: o valor do ativo subjacente sujeito ao risco (valor do projeto ou do ativo real, desconsiderando as flexibilidades gerenciais); os dividendos, que são os fluxos de caixa descontados futuros produzidos pelo projeto; a volatilidade do preço do ativo (riscos e incertezas relativos ao retorno futuro esperado do investimento); o preço de exercício; o tempo de expiração da opção (seu prazo de vencimento) e a taxa de juros livre de risco.

De acordo com Pindyck (1991) um projeto com investimento irreversível é semelhante a uma opção de compra, pois, quem a possui, tem o direito e não a obrigação, de numa determinada data, pagar o preço de exercício e receber o valor do ativo. Da mesma forma, uma empresa que tem a oportunidade de investir, pode optar por exercer o investimento imediato ou no futuro, recebendo da mesma maneira um valor, que no caso da empresa são os fluxos de caixa gerados pelo projeto. Tanto na opção financeira, quanto na empresa, uma vez exercida a opção, o investidor não mais poderá recuperar o valor do desembolso.

Segundo Copeland e Antikarov (2001), o modelo de Black \& Scholes (1973) é limitado para análise de opções reais, pois, a sua aplicação para maioria dos projetos exige que se despreze pelo menos uma de suas premissas. As opções mais comuns à maioria dos projetos possuem características de opções americanas, enquanto que umas das premissas o referido modelo considera que ele deverá ser usado para opções europeias. Ainda segundo Copeland e Antikarov (2001) um método muito utilizado para avaliar esses tipos de opções é o modelo binomial proposto por Cox, Ross e Rubinstein (1979).

\subsection{6}

\section{O Modelo Binomial}

O primeiro modelo de árvores binomiais foi desenvolvido por Cox, Ross e Rubinstein (1979) e foi baseado na ideia de que o preço do ativo-objeto segue um processo binomial multiplicativo ao longo de sucessivos intervalos de tempos discretos. 
Segundo Hull (2009), a árvore binomial é uma técnica muito conhecida e trata-se de um diagrama que representa os diferentes caminhos que podem ser seguidos pelo preço do ativo-objeto durante a vida da opção.

De acordo com Mikoszewski (2003), o modelo binomial é considerado intuitivo, flexível e de fácil desenvolvimento, não necessitando de uma aplicação matemática muito sofisticada. O autor ressalta que o modelo pode ser aplicado tanto para opções europeias, como para as americanas, podendo ser aplicado a todos os mercados.

Segundo Macedo e Nardelli (2008), por meio do modelo binomial, pode-se avaliar projetos que apresentem um grande número de períodos, sendo que, em cada um desses períodos é possível que o preço da opção real assuma somente dois valores distintos no tempo: o valor ascendente ou o valor descendente.

Bastian-Pinto (2009) ressalta que a aproximação binomial recombinante, ou lattice, é robusta, versátil e talvez uma das metodologias mais utilizadas para discretização de processos estocásticos.

Segundo Santos Filho (2003), o modelo binomial tem como base as seguintes premissas:

- A existência de uma taxa livre de risco positiva e constante;

- A possibilidade de indivíduos aplicarem ou tomarem emprestado o montante desejado a esta mesma taxa livre de risco;

- A não existência de custos de transações, de tributações e de requerimentos de depósitos de margem de garantia;

- O empréstimo tomado pode ser pago somente com a receita das vendas das ações, mas caso esta seja menor que o valor do empréstimo atualizado é dado a moratória da diferença;

- A independência do valor da opção em relação à posição do investidor diante do risco e,

- A dependência do valor da opção ao valor e volatilidade da ação e à taxa de juros livre de risco.

Brandão (2002) ressalta que uma árvore binomial discreta pode ser utilizada para modelar a distribuição de probabilidade lognormal contínua. 
Segundo Cox, Ross e Rubinstein (1979), a cada momento (passo temporal), são possíveis apenas dois comportamentos e o preço $\left(\mathrm{S}_{\mathrm{t}}\right)$ é multiplicado por uma variável aleatória de subida (u) ou de descida (d), conforme graficamente representado abaixo:

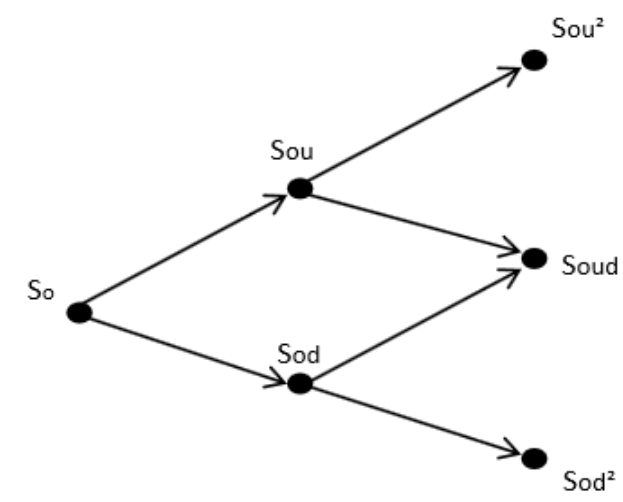

Figura 6 - Modelo de Cox, Ross e Rubinstein

Onde:

$\mathrm{S}_{\mathrm{o}}=$ preço da ação no período inicial;

u = subida da ação (sendo que “u” > 1)

d = “descida" da ação (sendo que "d" < 1)

$\mathrm{S}_{\mathrm{ou}}=$ preço da ação depois de uma subida (sendo que “u” $>1$ )

$\mathrm{S}_{\mathrm{od}}=$ preço da ação depois de uma descida (sendo que "d" < 1)

Brandão (2002) ressalta também que para que essa representação emule uma distribuição lognormal é necessário que sejam escolhidos valores apropriados para $\boldsymbol{u}, \boldsymbol{d}$ e a probabilidade $\boldsymbol{p}$, de forma que a média e a variância dos retornos de $\mathbf{S}$ sejam os mesmos que os do Movimento Geométrico Browniano (MGB) de S, dS $=\mu \mathrm{Sdt}+\sigma \mathrm{S} \mathrm{dz}$.

Considerando que $\mathbf{S}_{\mathbf{1}}=\mathbf{S}_{\mathbf{0}} \mathbf{e}^{\mathbf{v} \Delta t}$ e desenvolvendo algebricamente, conseguimos demonstrar que $\mathbf{S}_{\mathbf{1}}$ assumirá o valor de $\mathbf{S}_{\mathbf{d}}$ ou $\mathbf{S}_{\mathbf{u}}$ com probabilidades p e (1-p) respectivamente, conforme figura abaixo: 


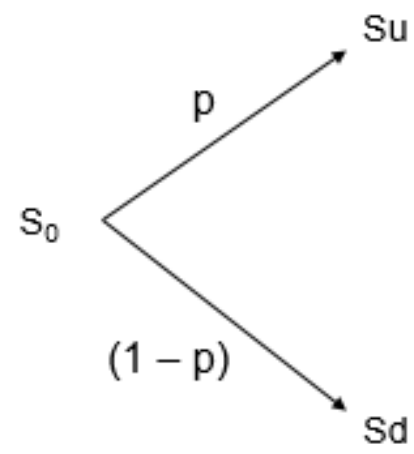

Figura 7 - Preço da Ação no Processo Binomial

Onde:

$$
\begin{aligned}
& u=e^{\sigma \sqrt{ } \Delta t} \\
& d=e^{-\sigma \sqrt{ } \Delta t}
\end{aligned}
$$

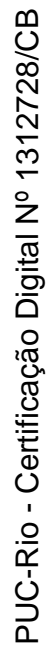

$$
p=\frac{e^{r \Delta t}-d}{u-d}
$$$$
\Delta \mathrm{t}=\text { Espaço Temporal }
$$ 


\section{A Modelagem do Estudo}

\section{1}

\section{Sistema Fotovoltaico Residencial}

A implantação de um sistema fotovoltaico residencial de pequeno porte deve ser precedida de um estudo de viabilidade técnica e financeira.

Essa análise de viabilidade pode ser realizada básica e resumidamente através dos seguintes passos:

- Identificação dos dados do consumidor: localização, consumo energético, local de montagem do sistema (tipo de telhado e espaço disponível);

- Verificação da disponibilidade solar e condições climáticas do local escolhido;

- Definição da capacidade e da quantidades de módulos fotovoltaico a serem instalados;

- Realização do estudo do potencial de geração do sistema fotovoltaico ao longo de uma ano típico;

- Avaliação do custo da eletricidade na concessionária local e a probabilidade de economia pela geração fotovoltaica;

- Realização da análise do custo de instalação (CAPEX) e manutenção (OPEX) do sistema com a estimativa de produção energética e economia financeira;

- Determinação do tempo de retorno do investimento.

\section{2}

\section{A Identificação do SFCR do Estudo}

O estudo em questão será realizado em uma residência (casa) localizada na região metropolitana de Belo Horizonte (Minas Gerais) e possui um telhado de 
“duas águas” com aproximadamente $27 \mathrm{~m}^{2}$ (9 m x $3 \mathrm{~m}$ ) cada uma. O consumo de energia elétrica ao longo do último ano foi medido conforme tabela abaixo:

Tabela 1 - Consumo de Mensal de Eletricidade em kWh

\begin{tabular}{lc}
\hline Mês & $\begin{array}{c}\text { Eletricidade total } \\
\text { consumida } \\
\text { [KWh] }\end{array}$ \\
\hline Janeiro & 778 \\
Fevereiro & 561 \\
Março & 679 \\
Abril & 545 \\
Maio & 522 \\
Junho & 423 \\
Julho & 455 \\
Agosto & 511 \\
Setembro & 437 \\
Outubro & 493 \\
Novembro & 411 \\
Dezembro & 496 \\
\hline Total Anual & 6.311 \\
\hline Média Anual & 526 \\
\hline
\end{tabular}

O consumo acima é o consumo dos meses de 2014, com exceção do mês de Dezembro (mês corrente), cuja referência é do ano de 2013. Vale ressaltar que fazendo-se uma comparação dos consumos, mês a mês, dos anos de 2013 e 2014, verifica-se uma manutenção da ordem de grandeza entre os mesmos meses, bem como é respeitada a mesma sazonalidade mensal ao longo desse período de amostragem.

\section{3}

\section{A Disponibilidade Solar}

Chigueru (2000), no Atlas Solarimétrico do Brasil, afirma que a disponibilidade de radiação solar (energia total incidente sobre a superfície terrestre) depende das condições atmosféricas (nebulosidade, umidade relativa do ar etc.), e da latitude do local e da posição no tempo (hora do dia e dia do ano). Em Belo Horizonte (Minas Gerais), onde está localizada a residência desse estudo, a radiação solar média diária varia entre 4,5 a $6,5 \mathrm{kWh} / \mathrm{m}^{2}$.

O Brasil possui um enorme potencial para utilização da energia solar, apresentando índices de insolação em seu território muito maiores do que os 
principais líderes no uso da tecnologia fotovoltaica. A insolação média diária do Brasil está demonstrada no mapa abaixo:

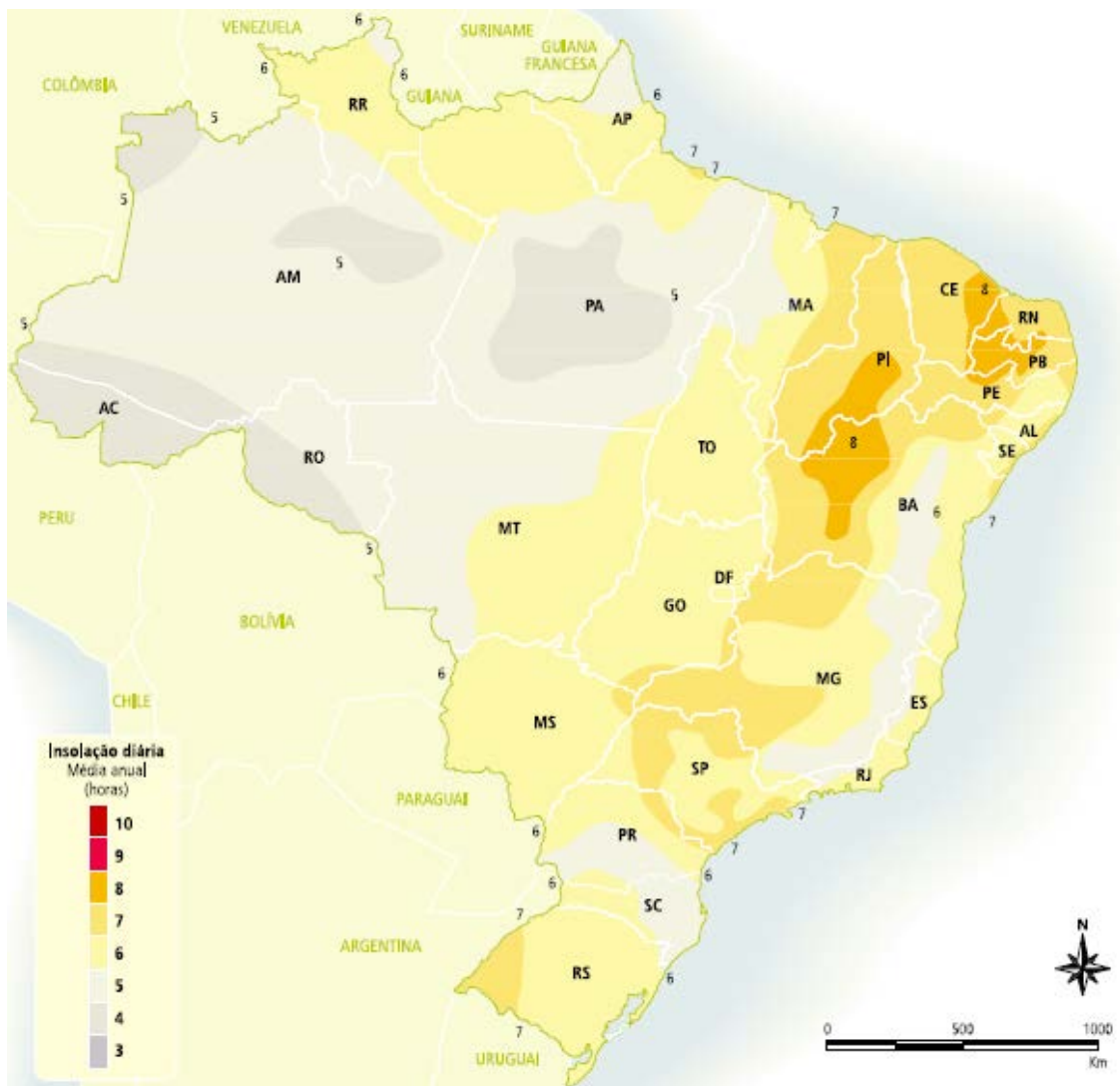

Figura 8 - Insolação Média Diária do Brasil

\section{4}

\section{A Capacidade Instalada e Geração Anual}

Para definição da capacidade do sistema fotovoltaico a ser instalado, além da localização, do espaço disponível, da insolação média anual e da demanda residencial por energia, deve-se levar em consideração as regras do sistema de compensação de energia estabelecida pela concessionária onde o sistema está implementado. Para o SFCR conectado à rede da CEMIG, o pagamento mínimo de $100 \mathrm{kWh} /$ mês é assegurado contratualmente, dessa forma, para garantir que a compensação da energia será maximizada, foi definido um sistema fotovoltaico com uma capacidade nominal de $3.3 \mathbf{~ k W}$ a ser implementado.

Considerando as premissas acima, o projeto do SFCR, incluindo a definição do número e tipos das placas fotovoltaicas a serem implantadas, foi 
definido com o auxílio do software de planejamento PVsyst Version 6 da empresa PVsyst Software (www.pvsyst.com).

Após inseridos os dados de entrada no software (localização, demandas de energia mensal, tipo de placas e etc), os dados do projeto fotovoltaico foram definidos e o sistema planejado, conforme figura abaixo:

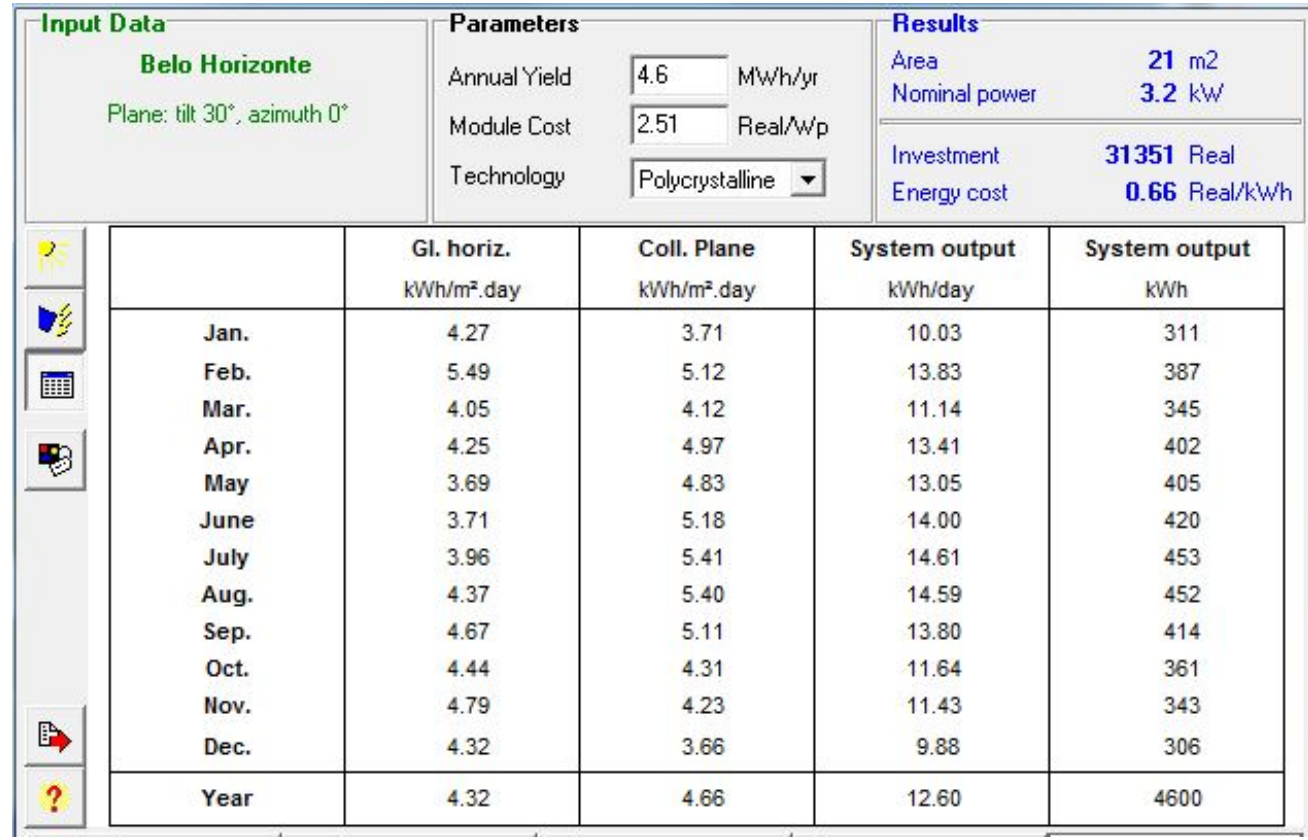

Figura 9 - Planejamento do Sistema Fotovoltaico

Como dados de saída da ferramenta de planejamento, temos ainda:

- O orçamento de Implantação do SFCR: R\$ 31.351,00;

- Área Utilizada do Telhado: $21 \mathbf{~ m}^{2}$;

- Previsão de Geração Mensal do Sistema, em kWh;

Considerando as premissas definidas e as informações obtidas acima, podemos iniciar a obtenção dos objetivos específicos definidos na seção 1.1.2 desse estudo.

\section{5}

\section{Cálculo do Cenário Base}

O objetivo desse estudo é realizar uma avaliação do investimento na implementação de um sistema fotovoltaico residencial de geração de energia. Portanto, a “receita” tratada no presente estudo é, na verdade, a economia feita 
através do sistema de compensação de energia definido pela ANEEL através da Resolução Normativa $n^{0}$ 482/2012. Vale ressaltar que a resolução em questão menciona somente a compensação da energia, uma vez que a energia gerada é usada para abater o consumo de energia elétrica residencial na fatura do mês subsequente e que esses créditos continuam válidos por 36 meses, podendo inclusive ser utilizado em outra unidade consumidora (desde que ambas estejam na mesma área de concessão e tenham como titular o portador do mesmo Cadastro de Pessoa Física). Ou seja, em nenhum momento, na resolução n ${ }^{0}$ 482/2012, a resolução da ANEEL menciona valores financeiros de compra e venda de eletricidade por parte do micro gerador.

Considerando as premissas do projeto, as regras estabelecidas pela concessionária CEMIG e o consumo da residência em questão, a tabela abaixo mostra o funcionamento do sistema de compensação de energia:

Tabela 2 - Funcionamento do Sistema de Compensação de Energia

\begin{tabular}{|c|c|c|c|c|c|c|}
\hline Mês & $\begin{array}{l}\text { Eletricidade total } \\
\text { consumida } \\
\text { (KWh] }\end{array}$ & $\begin{array}{c}\text { Eletricidade } \\
\text { gerada pelo } \\
\text { sistema FV } \\
\text { [KWh] }\end{array}$ & $\begin{array}{c}\text { Crédito } \\
\text { Acumulado }\end{array}$ & $\begin{array}{c}\text { Valor da } \\
\text { Conta [R\$] } \\
\text { [Ref_2014] } \\
\text { sem GD }\end{array}$ & $\begin{array}{c}\text { Eletricidade } \\
\text { fornecida } \\
\text { pela rede } \\
\text { (KWh] }\end{array}$ & $\begin{array}{c}\text { Eletricidade } \\
\text { a Pagar } \\
\text { [KWh] }\end{array}$ \\
\hline Janeiro & 778 & 311 & 0 & RS 593,37 & 467 & 467 \\
\hline Fevereiro & 561 & 387 & 0 & RS 436,81 & 174 & 174 \\
\hline Março & 679 & 345 & 0 & RS 521,94 & 334 & 334 \\
\hline Abril & 545 & 402 & 0 & RS 425,27 & 143 & 143 \\
\hline Maio & 522 & 405 & 0 & RS 408,68 & 117 & 117 \\
\hline Junho & 423 & 420 & 0 & RS 337,25 & 3 & 100 \\
\hline Julho & 455 & 453 & 0 & RS 360,34 & 2 & 100 \\
\hline Agosto & 511 & 452 & 0 & RS 400,74 & 59 & 100 \\
\hline Setembro & 437 & 414 & 0 & RS 347,35 & 23 & 100 \\
\hline Outubro & 493 & 361 & 0 & RS 387,75 & 132 & 132 \\
\hline Novembro & 411 & 343 & 0 & RS 328,60 & 68 & 100 \\
\hline Dezembro & 496 & 306 & 0 & RS 389,92 & 190 & 190 \\
\hline Total Anual & 6.311 & 4.599 & 0 & $\mathrm{R} \$ 4.938,02$ & 1.712 & 2.057 \\
\hline Média Anual & 526 & 383 & 0 & $\mathrm{R} \$ \mathbf{4 1 1 , 5 0}$ & 143 & 171 \\
\hline
\end{tabular}

Vale ressaltar que no contrato com a CEMIG está definido que será cobrado da unidade consumidora integrante do sistema de compensação de energia elétrica, no mínimo, o valor referente ao custo de disponibilidade para o consumidor do grupo B, cujos valores são determinados pelo tipo de ligação. Para a residência em questão (classe B1), cujo sistema é Trifásico, foi definido na 
resolução em questão o valor, em moeda corrente, equivalente valor monetário equivalente a $100 \mathrm{kWh}$.

Por essa razão, nos meses de Junho, Julho, Agosto, Setembro e Novembro está sendo considerado o valor a pagar equivalente a 100 kWh, que está ressaltado, em negrito, na tabela acima.

Com base no sistema de compensação de energia apresentado e considerando o valor da tarifa de energia (incluindo encargos), definimos os valores a pagar e os valores economizados pela implantação do sistema fotovoltaico na residência.

É importante destacar que após a homologação da Resolução n 482/2012 por parte da ANEEL, o Conselho Nacional de Política Fazendária (CONFAZ) aprovou o Convênio ICMS 6, de 5 de abril de 2013, estabelecendo que o ICMS apurado teria como base de cálculo toda a energia que chega à unidade consumidora proveniente da distribuidora, sem considerar qualquer compensação de energia produzida pelo micro gerador. Com isso, a alíquota aplicável do ICMS incidiria sobre toda a energia consumida no mês e não pela diferença do sistema de compensação, conforme havia estabelecido a agência reguladora.

A ANEEL, em seu caderno temático sobre o tema, ressaltou que possui entendimento diverso em relação à cobrança do ICMS no âmbito do sistema de compensação, pois, a energia elétrica injetada é cedida, por meio de empréstimo gratuito, à distribuidora e posteriormente compensada no consumo dessa mesma unidade consumidora ou de outra unidade consumidora de mesma titularidade onde os créditos foram gerados.

Porém, o Estado de Minas Gerais publicou, em 31 de julho de 2013, a Lei $\mathrm{n}^{\circ} 20.824$ com o objetivo de estabelecer que o ICMS no Estado deveria ser cobrado apenas sobre a diferença positiva entre a energia consumida e a energia injetada pelos micro e mini geradores, durante um prazo de cinco anos. Vale a ressalva que o posicionamento do Estado de Minas Gerais foi uma das exceções dentre todos os Estados que, de maneira geral, não aceitaram o incentivo à implantação dos sistemas fotovoltaicos através de perdas fiscais não compensadas.

Para efeito do estudo em questão foi adotada a premissa de que o benefício estabelecido nessa lei (cobrança de ICMS somente pela diferença positiva) será mantido após o período inicial de 5 anos. 
Após a conclusão desse estudo (Janeiro de 2015), ocorreram dois reajustes tarifários que foram contemplados nessa versão final do presente trabalho: o reajuste extraordinário da tarifa e o reajuste ordinário da tarifa CEMIG.

O reajuste extraordinário ocorreu no final de Fevereiro de 2015 e foi de 21.39\% para o consumidor residencial da CEMIG, visando compensar o aumento do encargo setorial pela utilização maior do sistema termelétrico de geração e também pelo aumento de custos com a compra de energia produzida em Itaipu. Além desse reajuste extraordinário, no mês de abril, data-base de reajuste da CEMIG, também ocorreu o reajuste de 7.07\%. Considerando esses dois reajustes ocorridos no início de 2015, em relação à 2014, o reajuste tarifário da CEMIG foi de $28.59 \%$.

Portanto, considerando o reajusta de $28.59 \%$ supra citado e esse novo modelo de bandeiras tarifárias, as tarifas de energia elétrica para o consumidor B1 da CEMIG, de acordo com as bandeiras, ficaram assim definidas:

Tabela 3 - Previsão da Tarifa de Energia Elétrica em 2015 para Consumidor B1 da CEMIG

\begin{tabular}{|c|c|c|c|c|c|c|c|}
\hline \multicolumn{4}{|c|}{ Previsão Tarifa em 04/2015 } & \multicolumn{4}{|c|}{ TARIFAS DE APLICAÇÃO } \\
\hline \multirow{2}{*}{ SUBGRUPO } & \multirow{2}{*}{ MODALIDADE } & \multirow{2}{*}{ CLASSE } & \multirow{2}{*}{ SUBCLASSE } & \multirow{2}{*}{$\begin{array}{c}\text { TUSD } \\
\text { [RS / kWh] }\end{array}$} & \multicolumn{3}{|c|}{ TE (RS / kWh) } \\
\hline & & & & & BANDEIRA VERDE & BANDEIRA AMARELA & BANDEIRA VERMELHA \\
\hline B1 & CONVENCIONAL & RESIDENCIAL & RESIDENCIAL & $\mathrm{R} \$ 0,26975$ & $\mathrm{R} \$ 0,24000$ & $R \$ 0,26500$ & $R \$ 0,29500$ \\
\hline
\end{tabular}

Feitas as considerações acima, ao longo do ano de 2015, em função das bandeiras tarifárias, teremos os seguintes valores de tarifas sem a incidência de impostos (TUSD + TE):

- Bandeira Verde: R\$ 0,50974 / kWh

- Bandeira Amarela: R\$ 0,53474 / kWh

- Bandeira Vermelha: R\$ 0,56474 / kWh

Para efeito desse estudo, foi considerado o cenário de bandeira VERMELHA ao longo do todo o período de análise (25 anos). Considerando o histórico do período de teste (bandeira VERMELHA) e que as condições dos reservatórios das usinas hidrelétricas que estão em níveis criticamente baixos, podemos considerar que essa é uma premissa bem realista para o mercado brasileiro de energia. 
A projeção dos reajustes tarifários ao longo dos demais anos (de 2016 em diante) foi realizada através de uma paridade com a taxa de inflação prevista anualmente. Para efeito desse estudo, foi considerada uma taxa de inflação anual de $5.5 \%$.

Portanto, considerando a previsão de geração da energia do sistema fotovoltaico, a previsão do consumo de energia da residência (baseado no consumo dos últimos 12 meses) e os valores da tarifa de energia, temos que a conta do consumo de energia anual da residência em questão é de $\mathbf{R} \mathbf{\$} \mathbf{4 . 9 3 8 , 0 2}$ distribuídos ao longo dos próximos 12 meses conforme tabela abaixo:

Tabela 4 - Previsão de Conta de Energia Mensal ao longo de 2015

\begin{tabular}{lcc}
\hline Mês & $\begin{array}{c}\text { Eletricidade total } \\
\text { consumida } \\
\text { [KWh] }\end{array}$ & $\begin{array}{c}\text { Valor da } \\
\text { Conta [R\$) } \\
\text { (Ref_2014) } \\
\text { sem GD }\end{array}$ \\
\hline Janeiro & 778 & RS 593,37 \\
Fevereiro & 561 & RS 436,81 \\
Março & 679 & RS 521,94 \\
Abril & 545 & RS 425,27 \\
Maio & 522 & RS 408,68 \\
Junho & 423 & RS 337,25 \\
Julho & 455 & RS 360,34 \\
Agosto & 511 & RS 400,74 \\
Setembro & 437 & RS 347,35 \\
Outubro & 493 & RS 387,75 \\
Novembro & 411 & RS 328,60 \\
Dezembro & 496 & RS 389,92 \\
\hline Total Anual & 6.311 & R\$ 4.938,02 \\
\hline Média Anual & 526 & RS 411,50 \\
\hline
\end{tabular}

O cenário acima reflete o consumo dos últimos 12 meses (Dezembro 2013 a Novembro de 2014) e os ajustes tarifários considerados acima, ou seja, é o valor da conta de energia previsto para os próximos 12 meses (consumo dos últimos 12 meses x o valor da tarifa previsto para o ano de 2015).

Feitas todas as considerações acima, o cenário base do sistema de compensação de energia do SFCR implementado na residência apresenta os seguintes valores de referência para o primeiro ano após a implantação (2015), considerado o cenário base do estudo: 
Tabela 5 - Previsão do Cenário Base do Sistema de Compensação de Energia Elétrica

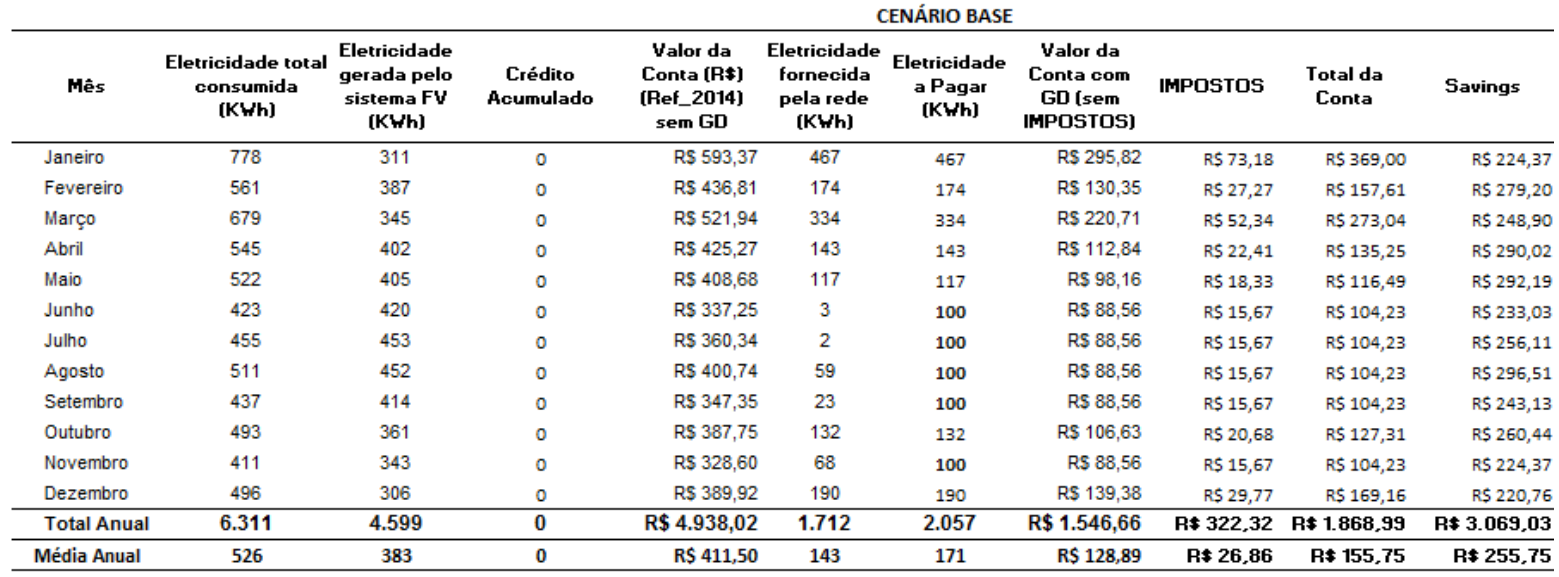

Considerando que a vida útil do sistema implementado é de 25 anos, com uma degradação anual de geração de energia de $0,65 \%$, os números absolutos do sistema implementado ficariam estabelecidos conforme tabela abaixo:

Tabela 6 - Previsão do Sistema de Compensação de Energia Elétrica ao longo dos 25 anos

\begin{tabular}{|c|c|c|c|c|c|c|c|c|c|c|}
\hline Mês & $\begin{array}{c}\text { Total de } \\
\text { Energia } \\
\text { Consumida } \\
\text { (kWh] }\end{array}$ & $\begin{array}{c}\text { Eletricidade } \\
\text { gerada pelo } \\
\text { sistema FV } \\
\text { [KWh] }\end{array}$ & $\begin{array}{c}\text { Crédito } \\
\text { Acumulado }\end{array}$ & $\begin{array}{c}\text { Valor da Conta } \\
\text { [R\$] } \\
\text { [Ref_2014] } \\
\text { sem GD }\end{array}$ & $\begin{array}{l}\text { Eletricidade } \\
\text { fornecida } \\
\text { pela rede } \\
\text { (KWh) }\end{array}$ & $\begin{array}{l}\text { Eletricidade } \\
\text { a Pagar } \\
\text { (KWh] }\end{array}$ & $\begin{array}{c}\text { Valor da } \\
\text { Conta com } \\
\text { GD (sem } \\
\text { IMPOSTOS) }\end{array}$ & IMPOSTOS & Total da Conta & Savings \\
\hline Janeiro & 19.450 & 7.169 & 0 & RS $30.352,21$ & 12.281 & 12.281 & RS $15.990,62$ & RS $3.981,45$ & RS $19.972,07$ & RS $10.380,14$ \\
\hline Fevereiro & 14.025 & 8.920 & 0 & RS $22.344,08$ & 5.105 & 5.105 & RS $7.736,15$ & RS $1.691,16$ & RS $9.427,31$ & RS $12.916,77$ \\
\hline Março & 16.975 & 7.952 & 0 & RS $26.698,73$ & 9.023 & 9.023 & RS $12.242,34$ & RS $2.941,45$ & RS $15.183,78$ & RS 11.514,95 \\
\hline Abril & 13.625 & 9.266 & 0 & RS $21.753,61$ & 4.359 & 4.359 & RS $6.882,03$ & RS $1.454,17$ & RS $8.336,20$ & RS $13.417,42$ \\
\hline Maio & 13.050 & 9.335 & 0 & RS $20.904,83$ & 3.715 & 3.715 & RS $6.139,21$ & RS $1.248,07$ & RS $7.387,28$ & RS $13.517,55$ \\
\hline Junho & 10.575 & 9.681 & 0 & RS $17.251,35$ & 894 & 2.500 & RS $4.529,87$ & RS 801,54 & RS $5.331,41$ & RS 11.919,94 \\
\hline Julho & 11.375 & 10.442 & 0 & RS $18.432,27$ & 933 & 2.500 & RS $4.529,87$ & RS 801,54 & RS $5.331,41$ & RS $13.100,86$ \\
\hline Agosto & 12.775 & 10.419 & 0 & RS $20.498,88$ & 2.356 & 2.663 & RS $4.815,44$ & RS 880,78 & RS $5.696,22$ & RS $14.802,66$ \\
\hline Setembro & 10.925 & 9.543 & 0 & RS $17.768,00$ & 1.382 & 2.500 & RS $4.529,87$ & RS 801,54 & RS $5.331,41$ & RS $12.436,59$ \\
\hline Outubro & 12.325 & 8.321 & 0 & RS $19.834,61$ & 4.004 & 4.004 & RS $6.446,80$ & RS $1.334,59$ & RS $7.781,39$ & RS $12.053,23$ \\
\hline Novembro & 10.275 & 7.906 & 0 & RS $16.808,50$ & 2.369 & 2.615 & RS $4.728,89$ & RS 857,64 & RS $5.586,53$ & RS $11.221,97$ \\
\hline Dezembro & 12.400 & 7.053 & 0 & RS $19.945,33$ & 5.347 & 5.347 & RS $7.974,72$ & RS $1.757,35$ & RS $9.732,07$ & RS $10.213,26$ \\
\hline Total Anual & 157.775 & 106.007 & 0 & $\mathrm{R} \$ 252.592,40$ & 51.768 & 56.611 & $R \$ 86.545,79$ & R* 18.551,28 & $R \neq 105.097,06$ & R* $147.495,33$ \\
\hline Média Anual & 13.148 & 8.834 & 0 & R\$ $21.049,37$ & 4.314 & 4.718 & RS 7.212,15 & $R \$ 1.545,94$ & R\$ $8.758,09$ & $R \leqslant 12.291,28$ \\
\hline
\end{tabular}

Em resumo, o cenário base apresenta os seguintes números ao longo dos 25 anos:

- Custo de Implantação do Sistema: R\$ 31.351,00

- Total da Energia Consumida: 157.775 kWh

- Total da Energia Gerada pelo SFCR: 106.007 kWh (67.19\% do Consumido)

- Total da Energia Fornecida pela Concessionária:51.768kWh(32.81\% do Consumido) 
- Total da Energia Paga à Concessionária: $\mathbf{5 6 . 6 1 1}$ kWh (35.88\% do Consumido)

- Valor Total da Conta de Energia do período sem SFCR: R\$ 252.592,40

- Valor Total da Conta de Energia do período com o SFCR: R\$ 105.097,06

- Total de Economia na Conta pela Implantação do SFCR: R\$ 147.495,33

Como a implantação desse projeto será realizada numa residência de classe média alta de uma pessoa física e o valor do investimento é relativamente baixo (R\$ 31.351,00), o presente estudo considerou que o investimento seria realizado com Capital Próprio do investidor. Ou seja, a taxa a ser considerada levará em conta o custo de oportunidade para o investidor e refletirá somente a concorrência de outros usos que poderia ser dado ao capital próprio de uma pessoa física. Portanto, para efeito desse estudo, está sendo considerada uma taxa anual de $\mathbf{1 1 \%}$ (aproximadamente equivalente ao retorno do investimento de capital num título do Tesouro Direto NTN-B (além de pagar juros, paga a variação da inflação)).

Considerando as premissas descritas ao longo do estudo e fazendo-se uma análise da viabilidade do projeto pelos métodos tradicionais de VPL, TIR e payback, verificamos que a implementação do SFCR é plenamente viável, conforme demonstrado abaixo por tais indicadores:

Tabela 7 - VPL, TIR e Payback do Modelo Determinístico

\begin{tabular}{|c|c|c|c|c|c|c|c|c|}
\hline Base & Ano & Custo & Subsídio Governo & $\begin{array}{l}\text { Redução } \\
\text { Custo } \\
\text { Eletricidade }\end{array}$ & $\begin{array}{c}\text { Fluzo de } \\
\text { Caixa Anual }\end{array}$ & $\begin{array}{l}\text { Fluxo de Caixa } \\
\text { Cumulativo }\end{array}$ & YPL do FCL & $\begin{array}{c}\text { YPL } \\
\text { Cumulativo }\end{array}$ \\
\hline 0 & 2015 & $-\mathrm{R} \$ 31.351$ & & $\mathrm{R} \$ 2.661$ & $-\mathrm{R} \$ 28.690$ & $-\mathrm{R} \$ 28.690$ & $-\mathrm{R} \$ 28.690$ & $-\mathrm{R} \$ 28.690$ \\
\hline 1 & 2016 & 0 & & $\mathrm{R} \$ 2.803$ & $\mathrm{R} \$ 2.803$ & $-\mathrm{R} \$ 25.887$ & $\mathrm{R} \$ 2.525$ & $-\mathrm{R} \$ 26.164$ \\
\hline 2 & 2017 & 0 & & $\mathrm{R} \$ 2.936$ & $\mathrm{R} \$ 2.936$ & $-\mathrm{R} \$ 22.951$ & $\mathrm{R} \$ 2.383$ & $-\mathrm{R} \$ 23.782$ \\
\hline 3 & 2018 & 0 & & $R \$ 3.084$ & $R \$ 3.084$ & $-R \$ 19.867$ & $\mathrm{R} \$ 2.255$ & $-R \$ 21.527$ \\
\hline 4 & 2019 & 0 & & $R \$ 3.239$ & $R \$ 3.239$ & $-R \$ 16.628$ & $\mathrm{R} \$ 2.133$ & $-R \$ 19.393$ \\
\hline 5 & 2020 & 0 & & $R \$ 3.401$ & $R \$ 3.401$ & $-\mathrm{R} \$ 13.227$ & $\mathrm{R} \$ 2.019$ & $-\mathrm{R} \$ 17.375$ \\
\hline 6 & 2021 & 0 & & $\mathrm{R} \$ 3.572$ & $\mathrm{R} \$ 3.572$ & $-\mathrm{R} \$ 9.655$ & $\mathrm{R} \$ 1.910$ & $-\mathrm{R} \$ 15.465$ \\
\hline 7 & 2022 & 0 & & $R \$ 3.751$ & $R \$ 3.751$ & $-R \$ 5.904$ & $R \$ 1.807$ & $-R \$ 13.658$ \\
\hline 8 & 2023 & 0 & & $R \$ 3.940$ & $R \$ 3.940$ & $-\mathrm{R} \$ 1.964$ & $R \$ 1.709$ & $-R \$ 11.949$ \\
\hline 9 & 2024 & 0 & & $\mathrm{R} \$ 4.137$ & $\mathrm{R} \$ 4.137$ & $\mathrm{R} \$ 2.173$ & $R \$ 1.617$ & $-\mathrm{R} \$ 10.331$ \\
\hline 10 & 2025 & 0 & & $R \$ 4.345$ & $R \$ 4.345$ & $R \$ 6.518$ & $R \$ 1.530$ & $-R \$ 8.801$ \\
\hline 11 & 2026 & 0 & & $\mathrm{R} \$ 4.562$ & $R \$ 4.562$ & $R \$ 11.080$ & $R \$ 1.448$ & $-\mathrm{R} \$ 7.354$ \\
\hline 12 & 2027 & 0 & & $R \$ 4.791$ & $R \$ 4.791$ & $\mathrm{R} \$ 15.871$ & $R \$ 1.369$ & $-\mathrm{R} \$ 5.984$ \\
\hline 13 & 2028 & 0 & & $R \$ 5.031$ & $R \$ 5.031$ & $R \$ 20.901$ & $R \$ 1.295$ & $-R \$ 4.689$ \\
\hline 14 & 2029 & 0 & & $R \$ 5.282$ & $R \$ 5.282$ & $R \$ 26.183$ & $R \$ 1.225$ & $-\mathrm{R} \$ 3.464$ \\
\hline 15 & 2030 & 0 & & $R \$ 5.539$ & $R \$ 5.539$ & $\mathrm{R} \$ 31.722$ & $R \$ 1.158$ & $-R \$ 2.306$ \\
\hline 16 & 2031 & 0 & & $R \$ 5.807$ & $R \$ 5.807$ & $\mathrm{R} \$ 37.530$ & $R \$ 1.093$ & $-\mathrm{R} \$ 1.212$ \\
\hline 17 & 2032 & 0 & & $R \$ 6.088$ & $R \$ 6.088$ & $R \$ 43.618$ & $R \$ 1.033$ & $-\mathrm{R} \$ 180$ \\
\hline 18 & 2033 & 0 & & $R \$ 6.382$ & $R \$ 6.382$ & $R \$ 50.000$ & $R \$ 975$ & $R \$ 796$ \\
\hline 19 & 2034 & 0 & & $R \$ 6.690$ & $R \$ 6.690$ & $R \$ 56.690$ & $R \$ 921$ & $R \$ 1.717$ \\
\hline 20 & 2035 & 0 & & $R \$ 7.013$ & $R \$ 7.013$ & $\mathrm{R} \$ 63.703$ & $\mathrm{R} \$ 870$ & $\mathrm{R} \$ 2.587$ \\
\hline 21 & 2036 & 0 & & $\mathrm{R} \$ 7.351$ & $\mathrm{R} \$ 7.351$ & $R \$ 71.054$ & $\mathrm{R} \$ 821$ & $R \$ 3.408$ \\
\hline 22 & 2037 & 0 & & $\mathrm{R} \$ 7.705$ & $R \$ 7.705$ & $R \$ 78.758$ & $\mathrm{R} \$ 776$ & $\mathrm{R} \$ 4.184$ \\
\hline 23 & 2038 & 0 & & $R \$ 8.075$ & $R \$ 8.075$ & $R \$ 86.833$ & $R \$ 732$ & $R \$ 4.916$ \\
\hline 24 & 2039 & 0 & & $R \$ 8.463$ & $R \$ 8.463$ & $R \$ 95.296$ & $R \$ 691$ & $R \$ 5.607$ \\
\hline Total & & $-R \$ 31.351$ & $R \leqslant 0$ & $R \leqslant 126.647$ & $R \leqslant 95.296$ & $R \$ 553.156$ & $R \leqslant 5.607,37$ & \\
\hline \multicolumn{3}{|c|}{$\begin{array}{c}\text { Inflação Anual } \\
\text { Base Anual Conta de } \\
\text { Tasa de Desconto }\end{array}$} & $\begin{array}{r}5,50 \% \\
R * 147.495,33 \\
11,0 \% \\
\end{array}$ & & $\begin{array}{l}\text { UPL } \\
\text { TIR } \\
\text { Payback } \\
\end{array}$ & $\begin{array}{c}\$ 5.607,37 \\
13,11 \% \\
10 \\
\end{array}$ & & \\
\hline
\end{tabular}


Apesar do cenário base apresentar uma viabilidade pelos métodos tradicionais de análise de projeto, estamos num cenário bastante dinâmico em que as variáveis que influenciaram o estudo podem mudar considerável e rapidamente. Nesse ambiente de incertezas é necessário levar em consideração a flexibilidade para que o investidor possa reagir frente às mudanças em andamento, fato esse ignorado por essa metodologia mais tradicional.

\section{6}

\section{Valor do Projeto com Investimento Postergado}

A possibilidade de postergação do investimento na implementação do SFCR desse estudo, com o objetivo de maximizar o retorno ao investidor, será analisada através da Teoria de Opções Reais, sendo necessário para isso estimar a volatilidade do projeto considerando as suas principais variáveis de incerteza: preço da energia elétrica e custo de implementação do sistema fotovoltaico. Essa volatilidade pode ser entendida como uma medida de dispersão do preço ao redor de seu valor esperado em um determinado período de tempo e deve ser devidamente medida e estimada para que o investidor possa tomar posições coerentes.

\subsection{1}

\section{A Volatilidade da Tarifa de Energia Elétrica}

A implementação do sistema fotovoltaico é um investimento que pode ser realizado imediatamente ou pode ser realizado num segundo momento em que o investidor tenha uma maior confiança nos resultados financeiros que serão obtidos. Caso o investidor decida por esperar um pouco mais pela implantação do sistema, existirá uma possibilidade de variação dos valores da tarifa de energia elétrica. Essa variação poderá ser tanto de aumento quanto de queda da tarifa de energia, dependendo de diversos fatores (perfil da geração, inflação, sistema tributário, políticas públicas etc) que independem da vontade do investidor. Essa possibilidade de variação cria uma flexibilidade na decisão de implementação do projeto. 
A volatilidade da tarifa de energia elétrica será calculada no estudo através da série histórica da tarifa de energia elétrica praticada pela CEMIG ao longo dos últimos 10 anos (2004 a 2014).

Essa volatilidade histórica mede a variação das tarifas de energia durante o período, sendo uma tentativa de estimar esse movimento. Ela é utilizada para mostrar quão acentuada é a variação de preço dessa tarifa, ajudando a definir o risco e ajudando a traçar uma estratégia. Quanto maior a volatilidade maior a variação desse preço e consequentemente maior o risco.

Os valores das tarifas da CEMIG ao longo dos últimos 10 anos está apresentado no gráfico abaixo:

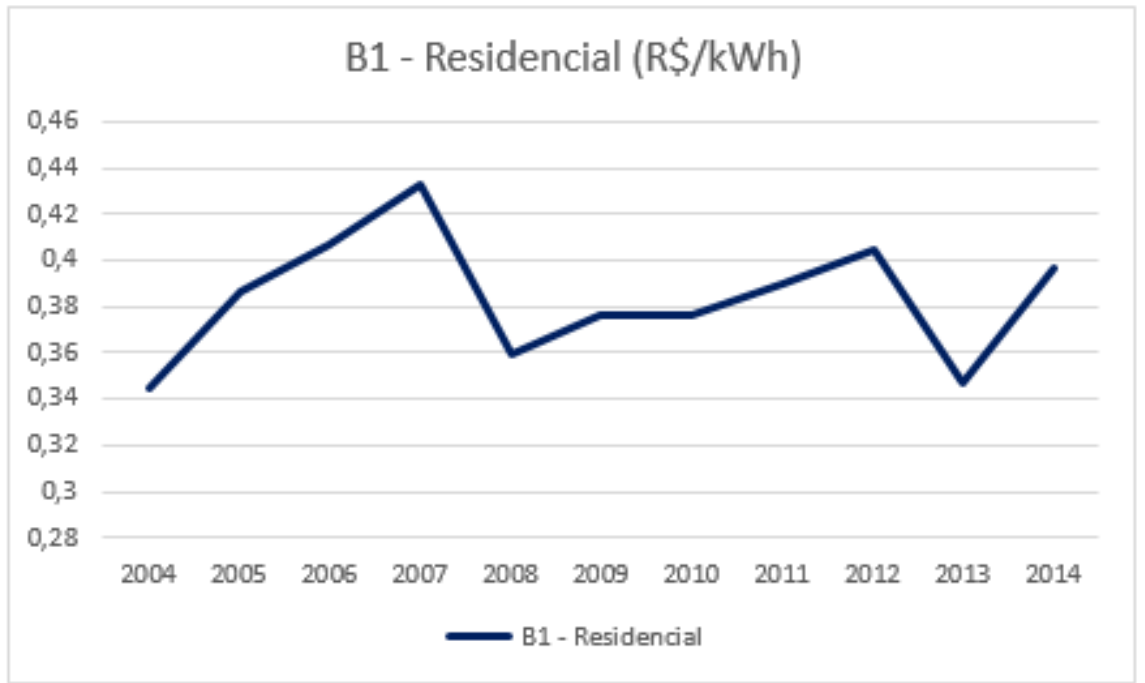

Figura 10 - Tarifas do Consumidor Residencial (B1) da CEMIG de 2004 a 2014

Durante todo esse período de observação podemos observar uma tendência de alta nos preços, porém, pudemos verificar uma inversão dessa tendência de alta nos anos de 2008 e 2013.

No ano de 2008, a redução tarifária ocorreu em função da ANEEL entender que a CEMIG teve ao longo do ano anterior um lucro acima do esperado e obedeceu ao critério dos menores custos operacionais das empresas concessionárias praticados pela agência reguladora.

Já em 2013, o governo federal aprovou a Lei 12.783/2013 com o objetivo de reduzir a tarifa de energia elétrica em todo o país. A referida lei extinguiu dois encargos setoriais: Conta de Consumo de Combustíveis (CCC) e a Reserva Global de Reversão (RGR) e determinou a redução de $75 \%$ da Conta de 
Desenvolvimento Energético (CDE), reduzindo a tarifa aplicada ao consumidor final.

Fazendo-se um análise da volatilidade histórica da tarifa de energia elétrica residencial praticado pela CEMIG ao longo desse período encontramos o valor de $\mathbf{1 0 . 5 \%}$, conforme demonstrado na tabela abaixo:

Tabela 8 - Volatilidade da Tarifa de Energia Elétrica da CEMIG de 2004 a 2014

\begin{tabular}{|c|c|c|c|c|c|c|c|c|c|c|c|}
\hline & 2004 & 2005 & 2006 & 2007 & 2008 & 2009 & 2010 & 2011 & 2012 & 2013 & 2014 \\
\hline \multicolumn{12}{|c|}{$\begin{array}{l}\text { Tarifa SEM Impostos } \\
\text { (R\$/kWh) }\end{array}$} \\
\hline B1 - Residencial & 0,34418 & 0,38672 & 0,40671 & 0,43315 & 0,35905 & 0,37652 & 0,37624 & 0,38978 & 0,40423 & 0,347 & 0,39642 \\
\hline Variação da Tarifa & & $12,36 \%$ & $5,17 \%$ & $6,50 \%$ & $-17,11 \%$ & $4,87 \%$ & $-0,07 \%$ & $3,60 \%$ & $3,71 \%$ & $-14,16 \%$ & $14,24 \%$ \\
\hline Variação & 0 & 1,1236 & 1,05169 & 1,06501 & 0,82893 & 1,04866 & 0,99926 & 1,03599 & 1,03707 & 0,85842 & 1,14242 \\
\hline Logarítmo & 0 & 0,11654 & 0,0504 & 0,06298 & $-0,18762$ & 0,04751 & $-0,00074$ & 0,03536 & 0,0364 & $-0,15266$ & 0,13315 \\
\hline
\end{tabular}

\subsection{2}

\section{A Volatilidade do Custo de Implementação do SFCR}

Da mesma forma que ocorre com o valor da tarifa de energia elétrica, com o adiamento da implementação do sistema fotovoltaico existirá uma possibilidade de variação dos custos de implementação do SFCR, com uma tendência de queda em função da curva de aprendizagem da tecnologia ao redor do mundo, bem como pelo desenvolvimento do setor no mercado nacional. Apesar dessa tendência de queda nos preços, não podemos assegurar qual a variação de custos vamos ter ao longo dos próximos anos. Essa possibilidade de variação dos custos de implementação e a incerteza acerca dessa variação cria uma flexibilidade na decisão do momento ótimo de implementação do SFCR.

Segundo os dados da Associação da Indústria Solar Alemã (BSW na sigla em Alemão), o preço de implantação dos sistemas fotovoltaicos, em suas mais de 800 empresas filiadas, vem caindo de forma bastante expressiva ao longo dos últimos anos. Em 2006, os custos de implantação de um sistema fotovoltaico eram de 5.10 EUR/kWp e caíram para 1.64 EUR/kWp em 2014, tornando a geração de energia através de um sistema fotovoltaico atrativa para o consumidor residencial alemão.

Segundo os relatórios da BSW, o preço variou ao longo desses anos conforme o gráfico abaixo: 


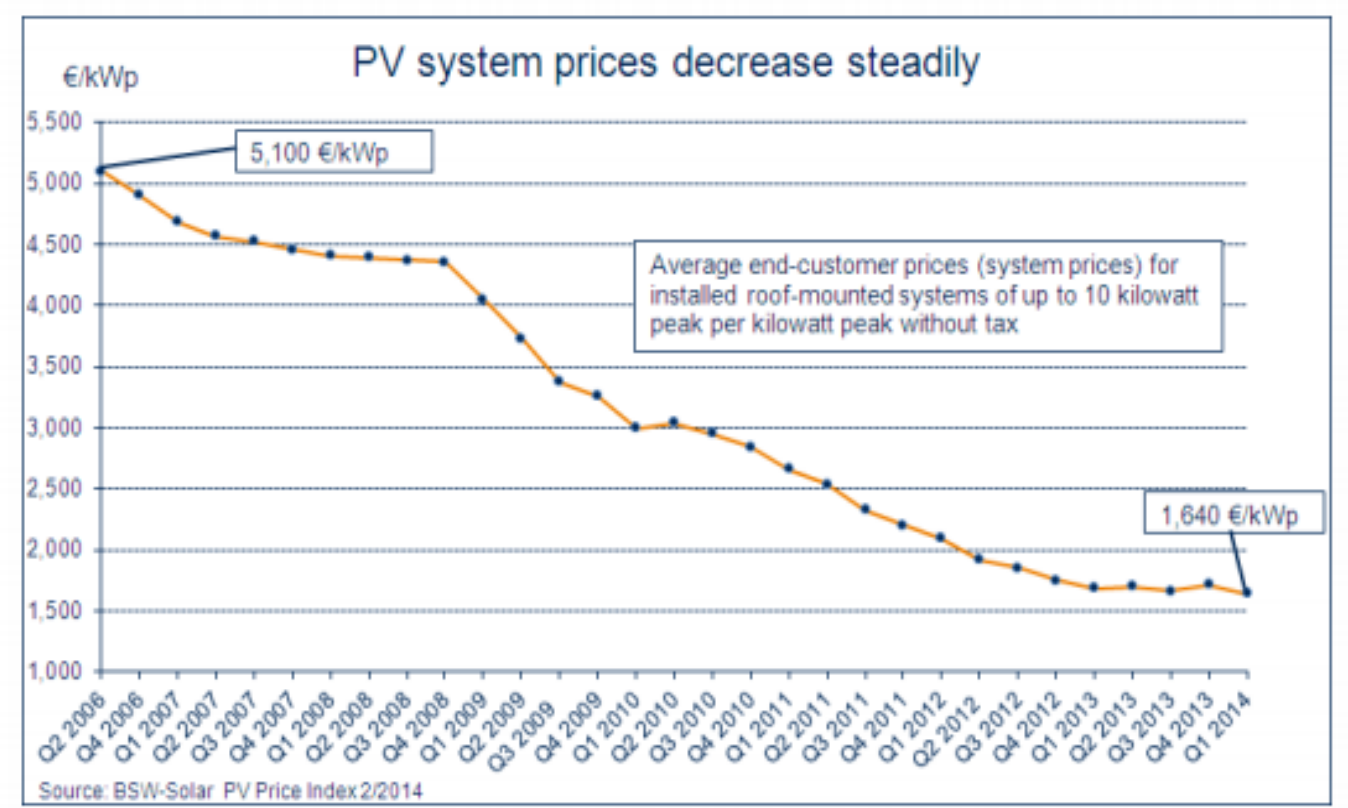

Figura 11 - Preço de Implementação do Sistema Fotovoltaico na Alemanha de 2006 a 2014

Essa mesma análise também foi feita pelo Departamento de Fontes Energéticas de Massachusetts em um estudo que foi divulgado em Julho de 2013. Em tal estudo, a consultoria Sustainable Energy Advantage estabeleceu uma previsão de que os custos de implementação de sistemas fotovoltaicos residenciais (até 15 kW) irão cair do atual patamar de 3.43 USD/kW a 5.09 USD/kW em 2014 para um patamar entre 2.01 USD/kW e 3.80 USD/kW em 2020.

Nesse estudo, ela considerou três cenários distintos de queda nos custos de implantação do sistema, conforme gráfico abaixo: 


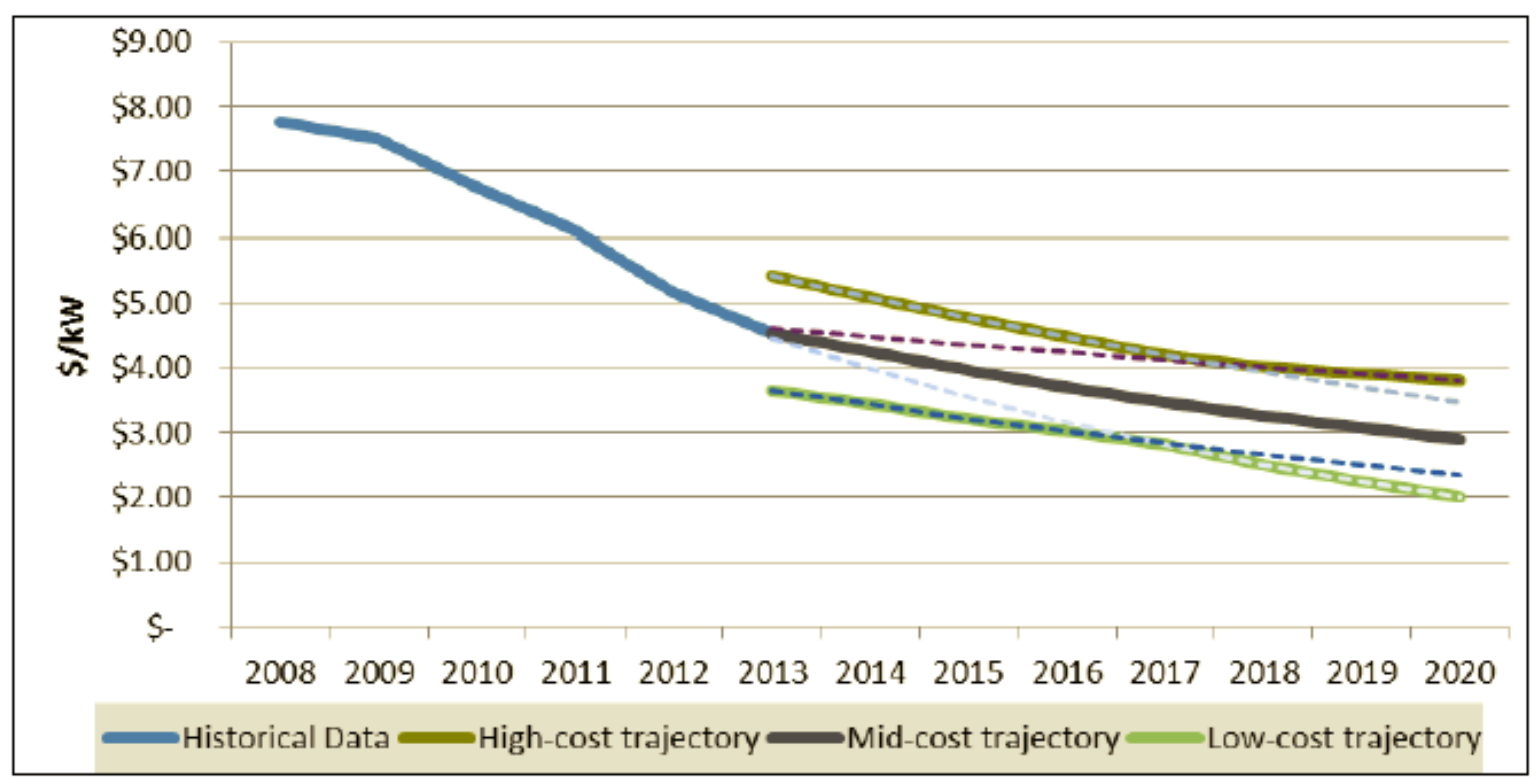

Figura 12 - Histórico e Previsão dos Custos de Implantação do Sistema Fotovoltaico nos EUA

Na tabela abaixo, encontram-se a previsão de valore por cada um dos cenários plotados acima:

Tabela 9 - Estimativa dos Custos de Implantação do Sistema Fotovoltaica nos EUA

\begin{tabular}{|c|c|c|c|c|c|c|c|c|c|}
\hline Size $(\mathbf{k W})$ & Cost Trend & $\mathbf{2 0 1 3}$ & $\mathbf{2 0 1 4}$ & $\mathbf{2 0 1 5}$ & $\mathbf{2 0 1 6}$ & $\mathbf{2 0 1 7}$ & $\mathbf{2 0 1 8}$ & $\mathbf{2 0 1 9}$ & $\mathbf{2 0 2 0}$ \\
\hline \multirow{3}{*}{$<15$} & High & $\$ 5.43$ & $\$ 5.09$ & $\$ 4.78$ & $\$ 4.48$ & $\$ 4.21$ & $\$ 4.01$ & $\$ 3.90$ & $\$ 3.80$ \\
\cline { 2 - 9 } & Base & $\$ 4.54$ & $\$ 4.26$ & $\$ 3.97$ & $\$ 3.71$ & $\$ 3.48$ & $\$ 3.26$ & $\$ 3.07$ & $\$ 2.89$ \\
\cline { 2 - 9 } & Low & $\$ 3.66$ & $\$ 3.43$ & $\$ 3.22$ & $\$ 3.02$ & $\$ 2.82$ & $\$ 2.52$ & $\$ 2.25$ & $\$ 2.01$ \\
\hline
\end{tabular}

No Brasil, a ABINEE (Associação Brasileira da Indústria Elétrica e Eletrônica), em seu estudo denominado Propostas para Inserção da Energia Solar Fotovoltaica na Matriz Elétrica Brasileira, elaborado conjuntamente com a consultoria PSR, ressaltava que nos últimos 30 anos, o preço dos módulos fotovoltaicos tem diminuído a uma taxa média de $8 \%$ ao ano e, em função da curva de aprendizado da tecnologia, a cada duplicação da capacidade global produzida (produção acumulada), o preço dos módulos fotovoltaicos diminui em aproximadamente $20 \%$.

Com base no histórico de queda do custo de implantação do SFCR e na previsão de continuidade dessa queda para os próximos anos, uma análise da opção de esperar o momento mais oportuno de investir nesse projeto deverá ser analisado antes de qualquer implementação. 
Para análise da volatilidade dos custos de implementação do sistema fotovoltaico, o presente estudo se utilizou da evolução dos custos históricos coletados pela BSW no mercado alemão ao longo dos últimos nove anos (de 2006 a 2014) e essa volatilidade histórica calculada no mercado alemão será utilizada como referência para o mercado brasileiro.

A volatilidade histórica dos custos da implantação do SFCR, obtidos através da pesquisa da BSW em suas 800 empresas filiadas, foi de $\mathbf{9 . 6 6 \% \text { , }}$ conforme tabela abaixo:

Tabela 10 - Volatilidade do Custo de Implantação do Sistema Fotovoltaico de 2006 a 2014

\begin{tabular}{|c|c|c|c|c|c|c|c|c|c|}
\hline & 2006 & 2007 & 2008 & 2009 & 2010 & 2011 & 2012 & 2013 & 2014 \\
\hline \multicolumn{10}{|c|}{ Custo de Implantação } \\
\hline \multicolumn{10}{|l|}{ (EUR/kWp) } \\
\hline Variação da Tarifa & & $-10,43 \%$ & $-5,80 \%$ & $-8,85 \%$ & $-26,98 \%$ & $-11,10 \%$ & $-22,66 \%$ & $-13,76 \%$ & $-3,42 \%$ \\
\hline Variação & 0 & 0,89569 & 0,94199 & 0,91146 & 0,73024 & 0,88897 & 0,77337 & 0,86237 & 0,96584 \\
\hline
\end{tabular}

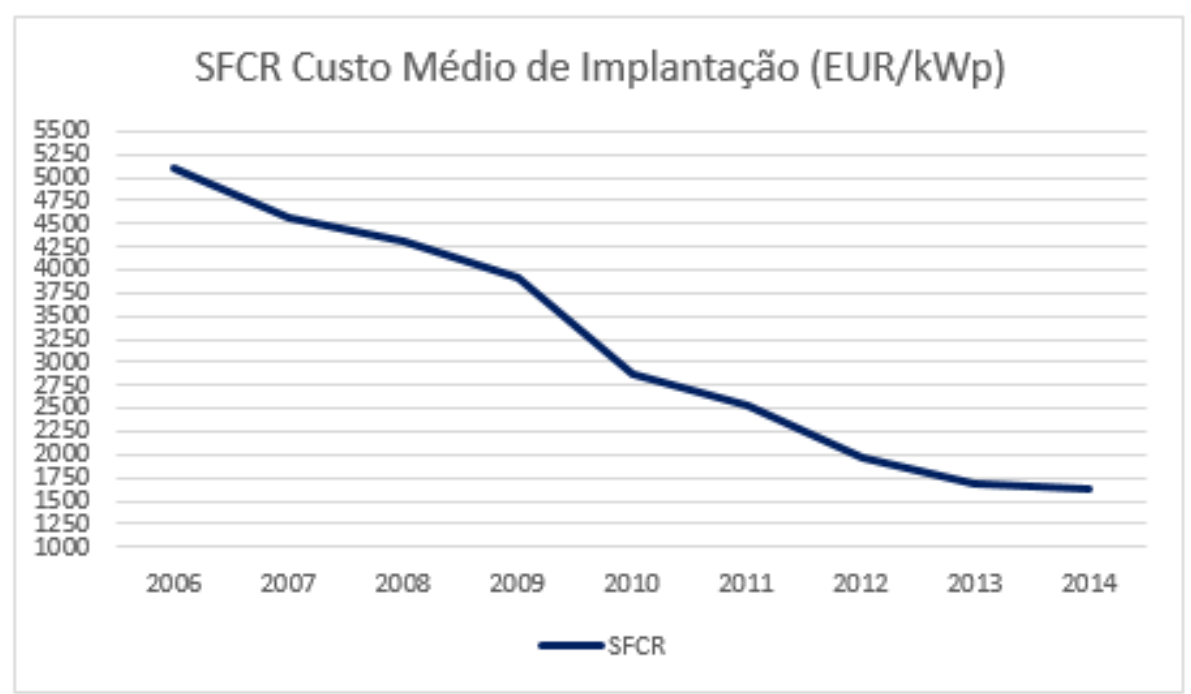

Figura 13 - Custo Médio de Implantação do SFCR de 2006 a 2014 


\section{A Análise dos Resultados}

O presente estudo visa analisar se o investidor deve investir na implantação do SFCR imediatamente ou deve adiar esse investimento até que tenha acesso às variáveis que o façam obter uma maior segurança para a realização desse investimento posteriormente.

Considerando as premissas adotadas no projeto, os dados obtidos nas análises acima e admitindo que o investidor possa realizar o investimento imediatamente ou adiar por alguns anos, podemos finalmente fazer uma análise da flexibilidade de adiamento desse projeto.

\section{1}

\section{Análise de Sensibilidade das Variáveis}

\subsection{1}

\section{Opção de Adiar 01 ano - Custo da Energia Elétrica}

Fazendo-se uma análise dessa opção de adiamento do projeto por um período de uma ano, tendo como referência somente o custo da energia (mantendo todas as demais variáveis constantes), verificamos que existirá uma possibilidade de variação desse custo, já que gerará uma expectativa de aumento ou diminuição da tarifa contratada $(0,5098 \mathrm{R} \$ / \mathrm{kWh}$ - Tarifa SEM Impostos na Bandeira Verde). Essa tarifa poderá tanto subir $11.07 \%(\mathrm{u}=1,1107)$, quanto cair $9.96 \%(\mathrm{~d}=0,9004)$ no próximo ano, baseado na volatilidade histórica das tarifas praticadas pela CEMIG $(\sigma=10.5 \%)$. Após esse período de um ano, se a energia subir para 0,5662 $\mathrm{R} \$ / \mathrm{kWh}$ ou cair para $0,4590 \mathrm{R} \$ / \mathrm{kWh}$, novos fluxos de caixa serão calculados ao longo de toda a vida útil de todo o projeto, da mesma maneira que foi realizado para a implementação do SFCR no ano de 2015. As probabilidades de aumento e queda da tarifa de energia foram calculadas respectivamente em 83,04\% $(p=0,8304)$ e $16,96 \%(1-p=0,1696)$.

O preço da tarifa, a volatilidade e as probabilidades de aumento e queda são demonstrados abaixo: 
Tabela 11 - Parâmetros do Modelo Binomial para o Adiamento de 01 ano - Energia Elétrica

\begin{tabular}{ccc}
\hline Tarifa Energia & & 2015 \\
& S & 0,5098 \\
p & 0,8304 \\
1-p & 0,1696 \\
u & 1,1107 \\
d & 0,9004 \\
1+r & 1,0750 \\
Su & 0,5662 \\
Sd & 0,4590
\end{tabular}

\section{Tarifa Energia}

Ano $0 \quad$ Ano 1

20152016

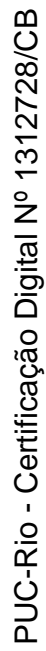

0,5662

Árvore Binomial $\quad 0,5098$

0,4590

Figura 14 - Árvore Binomial para o Adiamento de 01 ano - Energia Elétrica

Fazendo-se uma análise considerando que daqui a um ano somente o preço da tarifa da energia aumente (o custo de implementação considerado conforme modelo determinístico), teremos o seguinte fluxo de caixa do projeto: 
Tabela 12 - VPL, TIR e Payback para o Adiamento de 01 ano - Aumento da Tarifa de Energia Elétrica

\begin{tabular}{|c|c|c|c|c|c|c|c|c|}
\hline Base & Ano & Custo & $\begin{array}{l}\text { Retorno de } \\
\text { Investimento } \\
\text { Financeiro }\end{array}$ & $\begin{array}{l}\text { Redução } \\
\text { Custo } \\
\text { Eletricidade }\end{array}$ & $\begin{array}{c}\text { Fluxo de Caiza } \\
\text { Anual }\end{array}$ & $\begin{array}{l}\text { Fluso de Caiza } \\
\text { Cumulativo }\end{array}$ & YPL do FCL & $\begin{array}{c}\text { YPL } \\
\text { Cumulativo }\end{array}$ \\
\hline 0 & 2015 & $-\mathrm{R} \$ 31.351$ & $\mathrm{R} \$ 787$ & $\mathrm{R} \$ 0$ & $-\mathrm{R} \$ 30.564$ & $-\mathrm{R} \$ 30.564$ & $-\mathrm{R} \$ 30.564$ & $-\mathrm{R} \$ 30.564$ \\
\hline 2 & 2017 & 0 & & $R \$ 3.089$ & $R \$ 3.089$ & $-\mathrm{R} \$ 24.528$ & $R \$ 2.507$ & $-R \$ 25.402$ \\
\hline 3 & 2018 & 0 & & $\mathrm{R} \$ 3.245$ & $\mathrm{R} \$ 3.245$ & $-\mathrm{R} \$ 21.284$ & $\mathrm{R} \$ 2.372$ & $-\mathrm{R} \$ 23.030$ \\
\hline 4 & 2019 & 0 & & $R \$ 3.408$ & $R \$ 3.408$ & $-\mathrm{R} \$ 17.876$ & $R \$ 2.245$ & $-\mathrm{R} \$ 20.785$ \\
\hline 7 & 2022 & 0 & & $R \$ 3.948$ & $R \$ 3.948$ & $-R \$ 6.588$ & $R \$ 1.902$ & $-R \$ 14.749$ \\
\hline 8 & 2023 & 0 & & $R \$ 4.147$ & $R \$ 4.147$ & $-\mathrm{R} \$ 2.441$ & $R \$ 1.799$ & $-R \$ 12.949$ \\
\hline 9 & 2024 & 0 & & $R \$ 4.355$ & $R \$ 4.355$ & $R \$ 1.914$ & $R \$ 1.703$ & $-R \$ 11.247$ \\
\hline 10 & 2025 & 0 & & $R \$ 4.574$ & $R \$ 4.574$ & $R \$ 6.488$ & $\mathrm{R} \$ 1.611$ & $-R \$ 9.636$ \\
\hline 11 & 2026 & 0 & & $R \$ 4.803$ & $R \$ 4.803$ & $R \$ 11.291$ & $R \$ 1.524$ & $-R \$ 8.112$ \\
\hline 12 & 2027 & 0 & & $R \$ 5.044$ & $R \$ 5.044$ & $R \$ 16.336$ & $R \$ 1.442$ & $-R \$ 6.670$ \\
\hline 17 & 2032 & 0 & & $R \$ 6.423$ & $R \$ 6.423$ & $R \$ 45.587$ & $R \$ 1.090$ & $-R \$ 551$ \\
\hline 18 & 2033 & 0 & & $\mathrm{R} \$ 6.734$ & $\mathrm{R} \$ 6.734$ & $R \$ 52.321$ & $R \$ 1.029$ & $\mathrm{R} \$ 478$ \\
\hline 19 & 2034 & 0 & & $R \$ 7.060$ & $R \$ 7.060$ & $R \$ 59.382$ & $\mathrm{R} \$ 972$ & $R \$ 1.450$ \\
\hline 20 & 2035 & 0 & & $R \$ 7.402$ & $R \$ 7.402$ & $R \$ 66.784$ & $\mathrm{R} \$ 918$ & $R \$ 2.368$ \\
\hline 21 & 2036 & 0 & & $R \$ 7.760$ & $R \$ 7.760$ & $R \$ 74.543$ & $R \$ 867$ & $R \$ 3.235$ \\
\hline 22 & 2037 & 0 & & $R \$ 8.134$ & $R \$ 8.134$ & $\mathrm{R} \$ 82.678$ & $\mathrm{R} \$ 819$ & $R \$ 4.054$ \\
\hline 23 & 2038 & 0 & & $R \$ 8.527$ & $R \$ 8.527$ & $R \$ 91.204$ & $R \$ 773$ & $R \$ 4.827$ \\
\hline 24 & 2039 & 0 & & $\mathrm{R} \$ 8.937$ & $\mathrm{R} \$ 8.937$ & $R \$ 100.142$ & $R \$ 730$ & $R \$ 5.558$ \\
\hline 25 & 2040 & 0 & & $R \$ 9.368$ & $R \$ 9.368$ & $R \$ 109.509$ & $R \$ 690$ & $R \$ 6.247$ \\
\hline Total & & $-R \$ 31.351$ & $R \leqslant 787$ & $R \leqslant 140.073$ & $R \neq 109.509$ & $R \leqslant 683.478$ & $R \leqslant 6.247$ & \\
\hline \multicolumn{3}{|c|}{$\begin{array}{c}\text { Inflação Anual } \\
\text { Base Anual Conta de } \\
\text { Energia } \\
\text { Tasa de Desconto }\end{array}$} & $\begin{array}{r}R * 160.921,08 \\
11,0 \% \\
\end{array}$ & & $\begin{array}{l}\text { VPL } \\
\text { TIR } \\
\text { Payback } \\
\end{array}$ & $\begin{array}{c}\$ 6.247,16 \\
13,14 \% \\
10 \\
\end{array}$ & & \\
\hline
\end{tabular}

Vale ressaltar que caso o investidor deseje realizar a implementação do SFCR somente no ano de 2016, o dinheiro do investimento adiado continuaria investido no título do Tesouro Direto NTN-B (paga juros, além da variação da inflação), com uma rentabilidade de $\sim 11 \%$, que corresponderia a $\mathrm{R} \$ 3.448,61$. Porém, o investidor não teria a economia de R $2.661,47$, via compensação de energia, prevista no modelo determinístico. Portanto, esse adiamento também geraria um resultado positivo para o investidor de $\mathrm{R} \$ 787,14$ que poderão ser utilizados como parte do investimento de implantação do sistema no ano subsequente. Nesse novo cenário, o VPL desse novo fluxo de caixa seria de R\$ 6.247,16, com uma TIR de $13.14 \%$.

Por outro lado, se o preço da energia cair, a somatória dos fluxos de caixa também cairá para (- R\$ 921,27), com uma TIR de 10.67\%. A tabela abaixo mostra o referido fluxo de caixa nesse novo cenário: 
Tabela 13 - VPL, TIR e Payback para o Adiamento de 01 ano - Queda da Tarifa de Energia Elétrica

\begin{tabular}{|c|c|c|c|c|c|c|c|c|}
\hline Base & Ano & Custo & $\begin{array}{c}\text { Retorno de } \\
\text { Investimento } \\
\text { Financeiro }\end{array}$ & $\begin{array}{c}\text { Redução } \\
\text { Custo } \\
\text { Eletricidade }\end{array}$ & $\begin{array}{c}\text { Fluzo de Caiza } \\
\text { Anual }\end{array}$ & $\begin{array}{l}\text { Fluzo de Caiza } \\
\text { Cumulativo }\end{array}$ & YPL do FCL & $\begin{array}{c}\text { YPL } \\
\text { Cumulativo }\end{array}$ \\
\hline 0 & 2015 & $-\mathrm{R} \$ 31.531$ & \multirow[t]{26}{*}{$\mathrm{R} \$ 787$} & $R \$ 0$ & $-\mathrm{R} \$ 30.744$ & $-\mathrm{R} \$ 30.744$ & $-\mathrm{R} \$ 30.744$ & $-\mathrm{R} \$ 30.744$ \\
\hline 1 & 2016 & 0 & & $\mathrm{R} \$ 2.392$ & $\mathrm{R} \$ 2.392$ & $-R \$ 28.351$ & $\mathrm{R} \$ 2.155$ & $-\mathrm{R} \$ 28.589$ \\
\hline 2 & 2017 & 0 & & $R \$ 2.505$ & $R \$ 2.505$ & $-R \$ 25.846$ & $R \$ 2.033$ & $-R \$ 26.555$ \\
\hline 3 & 2018 & 0 & & $\mathrm{R} \$ 2.631$ & $R \$ 2.631$ & $-\mathrm{R} \$ 23.215$ & $R \$ 1.924$ & $-\mathrm{R} \$ 24.631$ \\
\hline 4 & 2019 & 0 & & $R \$ 2.763$ & $R \$ 2.763$ & $-R \$ 20.452$ & $R \$ 1.820$ & $-\mathrm{R} \$ 22.811$ \\
\hline 5 & 2020 & 0 & & $\mathrm{R} \$ 2.902$ & $\mathrm{R} \$ 2.902$ & $-R \$ 17.550$ & $R \$ 1.722$ & $-R \$ 21.089$ \\
\hline 6 & 2021 & 0 & & $R \$ 3.047$ & $\mathrm{R} \$ 3.047$ & $-\mathrm{R} \$ 14.502$ & $R \$ 1.629$ & $-\mathrm{R} \$ 19.460$ \\
\hline 7 & 2022 & 0 & & $R \$ 3.200$ & $R \$ 3.200$ & $-R \$ 11.302$ & $R \$ 1.541$ & $-R \$ 17.918$ \\
\hline 8 & 2023 & 0 & & $R \$ 3.361$ & $R \$ 3.361$ & $-\mathrm{R} \$ 7.941$ & $R \$ 1.458$ & $-R \$ 16.460$ \\
\hline 9 & 2024 & 0 & & $R \$ 3.529$ & $R \$ 3.529$ & $-R \$ 4.412$ & $R \$ 1.380$ & $-R \$ 15.080$ \\
\hline 10 & 2025 & 0 & & $R \$ 3.706$ & $\mathrm{R} \$ 3.706$ & $-\mathrm{R} \$ 707$ & $R \$ 1.305$ & $-R \$ 13.775$ \\
\hline 11 & 2026 & 0 & & $R \$ 3.891$ & $R \$ 3.891$ & $R \$ 3.185$ & $R \$ 1.235$ & $-R \$ 12.541$ \\
\hline 12 & 2027 & 0 & & $R \$ 4.086$ & $R \$ 4.086$ & $\mathrm{R} \$ 7.270$ & $R \$ 1.168$ & $-\mathrm{R} \$ 11.373$ \\
\hline 13 & 2028 & 0 & & $R \$ 4.290$ & $R \$ 4.290$ & $R \$ 11.561$ & $R \$ 1.105$ & $-R \$ 10.268$ \\
\hline 14 & 2029 & 0 & & $R \$ 4.505$ & $R \$ 4.505$ & $R \$ 16.065$ & $R \$ 1.045$ & $-R \$ 9.223$ \\
\hline 15 & 2030 & 0 & & $R \$ 4.729$ & $R \$ 4.729$ & $R \$ 20.794$ & $\mathrm{R} \$ 988$ & $-\mathrm{R} \$ 8.234$ \\
\hline 16 & 2031 & 0 & & $R \$ 4.959$ & $R \$ 4.959$ & $R \$ 25.754$ & $R \$ 934$ & $-R \$ 7.301$ \\
\hline 17 & 2032 & 0 & & $R \$ 5.199$ & $R \$ 5.199$ & $R \$ 30.952$ & $\mathrm{R} \$ 882$ & $-\mathrm{R} \$ 6.419$ \\
\hline 18 & 2033 & 0 & & $R \$ 5.449$ & $R \$ 5.449$ & $R \$ 36.402$ & $\mathrm{R} \$ 833$ & $-R \$ 5.586$ \\
\hline 19 & 2034 & 0 & & $R \$ 5.712$ & $R \$ 5.712$ & $R \$ 42.114$ & $R \$ 786$ & $-R \$ 4.800$ \\
\hline 20 & 2035 & 0 & & $R \$ 5.987$ & $R \$ 5.987$ & $R \$ 48.101$ & $\mathrm{R} \$ 743$ & $-\mathrm{R} \$ 4.057$ \\
\hline 21 & 2036 & 0 & & $\mathrm{R} \$ 6.275$ & $R \$ 6.275$ & $\mathrm{R} \$ 54.376$ & $R \$ 701$ & $-R \$ 3.356$ \\
\hline 22 & 2037 & 0 & & $R \$ 6.577$ & $R \$ 6.577$ & $R \$ 60.953$ & $R \$ 662$ & $-R \$ 2.694$ \\
\hline 23 & 2038 & 0 & & $R \$ 6.893$ & $R \$ 6.893$ & $R \$ 67.845$ & $R \$ 625$ & $-R \$ 2.069$ \\
\hline 24 & 2039 & 0 & & $\mathrm{R} \$ 7.223$ & $\mathrm{R} \$ 7.223$ & $R \$ 75.069$ & $R \$ 590$ & $-\mathrm{R} \$ 1.478$ \\
\hline 25 & 2040 & 0 & & $R \$ 7.569$ & $R \$ 7.569$ & $R \$ 82.638$ & $R \$ 557$ & $-\mathrm{R} \$ 921$ \\
\hline \multicolumn{2}{|l|}{ Total } & $-R \$ 31.531$ & $R \leqslant 787$ & $R \leqslant 113.382$ & $R \$ 82.638$ & $R \$ 398.054$ & \multicolumn{2}{|l|}{$-R \leqslant 921$} \\
\hline \multicolumn{3}{|c|}{$\begin{array}{c}\text { Inflação Anual } \\
\text { Base Anual Conta de } \\
\text { Tasa de Desconto } \\
\end{array}$} & $\begin{array}{r}5,50 \% \\
R * 134.229,80 \\
11,0 \% \\
\end{array}$ & & \multicolumn{2}{|c|}{$\begin{array}{lc}\text { WPL } & -R * 921,27 \\
\text { TIR } & 10,67 \% \\
\text { Payback } & 12 \\
\end{array}$} & & \\
\hline
\end{tabular}

Considerando o cenário de adiamento de implantação do projeto em um ano e a possibilidade de variação somente do valor da tarifa de energia elétrica praticado pela CEMIG, verificamos que somente vale a pena investir, se a situação for favorável, conforme mostrado nos fluxos de caixa acima.

Na situação favorável; (aumento do preço da energia), temos:

$F 1_{u}=\max \left(V 1_{u}-I, 0\right)=\max (R \$ 6.247,16,0)=R \$ 6.247,76$

Enquanto que na situação desfavorável (queda do preço da energia), temos:

$F 1_{d}=\max \left(V 1_{d}-I, 0\right)=\max (-R \$ 921,27,0)=0$

Dessa forma, considerando somente uma possível variação do preço da tarifa, o valor da oportunidade de adiamento do investimento em 1 ano $(t=1)$ fica assim estabelecido: 
$F 1=p . F 1 u+(1-p) . F 1 d=(0,8303 \times R \$ 6.247,76+0,1696 \times 0)=R \$ 5.187,57$

Trazendo-se o valor da oportunidade de espera para a data atual $(\mathrm{t}=0)$ teremos que:

$F_{0}=F_{1} /\left(1+r_{f}\right)=R \$ 5.187,57 / 1,11=R \$ 4.673,49$

Portanto, nessas condições, caso o investidor decida adiar a implantação do projeto em um ano, ele obterá um valor de oportunidade de $\mathrm{R} \$ 4.673,49$ por essa decisão de adiamento, enquanto que, caso sua decisão seja implementá-lo imediatamente, o VPL calculado seria de R\$ 5.607,37. Essa diferença entre o valor da oportunidade de adiamento em um ano $(\mathrm{t}=1)$ e o VPL é exatamente o valor da opção de espera. Esse valor obtido para a opção de espera, considerando somente a possibilidade de variação do custo da tarifa da energia elétrica praticada pela CEMIG, recomenda ao investidor a implantação imediata do projeto sistema fotovoltaico para o ano de 2016.

\subsection{2}

\section{Opção de Adiar 01 ano - Custos de Implantação}

Conforme já demonstrado ao longo do estudo, o custo de implantação do SFCR tem apresentado nos últimos anos uma queda bastante acentuada em função da curva de aprendizagem da tecnologia fotovoltaica. Fazendo-se uma análise dessa opção de adiamento do projeto em um ano, verificamos que existirá uma possibilidade de variação do custo de implantação do sistema, já que gerará uma expectativa de aumento ou diminuição do investimento orçado para realização do referido projeto (9,50 R \$/W - incluindo todos os custos de implantação). Esse custo poderá tanto subir 10.14\% $(\mathrm{u}=1,1014)$, quanto cair $9.20 \%(\mathrm{~d}=0,9080)$ no próximo ano, tendo como base a volatilidade histórica do custo de implantação das empresas filiadas a BSW $(\sigma=9.66 \%)$. Após esse período de um ano, se o custo de implantação subir para 10,4635 R \$/W ou cair para 8,6258 R \$/W, novos fluxos de caixa serão calculados ao longo de toda a vida útil do projeto, da mesma maneira que foi realizado para a implementação do SFCR no ano de 2015. As 
probabilidades de aumento e queda desses custos foram calculadas respectivamente em 86,36 \% $(p=0,8636)$ e 13,64\% $(1-p=0,1364)$.

O preço da tarifa, a volatilidade e as probabilidades de aumento e queda são demonstrado abaixo:

Tabela 14 - Parâmetros do Modelo Binomial para o Adiamento de 01 ano - SFCR

\begin{tabular}{cr}
\hline Implantação do SFCR & \\
\cline { 1 - 2 } S & 9,5003 \\
p & 0,8636 \\
1-p & 0,1364 \\
u & 1,1014 \\
d & 0,9080 \\
1+r & 1,0750 \\
Su & 10,4635 \\
Sd & 8,6258
\end{tabular}

Implantação do SFCR

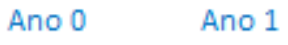

$2015 \quad 2016$

10,4635

Árvore Binomial $\quad 9,5003$

8,6258

Figura 15 - Árvore Binomial para o Adiamento de 01 ano - SFCR

Fazendo-se uma análise considerando que daqui a um ano somente o preço desse custo de implantação do SFCR aumente (o valor a tarifa de energia segue conforme o modelo determinístico), teremos o seguinte fluxo de caixa do projeto: 
Tabela 15 - VPL, TIR e Payback para o Adiamento de 01 ano - Aumento do Custo de Implantação

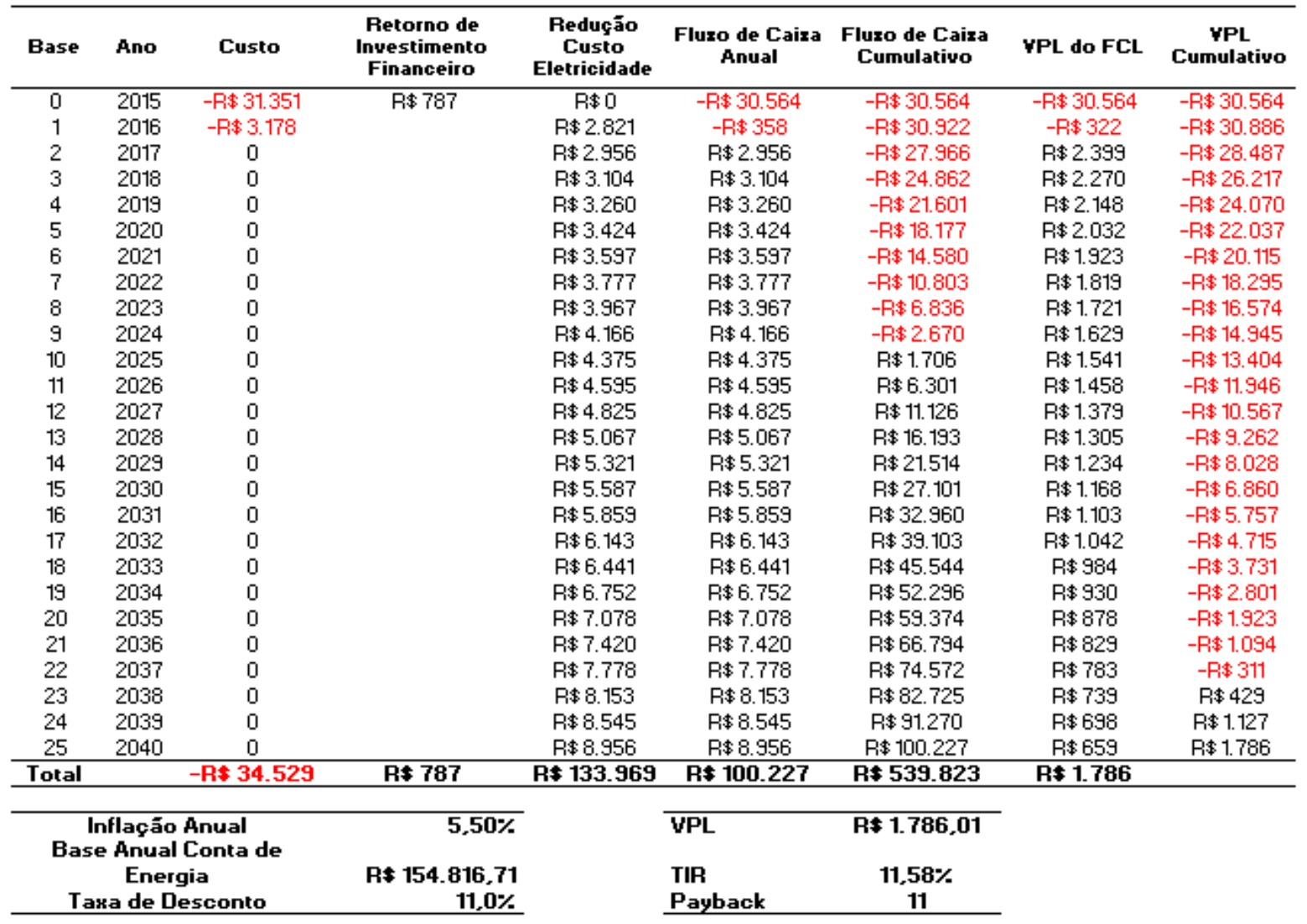

Uma vez mais, aqui também vale a ressalva de que caso o investidor deseje realizar a implementação do SFCR somente no ano de 2016, seu capital continuaria investido no título do Tesouro Direto NTN-B (paga juros e variação da inflação), com uma rentabilidade de $11 \%$ e geraria um rendimento de $\mathrm{R} \$$ 3.448,61. Porém, o investidor não teria a economia, via sistema de compensação de energia, prevista no modelo determinístico que era de aproximadamente $\mathrm{R} \$$ 2.661,47. Portanto, esse adiamento ainda geraria um resultado positivo para o investidor de R\$787,14, que poderão ser utilizados como parte do investimento de implantação do sistema no ano subsequente. Nesse novo cenário, o VPL desse novo fluxo de caixa seria R\$1.786,01, com uma TIR de $\mathbf{1 1 . 5 8 \% . ~}$

Por outro lado, se o custo de implementação do sistema fotovoltaico cair, a somatória dos fluxos de caixa aumentará para R\$ 7.249,33, com uma TIR de 13.66\%. Nesse cenário de queda dos custos de implantação do SFCR, o investidor, além da rentabilidade do investimento, também terá a vantagem de 
uma redução de $\mathbf{R} \mathbf{\$} \mathbf{2 . 8 8 5 , 8 6}$ no custo de execução do projeto. A tabela abaixo mostra o referido fluxo de caixa nesse novo cenário:

Tabela 16 - VPL, TIR e Payback para o Adiamento de 01 ano - Queda do Custo de Implantação

\begin{tabular}{|c|c|c|c|c|c|c|c|c|}
\hline Base & Ano & Custo & $\begin{array}{c}\text { Retorno de } \\
\text { Investimento } \\
\text { Financeiro }\end{array}$ & $\begin{array}{l}\text { Redução } \\
\text { Custo } \\
\text { Eletricidade }\end{array}$ & $\begin{array}{c}\text { Fluso de Caiza } \\
\text { Anual }\end{array}$ & $\begin{array}{c}\text { Fluxo de Caixa } \\
\text { Cumulativo }\end{array}$ & YPL do FCL & $\begin{array}{c}\text { YPL } \\
\text { Cumulativo }\end{array}$ \\
\hline 0 & 2015 & $-\mathrm{R} \$ 31.351$ & $\mathrm{R} \$ 787$ & $\mathrm{R} \$ 0$ & $-R \$ 30.564$ & $-\mathrm{R} \$ 30.564$ & $-R \$ 30.564$ & $-\mathrm{R} \$ 30.564$ \\
\hline 1 & 2016 & 0 & $\mathrm{R} \$ 2.886$ & $\mathrm{R} \$ 2.821$ & $R \$ 5.707$ & $-\mathrm{R} \$ 24.857$ & $\mathrm{R} \$ 5.141$ & $-\mathrm{R} \$ 25.423$ \\
\hline 2 & 2017 & 0 & & $R \$ 2.956$ & $R \$ 2.956$ & $-\mathrm{R} \$ 21.902$ & $R \$ 2.399$ & $-\mathrm{R} \$ 23.024$ \\
\hline 3 & 2018 & 0 & & $\mathrm{R} \$ 3.104$ & $R \$ 3.104$ & $-R \$ 18.797$ & $R \$ 2.270$ & $-R \$ 20.754$ \\
\hline 4 & 2019 & 0 & & $R \$ 3.260$ & $R \$ 3.260$ & $-\mathrm{R} \$ 15.537$ & $\mathrm{R} \$ 2.148$ & $-\mathrm{R} \$ 18.606$ \\
\hline 5 & 2020 & 0 & & $R \$ 3.424$ & $R \$ 3.424$ & $-R \$ 12.113$ & $R \$ 2.032$ & $-R \$ 16.574$ \\
\hline 6 & 2021 & 0 & & $R \$ 3.597$ & $R \$ 3.597$ & $-R \$ 8.516$ & $R \$ 1.923$ & $-R \$ 14.651$ \\
\hline 7 & 2022 & 0 & & $R \$ 3.777$ & $R \$ 3.777$ & $-\mathrm{P} \$ 4.739$ & $\mathrm{R} \$ 1.819$ & $-\mathrm{R} \$ 12.832$ \\
\hline 8 & 2023 & 0 & & $R \$ 3.967$ & $R \$ 3.967$ & $-\mathrm{R} \$ 772$ & $R \$ 1.721$ & $-R \$ 11.110$ \\
\hline 9 & 2024 & 0 & & $R \$ 4.166$ & $R \$ 4.166$ & $R \$ 3.395$ & $R \$ 1.629$ & $-R \$ 9.482$ \\
\hline 10 & 2025 & 0 & & $R \$ 4.375$ & $R \$ 4.375$ & $R \$ 7.770$ & $R \$ 1.541$ & $-\mathrm{R} \$ 7.941$ \\
\hline 11 & 2026 & 0 & & $R \$ 4.595$ & $R \$ 4.595$ & $R \$ 12.365$ & $R \$ 1.458$ & $-\mathrm{R} \$ 6.483$ \\
\hline 12 & 2027 & 0 & & $R \$ 4.825$ & $R \$ 4.825$ & $R \$ 17.190$ & $R \$ 1.379$ & $-R \$ 5.104$ \\
\hline 13 & 2028 & 0 & & $R \$ 5.067$ & $R \$ 5.067$ & $\mathrm{R} \$ 22.257$ & $\mathrm{R} \$ 1.305$ & $-\mathrm{R} \$ 3.799$ \\
\hline 14 & 2029 & 0 & & $\mathrm{R} \$ 5.321$ & $\mathrm{R} \$ 5.321$ & $R \$ 27.578$ & $\mathrm{R} \$ 1.234$ & $-\mathrm{R} \$ 2.565$ \\
\hline 15 & 2030 & 0 & & $R \$ 5.587$ & $R \$ 5.587$ & $R \$ 33.165$ & $R \$ 1.168$ & $-R \$ 1.397$ \\
\hline 16 & 2031 & 0 & & $R \$ 5.859$ & $R \$ 5.859$ & $R \$ 39.024$ & $R \$ 1.103$ & $-\mathrm{R} \$ 294$ \\
\hline 17 & 2032 & 0 & & $R \$ 6.143$ & $R \$ 6.143$ & $R \$ 45.167$ & $R \$ 1.042$ & $R \$ 749$ \\
\hline 18 & 2033 & 0 & & $R \$ 6.441$ & $\mathrm{R} \$ 6.441$ & $R \$ 51.608$ & $\mathrm{R} \$ 984$ & $R \$ 1.733$ \\
\hline 19 & 2034 & 0 & & $R \$ 6.752$ & $R \$ 6.752$ & $R \$ 58.360$ & $R \$ 930$ & $\mathrm{R} \$ 2.662$ \\
\hline 20 & 2035 & 0 & & $R \$ 7.078$ & $R \$ 7.078$ & $R \$ 65.438$ & $\mathrm{R} \$ 878$ & $R \$ 3.540$ \\
\hline 21 & 2036 & 0 & & $R \$ 7.420$ & $R \$ 7.420$ & $R \$ 72.858$ & $R \$ 829$ & $R \$ 4.369$ \\
\hline 22 & 2037 & 0 & & $R \$ 7.778$ & $R \$ 7.778$ & $R \$ 80.636$ & $R \$ 783$ & $R \$ 5.152$ \\
\hline 23 & 2038 & 0 & & $\mathrm{R} \$ 8.153$ & $\mathrm{R} \$ 8.153$ & $R \$ 88.789$ & $R \$ 739$ & $R \$ 5.892$ \\
\hline 24 & 2039 & 0 & & $R \$ 8.545$ & $R \$ 8.545$ & $R \$ 97.334$ & $R \$ 698$ & $R \$ 6.590$ \\
\hline 25 & 2040 & 0 & & $R \$ 8.956$ & $R \$ 8.956$ & $R \$ 106.291$ & $\mathrm{R} \$ 659$ & $\mathrm{R} \$ 7.249$ \\
\hline Total & & $-R \$ 31.351$ & $R \leqslant 3.673$ & $R \$ 133.969$ & $R \$ 106.291$ & R\$ 691.431 & $R \leqslant 7.249$ & \\
\hline \multicolumn{3}{|c|}{$\begin{array}{c}\text { Inflação Anual } \\
\text { Base Anual Conta de } \\
\text { Tasa de Desconto }\end{array}$} & $\begin{array}{r}5,50 \% \\
R * 154.816,71 \\
11,0 \% \\
\end{array}$ & & $\begin{array}{l}\text { VPL } \\
\text { TIR } \\
\text { Payback } \\
\end{array}$ & $\begin{array}{c}\$ 7.249,33 \\
13,66 \% \\
10 \\
\end{array}$ & & \\
\hline
\end{tabular}

Portanto, considerando o cenário de adiamento de implantação do projeto em um ano e com a possibilidade de variação somente do valor da custo do sistema fotovoltaico, verificamos que somente valeria a pena investir, se a situação fosse favorável (redução nos custos de implantação do sistema), conforme mostrado nos fluxos de caixa acima.

Na situação favorável (redução do custo de implantação), teríamos:

$F_{1 d}=\max \left(V_{1 d}-I, 0\right)=\max (R \$ 7.249,33,0)=R \$ 7.249,33$

Enquanto que na situação desfavorável (aumento do custo de implantação), teríamos:

$F_{1 u}=\max \left(V_{1 u}-I, 0\right)=\max (R \$ 1.786,01,0)=R \$ 1.786,01$ 
Dessa forma, considerando somente uma possível variação do custo de implantação, valor da oportunidade de adiamento do investimento em 1 ano (t=1) fica assim estabelecido:

$F 1=p . F 1 u+(1-p) . F 1 d=(0,8636 \times R \$ 1.786,01+0,1364 \times R \$ 3.874,57)$

$F 1=R \$ 2.070,89$

Trazendo-se o valor da oportunidade de espera para a data atual $(\mathrm{t}=0)$ teremos que:

$F 0=F 1 /\left(1+r_{f}\right)=R \$ 2.070,89 / 1,11=R \$ 1.865,67$

Portanto, nessas condições, caso o investidor decida esperar um ano para implementar o projeto do SFCR, ele obterá um valor de oportunidade de R\$ 1.865,67 por essa decisão de adiamento, enquanto que, caso decida implementá-lo imediatamente, o VPL calculado seria de R\$ 5.607,37. Essa diferença entre o valor da oportunidade de adiamento em um ano (t=1) e o VPL é exatamente o valor da opção de espera. Esse valor obtido para a opção de espera, considerando somente a possibilidade de variação do custo de implementação do sistema fotovoltaico, recomenda ao investidor a implantação imediata do projeto de geração de energia elétrica.

\section{2}

\section{A Opção de Espera - Tarifa e Custo de Implantação}

Ao analisarmos a sensibilidade da variação de cada uma das variáveis isoladamente, verificamos que cada uma delas recomenda ao investidor uma diferente decisão de investimento. Enquanto a análise da opção de espera de um ano tendo como referência somente a tarifa de energia recomenda o adiamento do investimento, a análise com base no custo de implantação do sistema recomenda a 
implantação imediata. Portanto, uma análise de ambas variações combinadas será necessária para analisarmos se a implantação do sistema fotovoltaico, do ponto de vista financeiro, deve ser realizada imediatamente ou adiado em um ano.

Esse modelo de aproximação árvore binomial recombinante de Cox, Ross e Rubinstein (1979) para duas variáveis foi inicialmente apresentada por Boyle (1988) e possibilita concatenar processos estocásticos distintos às duas variáveis de incerteza do projeto, podendo essas variáveis serem correlacionadas ou não correlacionadas. Copeland e Antikarov (2001) também apresentam um modelo bivariável com os dois fatores de incerteza correlacionados.

Vale ressaltar que as duas variáveis de incerteza do presente estudo não apresentam nenhuma correlação entre elas, pois a tarifa da CEMIG depende basicamente da matriz de geração da energia elétrica e de outras regras por parte da ANEEL, enquanto que a variação do custo de implantação do sistema depende da curva de aprendizagem da tecnologia no Brasil e das condições do mercado de painéis fotovoltaicos.

Segundo Bastian-Pinto (2009), nos modelos bivariáveis em geral, para cada nó da árvore existem quatro ramificações com probabilidades de subida e descida associadas de duas variáveis (x e y, por exemplo). Para se construir uma árvore bivariável, as probabilidades conjuntas de subida de cada uma das quatro ramificações de saída do nó precisam ser determinadas. Considerando essas quatro possíveis combinações de subida e descida e denotando com os caracteres u e d subscritos de cada probabilidade, podemos visualizar mais facilmente essa árvore binomial na figura abaixo:

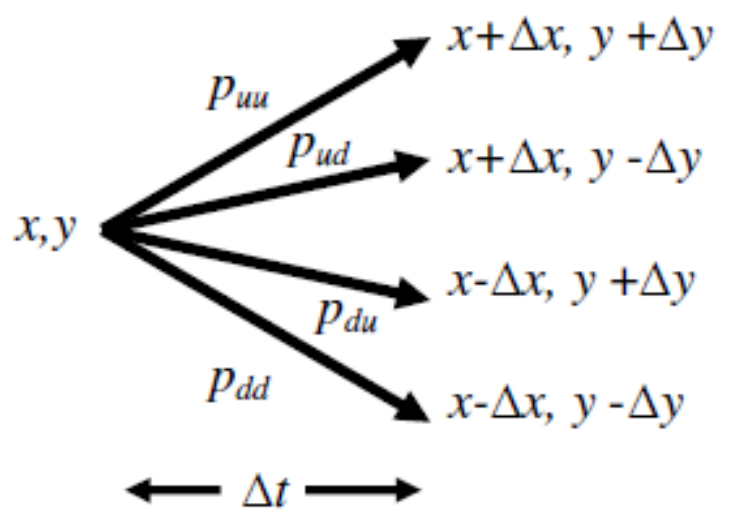

Figura 16 - Árvore Binomial - Bivariável 
Considerando que as variáveis não possuem correlação, as árvores binomiais elaboradas individualmente para uma das variáveis e as probabilidades de subida e descida temos:

- Árvore Binomial para Variação da Tarifa de Energia

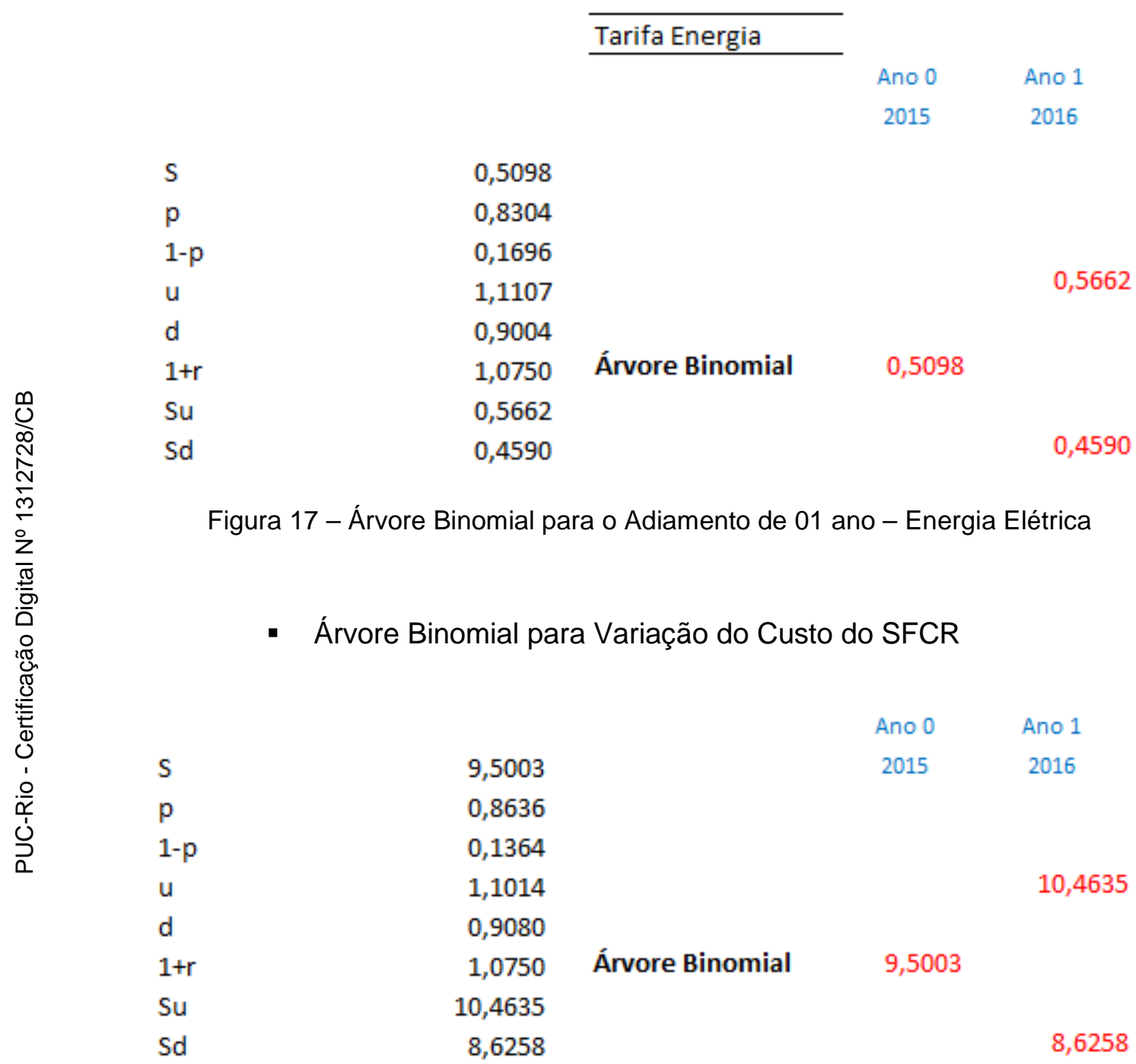

Figura 18 - Árvore Binomial para o Adiamento de 01 ano - SFCR

Fazendo-se a combinação das árvores binomiais das duas variáveis individuais e suas respectivas probabilidades temos a seguinte árvore binomial bivariável e suas novas probabilidades: 

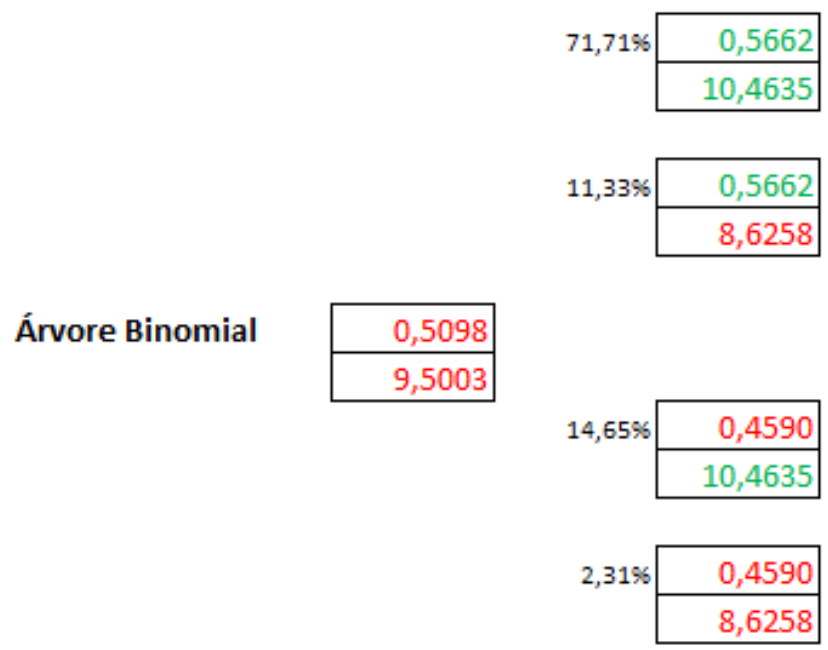

Figura 19 - Árvore Binomial Bivariável para o Adiamento de 01 ano - Energia Elétrica e SFCR

Vale ressaltar que na árvore binomial acima, os valores de tarifas de energia estão representados na parte superior de cada retângulo, enquanto o na parte inferior estão os custos de implantação do sistema fotovoltaico. Em verde estão considerados os valores de subida de cada variável e em vermelho os valores de descida. A probabilidade de cada combinação é dada pela multiplicação da probabilidade individual de cada variável.

Exemplificando, os dados do primeiro retângulo acima indica que, no ano 2016, temos um probabilidade de $\mathbf{7 1 . 7 1 \%}$ (83.04\% de probabilidade da tarifa de energia subir para $0.5662 \mathrm{R} \$ / \mathrm{kWh}$ e $86.36 \%$ de probabilidade do custo de implantação do SFCR subir para 10.4635 R\$/W). O mesmo raciocínio se aplica aos demais ramos da árvore binomial.

Agora, com base nesse novo cenário representado na árvore binomial bivariável, podemos efetuar a análise da opção de espera de adiamento do projeto por um período de um ano e verificar se o mesmo, pelo ponto de vista financeiro, deve ser implementado imediatamente ou não.

Para que essa análise possa ser feita, devemos novamente calcular os fluxos de caixa ao longo de toda a vida útil de todo o projeto com essa nova premissa, da mesma maneira que foi realizado para a implementação do SFCR no ano de 2015. 
Para a primeira combinação possível (aumento da tarifa de energia e aumento do custo de implantação do SFCR) temos as seguintes premissas:

- Probabilidade de Ocorrência: $\mathbf{7 1 . 7 1 \%}$

- Preço da Tarifa:0,5662 R\$/kWh

- Custo de Implantação do Sistema: 10,4635 R\$/W

Como resultado deste primeiro cenário, temos o seguinte fluxo de caixa para o projeto:

Tabela 17 - VPL, TIR e Payback para o Adiamento de 01 ano - Aumento da Energia E Aumento da Implantação

\begin{tabular}{|c|c|c|c|c|c|c|c|c|}
\hline Base & Ano & Custo & $\begin{array}{c}\text { Retorno de } \\
\text { Investimento } \\
\text { Financeiro }\end{array}$ & $\begin{array}{c}\text { Reduçāo } \\
\text { Custo } \\
\text { Eletricidade }\end{array}$ & $\begin{array}{c}\text { Fluxo de Caiza } \\
\text { Anual }\end{array}$ & $\begin{array}{l}\text { Fluxo de Caiza } \\
\text { Cumulativo }\end{array}$ & YPL do FCL & $\begin{array}{c}\text { YPL } \\
\text { Cumulativo }\end{array}$ \\
\hline 0 & 2015 & $-\mathrm{R} \$ 31.351$ & $\mathrm{R} \$ 787$ & $\mathrm{R} \$ 0$ & $-\mathrm{R} \$ 30.564$ & $-\mathrm{R} \$ 30.564$ & $-\mathrm{R} \$ 30.564$ & $-\mathrm{R} \$ 30.564$ \\
\hline 2 & 2017 & 0 & & $R \$ 3.118$ & $R \$ 3.118$ & $-R \$ 27.650$ & $R \$ 2.530$ & $-R \$ 28.217$ \\
\hline 3 & 2018 & 0 & & $R \$ 3.275$ & $R \$ 3.275$ & $-R \$ 24.375$ & $R \$ 2.394$ & $-R \$ 25.822$ \\
\hline 4 & 2019 & 0 & & $R \$ 3.439$ & $R \$ 3.439$ & $-R \$ 20.936$ & $\mathrm{R} \$ 2.266$ & $-R \$ 23.557$ \\
\hline 7 & 2022 & 0 & & $R \$ 3.985$ & $R \$ 3.985$ & $-R \$ 9.544$ & $R \$ 1.919$ & $-R \$ 17.465$ \\
\hline 8 & 2023 & 0 & & $R \$ 4.185$ & $R \$ 4.185$ & $-\mathrm{R} \$ 5.358$ & $\mathrm{R} \$ 1.816$ & $-R \$ 15.649$ \\
\hline 9 & 2024 & 0 & & $R \$ 4.396$ & $R \$ 4.396$ & $-R \$ 963$ & $R \$ 1.718$ & $-R \$ 13.930$ \\
\hline 10 & 2025 & 0 & & $R \$ 4.616$ & $R \$ 4.616$ & $R \$ 3.654$ & $R \$ 1.626$ & $-R \$ 12.305$ \\
\hline 11 & 2026 & 0 & & $R \$ 4.848$ & $R \$ 4.848$ & $R \$ 8.502$ & $R \$ 1.538$ & $-R \$ 10.766$ \\
\hline 12 & 2027 & 0 & & $R \$ 5.091$ & $R \$ 5.091$ & $R \$ 13.593$ & $R \$ 1.455$ & $-R \$ 9.311$ \\
\hline 17 & 2032 & 0 & & $R \$ 6.483$ & $R \$ 6.483$ & $R \$ 43.117$ & $R \$ 1.100$ & $-\mathrm{R} \$ 3.135$ \\
\hline 18 & 2033 & 0 & & $R \$ 6.797$ & $R \$ 6.797$ & $R \$ 49.914$ & $R \$ 1.039$ & $-R \$ 2.097$ \\
\hline 19 & 2034 & 0 & & $R \$ 7.126$ & $R \$ 7.126$ & $R \$ 57.041$ & $\mathrm{R} \$ 981$ & $-R \$ 1.115$ \\
\hline 20 & 2035 & 0 & & $R \$ 7.471$ & $R \$ 7.471$ & $R \$ 64.512$ & $R \$ 927$ & $-\mathrm{R} \$ 189$ \\
\hline 21 & 2036 & 0 & & $\mathrm{R} \$ 7.832$ & $\mathrm{R} \$ 7.832$ & $\mathrm{R} \$ 72.344$ & $\mathrm{R} \$ 875$ & $\mathrm{R} \$ 687$ \\
\hline 22 & 2037 & 0 & & $R \$ 8.210$ & $R \$ 8.210$ & $R \$ 80.554$ & $\mathrm{R} \$ 827$ & $R \$ 1.513$ \\
\hline 23 & 2038 & 0 & & $R \$ 8.606$ & $R \$ 8.606$ & $R \$ 89.161$ & $\mathrm{R} \$ 781$ & $R \$ 2.294$ \\
\hline 24 & 2039 & 0 & & $R \$ 9.021$ & $R \$ 9.021$ & $\mathrm{R} \$ 98.182$ & $R \$ 737$ & $R \$ 3.031$ \\
\hline 25 & 2040 & 0 & & $R \$ 9.456$ & $R \$ 9.456$ & $R \$ 107.638$ & $\mathrm{~A} \$ 696$ & $\mathrm{R} \$ 3.727$ \\
\hline Total & & $-R * 34.529$ & $R \$ 787$ & $R * 141.380$ & $R * 107.638$ & $R \$ 617.781$ & $R \leqslant 3.727$ & \\
\hline \multicolumn{3}{|c|}{$\begin{array}{c}\text { Inflação Anual } \\
\text { Base Anual Conta de } \\
\text { Energia } \\
\text { Taxa de Desconto }\end{array}$} & $\begin{array}{r}5,50 \% \\
R * 162.228,02 \\
11,0 \% \\
\end{array}$ & & $\begin{array}{l}\text { VPL } \\
\text { TIR } \\
\text { Payback }\end{array}$ & $\begin{array}{c}\text { R\$ } 3.726,67 \\
12,20 \% \\
11 \\
\end{array}$ & & \\
\hline
\end{tabular}

Aqui valem os mesmos comentários feitos para a análise de variação de cada modelo separadamente. Portanto, caso o investidor deseje realizar a implementação do SFCR somente no ano de 2016, o dinheiro do investimento adiado continuaria investido no título do Tesouro Direto NTN-B (paga juros, além da variação da inflação), com uma rentabilidade de $~ 11 \%$, que corresponderia a R\$ 3.448,61. Porém, o investidor não teria a economia de $\mathrm{R} \$ 2.661,47$, via compensação de energia, prevista no modelo determinístico. Portanto, esse adiamento também geraria um resultado positivo para o investidor de $\mathrm{R} \$ \mathbf{7 8 7 , 1 4}$ 
que poderão ser utilizados como parte do investimento de implantação do sistema no ano subsequente. O investidor, em função do aumento do custo de implantação do sistema teria que desembolsar adicionalmente ao investimento inicial previsto um de R\$ 3.178. Feitas todas as considerações acima, o VPL desse novo fluxo de caixa seria de R\$ 3.726,67, com uma TIR de 12,20\%.

Fazendo-se o mesmo tipo de análise para o segundo cenário (aumento da tarifa de energia e redução do custo de implantação do SFCR) temos as seguintes premissas:

- Probabilidade de Ocorrência: 11,33\%

- Preço da Tarifa:0,5662 R\$/kWh

- Custo de Implantação do Sistema: 8,6258 R\$/W

Nesse segundo cenário, teremos o seguinte fluxo de caixa:

Tabela 18 - VPL, TIR e Payback para o Adiamento de 01 ano - Aumento da Energia E Queda da Implantação

\begin{tabular}{|c|c|c|c|c|c|c|c|c|}
\hline Base & Ano & Custo & $\begin{array}{c}\text { Retorno de } \\
\text { Investimento } \\
\text { Financeiro }\end{array}$ & $\begin{array}{c}\text { Redução } \\
\text { Custo } \\
\text { Eletricidade }\end{array}$ & $\begin{array}{c}\text { Fluxo de Caixa } \\
\text { Anual }\end{array}$ & $\begin{array}{l}\text { Fluso de Caixa } \\
\text { Cumulativo }\end{array}$ & YPL do FCL & $\begin{array}{c}\text { YPL } \\
\text { Cumulativo }\end{array}$ \\
\hline 0 & 2015 & $-\mathrm{R} \$ 31.351$ & $R \$ 787$ & $R \$ 0$ & $-R \$ 30.564$ & $-\mathrm{R} \$ 30.564$ & $-\mathrm{R} \$ 30.564$ & $-\mathrm{R} \$ 30.564$ \\
\hline 1 & 2016 & 0 & $\mathrm{R} \$ 2.886$ & $\mathrm{R} \$ 2.975$ & $\mathrm{R} \$ 5.861$ & $-\mathrm{R} \$ 24.703$ & $R \$ 5.280$ & $-\mathrm{R} \$ 25.284$ \\
\hline 2 & 2017 & 0 & & $R \$ 3.118$ & $\mathrm{R} \$ 3.118$ & $-\mathrm{R} \$ 21.585$ & $R \$ 2.530$ & $-\mathrm{R} \$ 22.753$ \\
\hline 3 & 2018 & 0 & & $R \$ 3.275$ & $\mathrm{R} \$ 3.275$ & $-R \$ 18.311$ & $R \$ 2.394$ & $-R \$ 20.359$ \\
\hline 4 & 2019 & 0 & & $R \$ 3.439$ & $\mathrm{R} \$ 3.439$ & $-\mathrm{R} \$ 14.871$ & $\mathrm{R} \$ 2.266$ & $-R \$ 18.093$ \\
\hline 5 & 2020 & 0 & & $R \$ 3.613$ & $R \$ 3.613$ & $-\mathrm{R} \$ 11.259$ & $R \$ 2.144$ & $-R \$ 15.950$ \\
\hline 6 & 2021 & 0 & & $\mathrm{R} \$ 3.794$ & $\mathrm{R} \$ 3.794$ & $-\mathrm{R} \$ 7.464$ & $\mathrm{R} \$ 2.029$ & $-\mathrm{R} \$ 13.921$ \\
\hline 7 & 2022 & 0 & & $R \$ 3.985$ & $R \$ 3.985$ & $-\mathrm{R} \$ 3.479$ & $R \$ 1.919$ & $-R \$ 12.002$ \\
\hline 8 & 2023 & 0 & & $R \$ 4.185$ & $R \$ 4.185$ & $R \$ 706$ & $R \$ 1.816$ & $-R \$ 10.185$ \\
\hline 9 & 2024 & 0 & & $R \$ 4.396$ & $R \$ 4.396$ & $R \$ 5.102$ & $\mathrm{R} \$ 1.718$ & $-\mathrm{R} \$ 8.467$ \\
\hline 10 & 2025 & 0 & & $R \$ 4.616$ & $R \$ 4.616$ & $R \$ 9.718$ & $R \$ 1.626$ & $-\mathrm{R} \$ 6.841$ \\
\hline 11 & 2026 & 0 & & $R \$ 4.848$ & $R \$ 4.848$ & $R \$ 14.566$ & $R \$ 1.538$ & $-R \$ 5.303$ \\
\hline 12 & 2027 & 0 & & $\mathrm{R} \$ 5.091$ & $R \$ 5.091$ & $R \$ 19.657$ & $R \$ 1.455$ & $-\mathrm{R} \$ 3.848$ \\
\hline 13 & 2028 & 0 & & $R \$ 5.347$ & $R \$ 5.347$ & $R \$ 25.004$ & $R \$ 1.377$ & $-R \$ 2.471$ \\
\hline 14 & 2029 & 0 & & $R \$ 5.615$ & $R \$ 5.615$ & $\mathrm{R} \$ 30.619$ & $R \$ 1.303$ & $-R \$ 1.168$ \\
\hline 15 & 2030 & 0 & & $\mathrm{R} \$ 5.896$ & $R \$ 5.896$ & $R \$ 36.515$ & $R \$ 1.232$ & $\mathrm{R} \$ 64$ \\
\hline 16 & 2031 & 0 & & $R \$ 6.183$ & $R \$ 6.183$ & $R \$ 42.698$ & $R \$ 1.164$ & $R \$ 1.228$ \\
\hline 17 & 2032 & 0 & & $R \$ 6.483$ & $R \$ 6.483$ & $R \$ 49.181$ & $R \$ 1.100$ & $R \$ 2.328$ \\
\hline 18 & 2033 & 0 & & $R \$ 6.797$ & $R \$ 6.797$ & $\mathrm{R} \$ 55.979$ & $R \$ 1.039$ & $R \$ 3.367$ \\
\hline 19 & 2034 & 0 & & $R \$ 7.126$ & $R \$ 7.126$ & $R \$ 63.105$ & $\mathrm{R} \$ 981$ & $R \$ 4.348$ \\
\hline 20 & 2035 & 0 & & $R \$ 7.471$ & $R \$ 7.471$ & $R \$ 70.576$ & $R \$ 927$ & $\mathrm{R} \$ 5.275$ \\
\hline 21 & 2036 & 0 & & $\mathrm{R} \$ 7.832$ & $\mathrm{R} \$ 7.832$ & $R \$ 78.408$ & $\mathrm{R} \$ 875$ & $R \$ 6.150$ \\
\hline 22 & 2037 & 0 & & $R \$ 8.210$ & $R \$ 8.210$ & $\mathrm{R} \$ 86.619$ & $R \$ 827$ & $R \$ 6.976$ \\
\hline 23 & 2038 & 0 & & $R \$ 8.606$ & $\mathrm{R} \$ 8.606$ & $R \$ 95.225$ & $R \$ 781$ & $\mathrm{R} \$ 7.757$ \\
\hline 24 & 2039 & 0 & & $R \$ 9.021$ & $R \$ 9.021$ & $R \$ 104.246$ & $R \$ 737$ & $R \$ 8.494$ \\
\hline 25 & 2040 & 0 & & $R \$ 9.456$ & $R \$ 9.456$ & $R \$ 113.702$ & $R \$ 696$ & $R \$ 9.190$ \\
\hline Total & & $-R \$ 31.351$ & $R \leqslant 3.673$ & $R \$ 141.380$ & $R \$ 113.702$ & $R * 769.389$ & $R \$ 9.190$ & \\
\hline \multicolumn{3}{|c|}{$\begin{array}{c}\text { Inflação Anual } \\
\text { Base Anual Conta de } \\
\text { Energia } \\
\text { Tasa de Desconto }\end{array}$} & $\begin{array}{r}5,50 \% \\
R * 162.228,02 \\
11,0 \% \\
\end{array}$ & & $\begin{array}{l}\text { VPL } \\
\text { TIR } \\
\text { Payback }\end{array}$ & $\begin{array}{c}\text { R\$ } 9.190,00 \\
14,33 \% \\
9 \\
\end{array}$ & & \\
\hline
\end{tabular}

Esse cenário é o mais favorável para o adiamento da implantação do sistema fotovoltaico, uma vez que o valor da tarifa está aumentando ao mesmo tempo que o custo de implantação do sistema está diminuindo. 
Caso o investidor deseje realizar a implementação do SFCR somente no ano de 2016, o dinheiro do investimento adiado continuaria investido no título do Tesouro Direto NTN-B (paga juros, além da variação da inflação), com uma rentabilidade de $\sim 11 \%$, que corresponderia a $\mathrm{R} \$ 3.448,61$. Porém, o investidor não teria a economia de $\mathrm{R} \$ 2.661,47$, via compensação de energia, prevista no modelo determinístico. Portanto, esse adiamento também geraria um resultado positivo para o investidor de $\mathrm{R} \$ 787,14$ que poderão ser utilizados como parte do investimento de implantação do sistema no ano subsequente. Nesse cenário de queda dos custos de implantação do SFCR, o investidor, além da rentabilidade do investimento, também terá a vantagem de uma redução de $\mathbf{R} \mathbf{\$} \mathbf{2 . 8 8 5 , 8 6}$ no custo de execução do projeto. Com isso, nesse cenário, o VPL desse novo fluxo de caixa seria de $\mathbf{R} \mathbf{9 . 1 9 0 , 0 0}$, com uma TIR de $\mathbf{1 4 . 3 3 \% \text { . }}$

Para a realizar a análise do terceiro cenário (redução da tarifa de energia e aumento do custo de implantação do SFCR) temos as seguintes premissas:

- Probabilidade de Ocorrência: $\mathbf{1 4 , 6 5 \%}$

- Preço da Tarifa:0,4590 R\$/kWh

- Custo de Implantação do Sistema: 10,4645 R \$/W

Recalculando os fluxos de caixa para esse terceiro cenário temos:

Tabela 19 - VPL, TIR e Payback para o Adiamento de 01 ano - Queda da Energia E Aumento da Implantação 


\begin{tabular}{|c|c|c|c|c|c|c|c|c|}
\hline Base & Ano & Custo & $\begin{array}{c}\text { Retorno de } \\
\text { Investimento } \\
\text { Financeiro }\end{array}$ & $\begin{array}{l}\text { Reduçāo } \\
\text { Custo } \\
\text { Eletricidade }\end{array}$ & $\begin{array}{c}\text { Fluxo de Caiza } \\
\text { Anual }\end{array}$ & $\begin{array}{l}\text { Fluzo de Caixa } \\
\text { Cumulativo }\end{array}$ & YPL do FCL & $\begin{array}{c}\text { VPL } \\
\text { Cumulativo }\end{array}$ \\
\hline 0 & 2015 & $-\mathrm{R} \$ 31.351$ & $\mathrm{R} \$ 787$ & $\mathrm{R} \$ 0$ & $-R \$ 30.564$ & $-\mathrm{R} \$ 30.564$ & $-\mathrm{R} \$ 30.564$ & $-\mathrm{R} \$ 30.564$ \\
\hline 1 & 2016 & $-\mathrm{R} \$ 3.178$ & & $\mathrm{R} \$ 2.392$ & $-\mathrm{R} \$ 786$ & $-\mathrm{R} \$ 31.350$ & $-\mathrm{R} \$ 708$ & $-\mathrm{R} \$ 31.272$ \\
\hline 2 & 2017 & 0 & & $\mathrm{R} \$ 2.505$ & $R \$ 2.505$ & $-R \$ 28.845$ & $R \$ 2.033$ & $-R \$ 29.239$ \\
\hline 3 & 2018 & 0 & & $R \$ 2.631$ & $R \$ 2.631$ & $-\mathrm{R} \$ 26.213$ & $R \$ 1.924$ & $-\mathrm{R} \$ 27.315$ \\
\hline 4 & 2019 & 0 & & $\mathrm{R} \$ 2.763$ & $\mathrm{R} \$ 2.763$ & $-\mathrm{A} \$ 23.450$ & $R \$ 1.820$ & $-\mathrm{R} \$ 25.495$ \\
\hline 5 & 2020 & 0 & & $\mathrm{R} \$ 2.902$ & $R \$ 2.902$ & $-\mathrm{R} \$ 20.548$ & $R \$ 1.722$ & $-\mathrm{R} \$ 23.772$ \\
\hline 6 & 2021 & 0 & & $\mathrm{R} \$ 3.047$ & $R \$ 3.047$ & $-R \$ 17.501$ & $R \$ 1.629$ & $-\mathrm{R} \$ 22.143$ \\
\hline 7 & 2022 & 0 & & $R \$ 3.200$ & $R \$ 3.200$ & $-R \$ 14.301$ & $R \$ 1.541$ & $-R \$ 20.602$ \\
\hline 8 & 2023 & 0 & & $R \$ 3.361$ & $R \$ 3.361$ & $-R \$ 10.940$ & $R \$ 1.458$ & $-R \$ 19.143$ \\
\hline 9 & 2024 & 0 & & $R \$ 3.529$ & $R \$ 3.529$ & $-\mathrm{R} \$ 7.411$ & $R \$ 1.380$ & $-R \$ 17.764$ \\
\hline 10 & 2025 & 0 & & $R \$ 3.706$ & $R \$ 3.706$ & $-R \$ 3.705$ & $R \$ 1.305$ & $-R \$ 16.459$ \\
\hline 11 & 2026 & 0 & & $R \$ 3.891$ & $R \$ 3.891$ & $R \$ 186$ & $R \$ 1.235$ & $-R \$ 15.224$ \\
\hline 12 & 2027 & 0 & & $R \$ 4.086$ & $R \$ 4.086$ & $\mathrm{R} \$ 4.272$ & $R \$ 1.168$ & $-R \$ 14.056$ \\
\hline 13 & 2028 & 0 & & $R \$ 4.290$ & $R \$ 4.290$ & $\mathrm{R} \$ 8.562$ & $R \$ 1.105$ & $-R \$ 12.951$ \\
\hline 14 & 2029 & 0 & & $R \$ 4.505$ & $R \$ 4.505$ & $R \$ 13.067$ & $R \$ 1.045$ & $-R \$ 11.906$ \\
\hline 15 & 2030 & 0 & & $R \$ 4.729$ & $R \$ 4.729$ & $R \$ 17.796$ & $\mathrm{R} \$ 988$ & $-R \$ 10.918$ \\
\hline 16 & 2031 & 0 & & $R \$ 4.959$ & $R \$ 4.959$ & $\mathrm{R} \$ 22.755$ & $\mathrm{R} \$ 934$ & $-R \$ 9.984$ \\
\hline 17 & 2032 & 0 & & $R \$ 5.199$ & $\mathrm{R} \$ 5.199$ & $R \$ 27.954$ & $R \$ 882$ & $-R \$ 9.102$ \\
\hline 18 & 2033 & 0 & & $R \$ 5.449$ & $R \$ 5.449$ & $\mathrm{R} \$ 33.403$ & $\mathrm{R} \$ 833$ & $-\mathrm{R} \$ 8.269$ \\
\hline 19 & 2034 & 0 & & $R \$ 5.712$ & $R \$ 5.712$ & $R \$ 39.115$ & $\mathrm{R} \$ 786$ & $-R \$ 7.483$ \\
\hline 20 & 2035 & 0 & & $R \$ 5.987$ & $R \$ 5.987$ & $R \$ 45.102$ & $R \$ 743$ & $-R \$ 6.740$ \\
\hline 21 & 2036 & 0 & & $\mathrm{R} \$ 6.275$ & $R \$ 6.275$ & $R \$ 51.377$ & $R \$ 701$ & $-R \$ 6.039$ \\
\hline 22 & 2037 & 0 & & $\mathrm{R} \$ 6.577$ & $R \$ 6.577$ & $R \$ 57.954$ & $R \$ 662$ & $-\mathrm{R} \$ 5.377$ \\
\hline 23 & 2038 & 0 & & $R \$ 6.893$ & $R \$ 6.893$ & $\mathrm{R} \$ 64.847$ & $R \$ 625$ & $-R \$ 4.752$ \\
\hline 24 & 2039 & 0 & & $\mathrm{R} \$ 7.223$ & $\mathrm{R} \$ 7.223$ & $R \$ 72.070$ & $\mathrm{R} \$ 590$ & $-R \$ 4.162$ \\
\hline 25 & 2040 & 0 & & $R \$ 7.569$ & $\mathrm{R} \$ 7.569$ & $R \$ 79.640$ & $R \$ 557$ & $-\mathrm{R} \$ 3.605$ \\
\hline Total & & $-R \leqslant 34.529$ & $R \leqslant 787$ & $R \leqslant 113.382$ & $R \leqslant 79.640$ & R\$ 323.273 & $-R \$ 3.605$ & \\
\hline \multicolumn{3}{|c|}{$\begin{array}{c}\text { Inflação Anual } \\
\text { Base Anual Conta de } \\
\text { Tasa de Desconto }\end{array}$} & $\begin{array}{r}5,50 \% \\
R * 134.229,80 \\
11,0 \% \\
\end{array}$ & & $\begin{array}{l}\text { VPL } \\
\text { TIR } \\
\text { Payback } \\
\end{array}$ & $\begin{array}{c}-R * 3.604,72 \\
9.78 \% \\
12 \\
\end{array}$ & & \\
\hline
\end{tabular}

Esse cenário é o menos favorável para implantação imediata do sistema fotovoltaico, uma vez que o valor da tarifa está caindo e ao mesmo tempo o custo de implantação do sistema está aumentando.

Caso o investidor deseje realizar a implementação do SFCR somente no ano de 2016, o dinheiro do investimento adiado continuaria investido no título do Tesouro Direto NTN-B (paga juros, além da variação da inflação), com uma rentabilidade de $\sim 11 \%$, que corresponderia a $\mathrm{R} \$ 3.448,61$. Porém, o investidor não teria a economia de $\mathrm{R} \$ 2.661,47$, via compensação de energia, prevista no modelo determinístico. Portanto, esse adiamento também geraria um resultado positivo para o investidor de R 787,14 que poderão ser utilizados como parte do investimento de implantação do sistema no ano subsequente, mas o investidor, em função do aumento do custo de implantação do sistema teria que desembolsar adicionalmente ao investimento inicial previsto um de R\$3.178. Nesse cenário, o VPL desse novo fluxo de caixa seria de (- R\$ 3.604,72), com uma TIR de $\mathbf{9 . 7 8 \% . ~}$

E finalmente, para a realizar a análise do quarto cenário (redução da tarifa de energia e redução do custo de implantação do SFCR) temos as seguintes premissas:

- Probabilidade de Ocorrência: 2,31\%

- Preço da Tarifa:0,4590 R\$/kWh 
Os fluxos de caixa considerando as premissas desse quarto cenário fica conforme tabela abaixo:

Tabela 20 - VPL, TIR e Payback para o Adiamento de 01 ano - Queda da Energia E Queda da Implantação

\begin{tabular}{|c|c|c|c|c|c|c|c|c|}
\hline Base & Ano & Custo & $\begin{array}{c}\text { Retorno de } \\
\text { Investimento } \\
\text { Financeiro }\end{array}$ & $\begin{array}{c}\text { Redução } \\
\text { Custo } \\
\text { Eletricidade }\end{array}$ & $\begin{array}{c}\text { Fluzo de } \\
\text { Caiza Anual }\end{array}$ & $\begin{array}{l}\text { Fluzo de Caiza } \\
\text { Cumulativo }\end{array}$ & YPL do FCL & $\begin{array}{c}\text { YPL } \\
\text { Cumulativo }\end{array}$ \\
\hline 0 & 2015 & $-\mathrm{R} \$ 31.531$ & $\mathrm{R} \$ 787$ & $\mathrm{R} \$ 0$ & $-\mathrm{R} \$ 30.744$ & $-\mathrm{R} \$ 30.744$ & $-\mathrm{R} \$ 30.744$ & $-\mathrm{R} \$ 30.744$ \\
\hline 2 & 2017 & 0 & & $R \$ 2.505$ & $\mathrm{R} \$ 2.505$ & $-\mathrm{R} \$ 22.960$ & $R \$ 2.033$ & $-\mathrm{R} \$ 23.955$ \\
\hline 3 & 2018 & 0 & & $R \$ 2.631$ & $\mathrm{R} \$ 2.631$ & $-\mathrm{R} \$ 20.329$ & $R \$ 1.924$ & $-\mathrm{R} \$ 22.031$ \\
\hline 4 & 2019 & 0 & & $R \$ 2.763$ & $R \$ 2.763$ & $-R \$ 17.566$ & $R \$ 1.820$ & $-R \$ 20.211$ \\
\hline 7 & 2022 & 0 & & $R \$ 3.200$ & $R \$ 3.200$ & $-\mathrm{R} \$ 8.416$ & $R \$ 1.541$ & $-R \$ 15.318$ \\
\hline 8 & 2023 & 0 & & $R \$ 3.361$ & $\mathrm{R} \$ 3.361$ & $-\mathrm{R} \$ 5.056$ & $R \$ 1.458$ & $-\mathrm{R} \$ 13.860$ \\
\hline 9 & 2024 & 0 & & $R \$ 3.529$ & $R \$ 3.529$ & $-R \$ 1.527$ & $R \$ 1.380$ & $-R \$ 12.480$ \\
\hline 10 & 2025 & 0 & & $R \$ 3.706$ & $\mathrm{R} \$ 3.706$ & $R \$ 2.179$ & $R \$ 1.305$ & $-R \$ 11.175$ \\
\hline 11 & 2026 & 0 & & $R \$ 3.891$ & $R \$ 3.891$ & $R \$ 6.070$ & $R \$ 1.235$ & $-\mathrm{R} \$ 9.941$ \\
\hline 12 & 2027 & 0 & & $R \$ 4.086$ & $R \$ 4.086$ & $R \$ 10.156$ & $R \$ 1.168$ & $-R \$ 8.773$ \\
\hline 17 & 2032 & 0 & & $R \$ 5.199$ & $R \$ 5.199$ & $R \$ 33.838$ & $R \$ 882$ & $-R \$ 3.819$ \\
\hline 18 & 2033 & 0 & & $R \$ 5.449$ & $R \$ 5.449$ & $R \$ 39.287$ & $\mathrm{R} \$ 833$ & $-\mathrm{R} \$ 2.986$ \\
\hline 19 & 2034 & 0 & & $R \$ 5.712$ & $R \$ 5.712$ & $R \$ 44.999$ & $R \$ 786$ & $-R \$ 2.200$ \\
\hline 20 & 2035 & 0 & & $R \$ 5.987$ & $R \$ 5.987$ & $R \$ 50.987$ & $R \$ 743$ & $-R \$ 1.457$ \\
\hline 21 & 2036 & 0 & & $\mathrm{R} \$ 6.275$ & $\mathrm{R} \$ 6.275$ & $R \$ 57.262$ & $\mathrm{R} \$ 701$ & $-R \$ 756$ \\
\hline 22 & 2037 & 0 & & $R \$ 6.577$ & $R \$ 6.577$ & $R \$ 63.839$ & $R \$ 662$ & $-R \$ 94$ \\
\hline 23 & 2038 & 0 & & $R \$ 6.893$ & $R \$ 6.893$ & $R \$ 70.731$ & $R \$ 625$ & $R \$ 531$ \\
\hline 24 & 2039 & 0 & & $R \$ 7.223$ & $R \$ 7.223$ & $R \$ 77.954$ & $R \$ 590$ & $R \$ 1.121$ \\
\hline 25 & 2040 & 0 & & $R \$ 7.569$ & $R \$ 7.569$ & $\mathrm{R} \$ 85.524$ & $R \$ 557$ & $R \$ 1.679$ \\
\hline Total & & $-R \leqslant 31.531$ & $R \leqslant 3.673$ & $R \leqslant 113.382$ & $R \leqslant 85.524$ & $R \leqslant 470.201$ & $R \leqslant 1.679$ & \\
\hline
\end{tabular}

As mesmas considerações dos cenários anteriores continuam válidas nesse cenário, ou seja, caso o investidor deseje realizar a implementação do SFCR 
somente no ano de 2016, o dinheiro do investimento adiado continuaria investido no título do Tesouro Direto NTN-B (paga juros, além da variação da inflação), com uma rentabilidade de $\sim 11 \%$, que corresponderia a R\$3.448,61. Porém, o investidor não teria a economia de $\mathrm{R}$ \$ 2.661,47, via compensação de energia, prevista no modelo determinístico. Portanto, esse adiamento também geraria um resultado positivo para o investidor de $\mathrm{R} \$ 787,14$ que poderão ser utilizados como parte do investimento de implantação do sistema no ano subsequente. Nesse cenário de queda dos custos de implantação do SFCR, o investidor, além da rentabilidade do investimento, também terá a vantagem de uma redução de $\mathbf{R} \$$ 2.885,86 no custo de execução do projeto. O VPL desse novo fluxo de caixa seria de R\$ 1.678,61 com uma TIR de 11.64\%.

Após o cálculo do fluxo de caixa de cada um dos quatro cenários, finalmente, podemos encontrar o valor da opção de espera do referido projeto:

- Cenário 1 - Aumento do custo de Energia e Aumento do Custo de Implantação:

$$
\text { Fuu }=\max (\text { Vuu }-I, 0)=\max (R \$ 3.726,67,0)=R \$ 3.726,67
$$

- Cenário 2 - Aumento do custo de Energia e Redução do Custo de Implantação:

Fud $=\max (\operatorname{Vud}-I, 0)=\max (R \$ 9.190,00,0)=R \$ 9.190,00$

- Cenário 3 - Redução do custo de Energia e Aumento do Custo de Implantação:

Fdu $=\max (\mathrm{Vdu}-\mathrm{I}, 0)=\max (-\mathrm{R} \$ 3.604,72,0)=\mathrm{R} \$ 0$

- Cenário 4 - Redução do custo de Energia e Redução do Custo de Implantação:

Fdd $=\max (\operatorname{Vdd}-I, 0)=\max (R \$ 1.678,61,0)=R \$ 1.678,61$ 
Dessa forma, considerando uma possível variação no custo da tarifa de energia e do custo de implantação, valor da oportunidade de adiamento do investimento em 1 ano $(t=1)$ ficaria assim estabelecido:

F1 $=$ puu. Fuu + pud. Fud + pdu. Fdu + pdd. Fdd. $=$ $F_{1}=(71,71 \% \times R \$ 3.726,67+11.33 \% \times R \$ 9.190,00+14.65 \% \times R \$ 0+2.31 \%$ $x \operatorname{R} 1.678,61)=$

$F_{1}=\mathbf{R} \$ 3.752,17$

Trazendo-se o valor da oportunidade de espera para a data atual $(\mathrm{t}=0)$ teremos que:

$F 0=F 1 /\left(1+r_{f}\right)=R \$ 3.752,17 / 1,11=R \$ 3.380,34$

Portanto, nessas condições, caso o investidor decida esperar um ano para implementar o projeto do SFCR, ele obterá um valor de oportunidade de R\$ 3.380,34 por essa decisão de adiamento, enquanto que, caso decida implementá-lo imediatamente, o VPL calculado seria de R\$ 5.607,37. Essa diferença entre o valor da oportunidade de adiamento em um ano $(\mathrm{t}=1)$ e o VPL é exatamente o valor da opção de espera para o cenário apresentado. 


\section{Conclusões}

\section{1}

\section{Principais Resultados e Considerações Finais}

O objetivo final desse estudo era fazer a avaliação do momento mais apropriado para a implementação de um sistema fotovoltaico residencial sob o ponto de vista financeiro, pela avaliação da opção de espera, utilizando a teoria de opções reais (TOR).

Fazendo-se uma análise dos resultados obtidos no Capítulo 4, concluímos que, dadas as condições do estudo, para o investidor é melhor investir na implantação do sistema de forma imediata do que esperar um ano para fazê-lo, uma vez que o VPL do Projeto com implementação imediata é de $\mathbf{R} \mathbf{5 . 6 0 7 , 3 7}$, com uma TIR de 13,11\%, enquanto a espera de um ano fará com que o projeto tenha um VPL de R\$ 3.380,34

Vale ressaltar que para a viabilidade imediata de implantação do sistema somente é possível em função da publicação da Lei n ${ }^{0} 20.824$ pelo Estado de Minas Gerais, uma vez que a maioria dos Estados da Federação, após a homologação da Resolução Normativa $n^{0} 482$ da ANEEL, criaram regras tributárias que reafirmaram que o ICMS sobre a conta de energia elétrica incide sobre a totalidade da energia elétrica fornecida pela distribuidora para o consumidor residencial, independente do sistema de compensação da energia. Portanto, a implantação de um modelo fotovoltaico de geração de energia elétrica, do ponto de vista financeiro, é inviável na maioria grande maioria dos estados brasileiros.

Para efeito de comparação desses dois cenários tributários (ICMS incidente sobre a energia total fornecida e ICMS incidente sobre a diferença entre a energia fornecida e a energia gerada), foi realizada uma simulação de implantação de um sistema fotovoltaico com as mesmas características geradoras no Estado do Rio de Janeiro e o VPL do projeto para implantação em 2015, em função do sistema tributário, foi de (- $\mathbf{R} \$ \mathbf{8 . 7 5 1 , 0 6 )}$ com uma TIR de 7,06\%, 
mostrando a inviabilidade de implantação e ineficiência da resolução $\mathrm{n}^{0} 482$ da ANEEL para fomentar tal interesse por parte do consumidor residencial. A simulação para a implantação no Rio de Janeiro encontra-se no Apêndice desse estudo.

Outro ponto a se destacar é que um dos fatores motivadores para a implantação de um sistema fotovoltaico residencial é a previsão de aumento da tarifa de energia elétrica. O presente estudo utilizou como premissa que a tarifa de energia elétrica da CEMIG sofreria um reajuste de 28,59\% para o ano de 2015 e de 5,5\% (inflação) para os anos subsequentes, além da utilização de bandeira tarifária VERMELHA. Porém, o cenário apresentado no primeiros dias de 2015 está sinalizando que os reajustes dessas tarifas de energia possam ser superiores às premissas adotadas, fator que certamente incentivará a implantação imediata do sistema.

Apesar do grande potencial para desenvolvimento e inclusão da geração fotovoltaica de energia na matriz energética brasileira, o mercado definitivamente necessita de alguma forma de incentivo para que consiga crescer, pois somente a resolução $n^{0} 482$ não conseguiu gerar a atratividade necessária e esperada pela ANEEL.

Apesar de o resultado final do estudo recomendar a implantação imediata do sistema fotovoltaico, as análises realizadas mostraram que em projetos dessa natureza, quando o investidor não possui a obrigação de implantação imediata, a flexibilidade gerencial agrega valor ao mesmo e deve ser levada em consideração da análise de viabilidade desse tipo de projeto.

\section{2}

\section{Sugestões de Estudos Futuros}

Esse estudo utilizou como referência a implantação de um modelo fotovoltaico, porém, pode ser realizado para qualquer projeto que possua flexibilidade gerencial, independente do setor. Sugerimos que a metodologia aqui utilizada possa ser aplicada na análise das diversas formas de mini geração e micro geração aceito na resolução $n^{0} 482$ da ANEEL (energia hidráulica, eólica, biomassa ou cogeração qualificada), bem como recomendamos a análise considerando a opção de espera por mais anos. 
Outra estudo bastante pertinente e relevante para o desenvolvimento do setor fotovoltaico seria a análise de viabilidade através de pagamentos mensais pelo serviço de "geração de energia solar”, onde caberia às empresas privadas a venda, a instalação e a manutenção dos sistema e uma cobrança de um valor fixo pelo serviço, nos mesmo moldes das prestadoras de TV por assinatura. Essa forma é muito utilizada em alguns estados do EUA e foi a responsável pela grande proliferação desse tipo de sistema no mercado norte-americano, podendo ser um dos modelos de incentivo a serem praticados no mercado brasileiro. 


\section{Referências Bibliográficas}

ABINEE - Associação Brasileira da Indústria Elétrica e Eletrônica - Propostas para Inserção da Energia Solar Fotovoltaica na Matriz Elétrica Brasileira Junho de 2012.2 Disponível em: $<$ http://www.abinee.org.br/informac/arquivos/profotov.pdf $>$

ANEEL - Agência Nacional de Energia Elétrica (2014) - Cadernos Temáticos ANEEL.

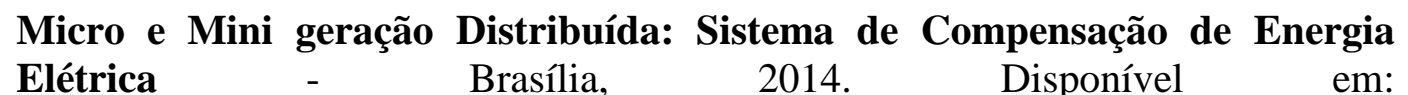
http://www.aneel.gov.br/biblioteca/downloads/livros/caderno-tematicomicroeminigeracao.pdf.

ANEEL - Agência Nacional de Energia Elétrica - Resolução Normativa n $\mathbf{n}^{\mathbf{0}} 482$ de 17 de Abril de 2012 - Brasília. Disponível em: $<$ http://www.aneel.gov.br/cedoc/ren2012482.pdf>.

ANEEL - Agência Nacional de Energia Elétrica - Resolução Normativa no 481 de 17 de Abril de 2012 - Brasília. Disponível em: $<$ http://www.aneel.gov.br/cedoc/ren2012481.pdf>.

ANEEL - Agência Nacional de Energia Elétrica - Resolução Normativa no 626 de 30 de Setembro de 2014 - Brasília. Disponível em: <http://www.aneel.gov.br/aplicacoes/audiencia/arquivo/2013/126/documento/min uta_ren_alteracao_bandeiras_tarifarias_6.pdf>.

ANEEL - Agência Nacional de Energia Elétrica - Dados históricos das tarifas residenciais da Concessionária CEMIG. Disponível em: $<$ http://www.aneel.gov.br/area.cfm?idArea=493>. Acesso em 30/12/2014.

ASHURI, B; KASHANI, H.; LU, J.I.A.N. A real options approach to evaluating investment in solar ready buildings. In: MISBE2011-Proceedings of the international Conference on Management and Innovation for a Sustainable Built Environment, 2011.

BLACK, F; SCHOLES, M. The Pricing of Options and Corporate Liabilities. The Journal of Political Economy, v. 81, n. 3, p. 637-654, 1973

BOYLE, P.P. A lattice framework for option pricing with two state variables. Journal of Financial and Quantitative Analysis, v. 23, n. 01, p. 1-12, 1988.

SILVA, N.; DE ARAÚJO, L.L.A. Opções: do tradicional ao exótico. São Paulo: Atlas, 1996. 
BRAGA, R.P. Energia Solar Fotovoltaica: Fundamentos e Aplicações. Rio de Janeiro, 2008.

BRANDÃO, L.E.T. Uma Aplicação da Teoria das Opções Reais em Tempo Discreto para Avaliação de um Projeto de Concessão Rodoviária. 2002. (Tese de Doutorado). Departamento de Engenharia Industrial, PUC-Rio, Rio de Janeiro.

BRANKER, K.; PATHAK, M.J.M.; PEARCE, J.M. A review of solar photovoltaic levelized cost of electricity. Renewable and Sustainable Energy Reviews, v. 15, n. 9, p. 4470-4482, 2011.

BSW - German Solar Industry Association - Statistic data on the German Solar Power (photovoltaic) Industry - Histórico do Custo de Implantação do SFCR mais de 800 empresas alemãs. Disponível em: $<$ http://www.solarwirtschaft.de/en/start/english-news.html>.

CHIGUERU, T. Atlas Solarimétrico do Brasil, Banco de dados terrestres. Ed. Universitária da UFPE, Recife, 2000.

CONFAZ - Conselho Nacional de Política Fazendária - Convênio ICMS 6, de 5 de abril de 2013 - Ipojuca-PE. Disponível em: <http://www1.fazenda.gov.br/confaz/confaz/convenios/ICMS/2013/CV006_13.ht $\mathrm{m}>$.

COPELAND, T.; ANTIKAROV, V. Real options: A practitioner's Guide. Texere, New York: v. 368, 2001.

COSTA, L.G.T.A.; COSTA, R.T.A.; ALVIM, M.A. Valuation: manual de avaliação e reestruturação econômica de empresas. São Paulo: Atlas, 2010

COX, J.C.; ROSS, S.A.; RUBINSTEIN, M. Option pricing: A simplified approach. Journal of Financial Economics, v. 7, n. 3, p. 229-263, 1979.

DA ROCHA, A.F. et al. Investimento em Adutoras e Barragens e a Opção de Espera: Uma Aplicação da Teoria das Opções Reais. XVII Simpósio Brasileiro de Recursos Hídricos. São Paulo, 2007

DIXIT, A.K.; PINDYCK, R.S. Investment under uncertainty, 1994.

DOS SANTOS, E.M.; DE OLIVEIRA PAMPLONA, E. Teoria das Opções Reais: uma atraente opção no processo de análise de investimentos. Revista de Administração da Universidade de São Paulo, v. 40, n. 3, 2005.

DOER - Massachusetts Department of Energy Resources - Evaluation of Current Solar Costs and Needed Incentive Levels across Market Segments Julho de 2013. Disponível em: <http://www.mass.gov/eea/docs/doer/rps-aps/doerpost-400-task-1.pdf>.

EPE, NOTA TÉCNICA. Análise da Inserção da Geração Solar na Matriz Elétrica Brasileira. Rio de Janeiro, 2012. Disponível em: <http://www.epe.gov.br/geracao/documents/estudos_23/nt_energiasolar_2012.pdf $>$. 
EPIA - European Photovoltaic Industry Association. (2014). Global Market Outlook for Photovoltaics 2014 - 2018 ISBN: 978-90-82-22840-3. Disponível em: $\quad<$ http://www.epia.org/news/publications/global-market-outlook-forphotovoltaics-2014-2018/>

FTHENAKIS, V.M.; KIM, H.C. Photovoltaics: Life-cycle analyses. Solar Energy, v. 85, n. 8, p. 1609-1628, 2011

GOMES, L.L. Avaliação de termelétricas no Brasil estudando o melhor momento de investimento por modelos de opções reais. 2002. $102 \mathrm{f}$. Tese (Doutorado em Engenharia de Produção) - Programa de Pós Graduação do Departamento de Engenharia Industrial, Pontifícia Universidade Católica, Rio de Janeiro, 2002.

GRIFFES, P.; HSU, M.; KAHN, E. Power Asset Valuation: Real Options, Ancillary Services, and Environmental Risks. The New Power Markets: Corporate Strategies for Risk and Reward, Risk Books, London, UK, p. 103-125, 1999.

HARTLEY, P. et al. Energy Sector Innovation and Growth: An Optimal Energy Crisis. Mimeo, Rice University, 2011.

HULL, J.C. Fundamentos dos mercados futuros e de opções. São Paulo: BM\&FBOVESPA, 2009.

IEA - International Energy Agency (2014). Technology Roadmap - Solar Photovoltaic Energy. Disponível em: <http://www.iea.org/publications/freepublications/publication/pv_roadmap.pdf>.

INPE - Instituto Nacional de Pesquisas Espaciais (2006) - Atlas Brasileiro de Energia Solar. ISBN 9788517000300. Disponível em: $<$ http://www.ccst.inpe.br/wp-content/themes/ccst-2.0/pdf/atlas_solarreduced.pdf $>$.

MACEDO, M.A. da S.; NARDELLI, P.M. Utilizando Opções Reais na Análise de Viabilidade de Projetos de Investimento Agropecuários: Um Ensaio Teórico. In: 46th Congress, July 20-23, 2008, Rio Branco, Acre, Brasil. Sociedade Brasileira de Economia, Administração e Sociologia Rural (SOBER), 2008.

MCDONALD, R.L.; SIEGEL, D. The value of waiting to invest. 1987

MERTON, R.C. Option pricing when underlying stock returns are discontinuous. Journal of Financial Economics, v. 3, n. 1, p. 125-144, 1976.

MIKOSZEWKI, R. Precificação de opções de compra no mercado brasileiro: uma abordagem relativa de método numérico frente ao modelo de Black\& Scholes. Dissertação (Mestrado em Administração) - Universidade Federal do Paraná, Curitiba, 2003.

MINARDI, A.M.A.F. Teoria de opções aplicada a projetos de investimento. RAE-Revista de Administração de Empresas, v. 40, n. 2, p. 74-79, 2000. 
MINARDI, A.M.A.F. Teoria de opções aplicada a projetos de investimento. São Paulo: Atlas, 2004.

NETO, A.A. Finanças corporativas e valor. Atlas, 2003. ISBN 978-85-2246014-4

PEREIRA, G.F. Avaliação de Estratégias no Mercado Brasileiro de opção de Ações.Tese de Doutorado. Universidade Federal do Rio de Janeiro - UFRJ, 2002

PINDYCK, R.S. Irreversibility, uncertainty, and investment. Journal of Economic Literature, v.29, n.3, p.1110-1148, 1991

PINTO, C. de L.B. Modelagem de Opções Reais com Processos de Reversão à Média em Tempo Discreto: Uma Aplicação na Indústria Brasileira de Etanol. Tese (Doutorado em Administração de Empresas) - Programa de Pós Graduação do Departamento de Administração de Empresas, Pontifícia Universidade Católica, Rio de Janeiro, 2009.

RAMOS DA SILVA, F.G. Análise e levantamento da composição tarifária brasileira. Deutsche Gesellschaft für Internationale Zusammenarbeit (GIZ) GmbH, 2013.

RIGOLON, F.J.Z. Opções reais e análise de projetos. BNDES, Área de Planejamento, Departamento Econômico-DEPEC, 1999.

ROSS, S. Uses, abuses, and alternatives to the net-present-value rule. Financial Management, v.24, n.3, p. 96-102, 1995.

RÜTHER, R.; ZILLES, R. Making the case for grid-connected photovoltaics in Brazil. Energy Policy, v. 39, n. 3, p. 1027-1030, 2011

SANTOS FILHO, A.D. dos. Teoria das opções reais aplicada a projetos de investimento em prestação de serviços de tecnologia da informação. Dissertação de Mestrado - Fundação Getúlio Vargas, Rio de Janeiro, 2003.

SEF - Secretaria de Estado e Fazenda do Governo de Minas Gerais - LEI No 20.824, DE 31 DE JULHO DE 2013 - Minas Gerais. Disponível em: $<$ http://www.fazenda.mg.gov.br/empresas/legislacao_tributaria/leis/2013/120824_ 2013.htm>.

SHERWOOD, L. US solar market trends. In: Proceedings of the Solar Conference. American Solar Energy Society; American Institute of Architects, 2007. p. 909.

TESOURO NACIONAL - Comercialização de Títulos do Tesouro. Disponível em: <http://www.tesouro.fazenda.gov.br/caracteristicas-dos-titulos-publicos>.

TRIGEORGIS, L. Real options: Managerial Flexibility and Strategy in Resource Allocation. Cambridge Massachusetts: MIT press, 1996.

Tutorial do Software de Planejamento PVsyst Version 6. Disponível em: $<$ www.pvsyst.com>. 


\section{Apêndice}

A tabela abaixo é a simulação para a implantação de um modelo equivalente ao originalmente proposto no estudo, porém, numa residência localizada no Rio de Janeiro. Nessa simulação foram considerados os dados solarimétricos do Rio de Janeiro, bem como as regras tributárias de ICMS vigentes nesse Estado:

Tabela 21 - Sistema de Compensação de Energia Elétrica - 25 anos - Rio de Janeiro.

\begin{tabular}{|c|c|c|c|c|c|c|c|c|c|c|}
\hline DTAL & & $67,82 \%$ & & & $32,18 \%$ & $3,22 \%$ & & & & \\
\hline Mês & $\begin{array}{c}\text { Total de } \\
\text { Energia } \\
\text { Consumida } \\
\text { (kWh) }\end{array}$ & $\begin{array}{c}\text { Eletricidade } \\
\text { gerada pelo } \\
\text { sistema FV } \\
\text { [KWh] }\end{array}$ & $\begin{array}{c}\text { Crédito } \\
\text { Acumulado }\end{array}$ & $\begin{array}{c}\text { Valor da Conta } \\
\text { (Rs) (Ref_2014) } \\
\text { sem GD }\end{array}$ & $\begin{array}{c}\text { Eletricidade } \\
\text { fornecida } \\
\text { pela rede } \\
\text { (KWh] }\end{array}$ & $\begin{array}{l}\text { Eletricidade } \\
\text { a Pagar } \\
\text { [KWh] }\end{array}$ & $\begin{array}{l}\text { Valor da } \\
\text { Conta com } \\
\text { GD (sem } \\
\text { IMPOSTOS) }\end{array}$ & IMPOSTOS & $\begin{array}{c}\text { Total da } \\
\text { Conta }\end{array}$ & Savings \\
\hline Janeiro & 19.450 & 9.335 & 0 & RS $26 \cdot 120,67$ & 10.115 & 10.115 & RS $9.816,00$ & RS 8.489,92 & RS $18.305,92$ & RS $7.814,76$ \\
\hline Fevereiro & 14.025 & 8.736 & 0 & RS $19.123,00$ & 5.289 & 5.289 & RS $5.688,03$ & RS $6.121,91$ & RS $11.809,94$ & RS $7.313,07$ \\
\hline Março & 16.975 & 10.073 & 0 & RS $22.928,19$ & 6.902 & 6.902 & RS 7.086,39 & RS $7.409,58$ & RS $14.495,97$ & RS $8.432,22$ \\
\hline Abril & 13.625 & 8.413 & 0 & RS $18.607,05$ & 5.212 & 5.212 & RS $5.616,81$ & RS $5.947,31$ & RS $11.564,12$ & RS $7.042,93$ \\
\hline Maio & 13.050 & 9.381 & 0 & RS $17.865,36$ & 3.669 & 3.669 & RS $4.315,69$ & RS $5.696,32$ & RS $10.012,01$ & RS $7.853,35$ \\
\hline Junho & 10.575 & 7.883 & 0 & RS $14.672,87$ & 2.692 & 2.783 & RS $3.501,51$ & RS $4.615,98$ & RS $8.117,49$ & RS $6.555,38$ \\
\hline Julho & 11.375 & 9.750 & 0 & RS $15.704,79$ & 1.625 & 2.500 & RS $3.165,74$ & RS $4.965,18$ & RS $8.130,93$ & RS $7.573,86$ \\
\hline Agosto & 12.775 & 9.404 & 0 & RS $17.510,64$ & 3.371 & 3.371 & RS $4.061,71$ & RS $5.576,28$ & RS $9.638,00$ & RS $7.872,64$ \\
\hline Setembro & 10.925 & 8.091 & 0 & RS $15.124,34$ & 2.834 & 2.885 & RS $3.605,78$ & RS $4.768,76$ & RS $8.374,54$ & RS $6.749,80$ \\
\hline Outubro & 12.325 & 8.782 & 0 & RS $16.930,19$ & 3.543 & 3.543 & RS $4.196,86$ & RS $5.379,86$ & RS $9.576,72$ & RS $7.353,47$ \\
\hline Novembro & 10.275 & 8.390 & 0 & RS $14.285,91$ & 1.885 & 2.505 & RS $3.171,89$ & RS $4.485,03$ & RS $7.656,92$ & RS $6.628,98$ \\
\hline Dezembro & 12.400 & 8.759 & 0 & RS $17.026,93$ & 3.641 & 3.641 & RS $4.281,97$ & RS $5.412,60$ & RS $9.694,56$ & RS $7.332,36$ \\
\hline Total Anual & 157.775 & 106.998 & 0 & $\mathrm{R} \$ 215.899,92$ & 50.777 & 52.414 & $\mathrm{R} \$ 58.508,37$ & R* $68.868,73$ & R* $127.377,11$ & R* 88.522,81 \\
\hline Média Anual & 13.148 & 8.917 & 0 & RS 17.991,66 & 4.231 & 4.368 & RS $4.875,70$ & Rะ 5.739,06 & $R \neq 10.614,76$ & $R * 7.376,90$ \\
\hline
\end{tabular}


Tabela 22 - VPL, TIR e Payback do Modelo Determinístico - Rio de Janeiro.

\begin{tabular}{|c|c|c|c|c|c|c|c|c|}
\hline Ano & Ano & Custo & $\begin{array}{l}\text { Subsídio } \\
\text { Governo }\end{array}$ & $\begin{array}{c}\text { Reduçāo } \\
\text { Custo }\end{array}$ & $\begin{array}{c}\text { Fluzo de } \\
\text { Caiza Anual }\end{array}$ & $\begin{array}{c}\text { Fluzo de Caixa } \\
\text { Cumulativo }\end{array}$ & VPL do FCL & $\begin{array}{c}\text { VPL } \\
\text { Cumulativo }\end{array}$ \\
\hline 0 & 2015 & $-R \$ 29.144$ & & $R \$ 1.493$ & $-R \$ 27.651$ & $-R \$ 27.651$ & $-\mathrm{R} \$ 27.651$ & $-\mathrm{R} \$ 27.651$ \\
\hline 1 & 2016 & 0 & & $R \$ 1.569$ & $R \$ 1.569$ & $-R \$ 26.082$ & $R \$ 1.414$ & $-R \$ 26.237$ \\
\hline 2 & 2017 & 0 & & $R \$ 1.643$ & $R \$ 1.643$ & $-R \$ 24.439$ & $R \$ 1.333$ & $-R \$ 24.904$ \\
\hline 3 & 2018 & 0 & & $R \$ 1.723$ & $R \$ 1.723$ & $-\mathrm{R} \$ 22.716$ & $R \$ 1.260$ & $-R \$ 23.644$ \\
\hline 4 & 2019 & 0 & & $R \$ 1.807$ & $R \$ 1.807$ & $-R \$ 20.909$ & $R \$ 1.190$ & $-R \$ 22.454$ \\
\hline 5 & 2020 & 0 & & $R \$ 1.895$ & $R \$ 1.895$ & $-R \$ 19.014$ & $R \$ 1.125$ & $-R \$ 21.329$ \\
\hline 6 & 2021 & 0 & & $R \$ 1.988$ & $R \$ 1.988$ & $-R \$ 17.026$ & $R \$ 1.063$ & $-R \$ 20.266$ \\
\hline 7 & 2022 & 0 & & $R \$ 2.083$ & $R \$ 2.083$ & $-\mathrm{R} \$ 14.943$ & $R \$ 1.003$ & $-R \$ 19.263$ \\
\hline 8 & 2023 & 0 & & $R \$ 2.183$ & $R \$ 2.183$ & $-R \$ 12.759$ & $R \$ 947$ & $-R \$ 18.315$ \\
\hline 9 & 2024 & 0 & & $R \$ 2.287$ & $R \$ 2.287$ & $-R \$ 10.472$ & $R \$ 894$ & $-R \$ 17.421$ \\
\hline 10 & 2025 & 0 & & $R \$ 2.395$ & $\mathrm{R} \$ 2.395$ & $-R \$ 8.077$ & $R \$ 844$ & $-R \$ 16.578$ \\
\hline 11 & 2026 & 0 & & $R \$ 2.508$ & $R \$ 2.508$ & $-\mathrm{R} \$ 5.569$ & $R \$ 796$ & $-\mathrm{R} \$ 15.782$ \\
\hline 12 & 2027 & 0 & & $R \$ 2.626$ & $R \$ 2.626$ & $-R \$ 2.942$ & $R \$ 751$ & $-R \$ 15.031$ \\
\hline 13 & 2028 & 0 & & $R \$ 2.750$ & $R \$ 2.750$ & $-R \$ 193$ & $R \$ 708$ & $-R \$ 14.323$ \\
\hline 14 & 2029 & 0 & & $\mathrm{R} \$ 2.879$ & $\mathrm{R} \$ 2.879$ & $R \$ 2.686$ & $R \$ 668$ & $-R \$ 13.655$ \\
\hline 15 & 2030 & 0 & & $R \$ 3.014$ & $R \$ 3.014$ & $R \$ 5.700$ & $R \$ 630$ & $-R \$ 13.025$ \\
\hline 16 & 2031 & 0 & & $R \$ 3.155$ & $R \$ 3.155$ & $R \$ 8.855$ & $R \$ 594$ & $-R \$ 12.431$ \\
\hline 17 & 2032 & 0 & & $R \$ 3.303$ & $R \$ 3.303$ & $R \$ 12.157$ & $R \$ 560$ & $-R \$ 11.871$ \\
\hline 18 & 2033 & 0 & & $R \$ 3.457$ & $\mathrm{R} \$ 3.457$ & $R \$ 15.614$ & $R \$ 528$ & $-R \$ 11.343$ \\
\hline 19 & 2034 & 0 & & $R \$ 3.618$ & $R \$ 3.618$ & $R \$ 19.232$ & $R \$ 498$ & $-R \$ 10.845$ \\
\hline 20 & 2035 & 0 & & $R \$ 3.786$ & $R \$ 3.786$ & $R \$ 23.019$ & $R \$ 470$ & $-\mathrm{R} \$ 10.375$ \\
\hline 21 & 2036 & 0 & & $R \$ 3.963$ & $R \$ 3.963$ & $\mathrm{R} \$ 26.981$ & $R \$ 443$ & $-R \$ 9.932$ \\
\hline 22 & 2037 & 0 & & $R \$ 4.147$ & $R \$ 4.147$ & $R \$ 31.128$ & $R \$ 417$ & $-R \$ 9.515$ \\
\hline 23 & 2038 & 0 & & $R \$ 4.337$ & $R \$ 4.337$ & $R \$ 35.465$ & $R \$ 393$ & $-R \$ 9.122$ \\
\hline 24 & 2039 & 0 & & $R \$ 4.534$ & $R \$ 4.534$ & $R \$ 39.999$ & $R \$ 370$ & $-\mathrm{R} \$ \mathbf{8 . 7 5 1}$ \\
\hline Total & & $-R \leqslant 29.144$ & $R \leqslant 0$ & $R \$ 69.143$ & $R * 39.999$ & $R \leqslant 8.045$ & $-R \$ 8.751$ & \\
\hline \multicolumn{3}{|c|}{$\begin{array}{l}\text { Inflação Anual } \\
\text { Base Anual Conta de Energia } \\
\text { Taxa de Desconto }\end{array}$} & $\begin{array}{l}5,50 \% \\
11,00 \%\end{array}$ & & $\begin{array}{l}\text { VPL } \\
\text { TIR } \\
\text { Payback }\end{array}$ & $\begin{array}{c}-\mathrm{R} \leqslant 8.751 \\
7.09 \% \\
15 \\
\end{array}$ & & \\
\hline
\end{tabular}

